vol. 58, no. 2, 2016

Published by NTEU ISSN 0818-8068

Special issue

Challenging the Privatised University

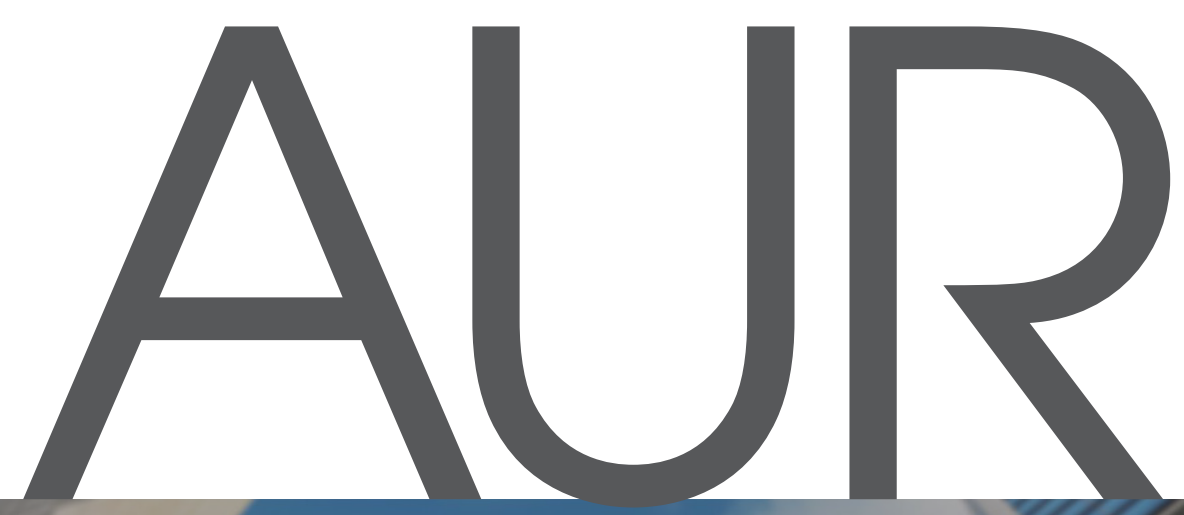

Australian Universities'Review

A Y,

82 


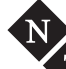 T U National Tertiary Education Union}

\section{AUR Editor}

Dr Ian R. Dobson, Monash University

\section{AUR Editorial Board}

Jeannie Rea, NTEU National President

Professor Timo Aarrevaara, University of Lapland

Professor Walter Bloom, Murdoch University

Professor Jamie Doughney, Victoria University

Professor Leo Goedegebuure, University of Melbourne

Professor Jeff Goldsworthy, Monash University

Dr Tseen Khoo, La Trobe University

Dr Mary Leahy, University of Melbourne

Kristen Lyons, University of Queensland

Professor Dr Simon Marginson, University of London

Mr Grahame McCulloch, NTEU General Secretary

Dr Alex Millmow, Federation University Australia

Dr Neil Mudford,UNSW@ADFA

Professor Paul Rodan, Swinburne University of Technology

Cathy Rytmeister, Macquarie University

Jim Smith, CAPA National President

\section{Production}

Design \& layout: Paul Clifton

Editorial Assistance: Anastasia Kotaidis

Cover photograph by Oleg Dudko.

\section{Contact Details}

Australian Universities' Review,

c/- NTEU National Office,

P0 Box 1323, South Melbourne VIC 3205 Australia

Phone: +61392541910

Fax: +61392541915

Email:editor@aur.org.au

\section{Website}

www.aur.org.an

$A U R$ is also available online as an e-book and pdf.

Visit www.aur.org. au for details.

NTEU members may opt for 'soft delivery' (email notification rather than printed copy) for all NTEU magazines. To access your membership details, log in to the members' area at www.nteu.org.au.

In accordance with NTEU policy to reduce our impact on the natural environment, $A U R$ has been printed using vegetable-based inks with alcohol-free printing initiatives on FSC certified paper by Printgraphics under ISO 14001 Environmental Certification.

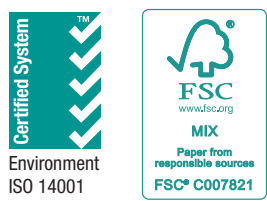

\section{Editorial Policy}

The Australian Universities' Review (AUR, formerly Vestes) is published by the National Tertiary Education Union (NTEU) to encourage debate and discussion about issues in higher education and its contribution to Australian public life, with an emphasis on those matters of concern to NTEU members.

Editorial decisions are made by the Editor, assisted by the AUR Editorial Board. The views expressed in articles in this publication, unless otherwise stated, are those of the authors and do not necessarily represent the views of the Editor, the Editorial Board or the publisher

Although some contributions are solicited by the Editor or the Editorial Board, AUR is anxious to receive contributions independently from staff and students in the higher education sector and other readers.

AUR publishes articles and other contributions, including short commentary and satire. Articles will be assessed by independent referees before publication. Priority is given to contributions that are substantial, lively, original and have a broad appeal. Responses to previously published contributions are encouraged.

AUR is listed on the DIISR (formerly DEEWR and DEST) register of refereed journals.

\section{Contributions}

Please adhere to the style notes outlined on this page.

Contributors should send digital manuscripts in Word format to editor@aur.org.au. Contributions should be between 2,000 and 7,000 words, although longer articles will be considered. All articles should be accompanied by an abstract that would not usually be longer than 150 words.

The author's full contact details should be provided, including email address, telephones and fax.

Contributions are sent to a minimum of two referees, in accordance with DIISR requirements for peer blind review.

Contributors should read the website before submitting a paper. It is presumed that authors have followed the standard scholarly ethical practices involved in seeking to have their work published. Authors should take their lead from the Australian Code for the Responsible Conduct of Research.

\section{Book reviews}

Books for review should be sent to the Editor. Our policy is to review books dealing either with tertiary education or with matters pertinent to issues in tertiary education. Book reviews should be between 200 and 1200 words; review essays may be longer.

\section{Replies and letters}

AUR welcomes letters of response to articles published in the journal. Longer responses to articles are also encouraged.

Responses should be a maximum of 1,000 words, and should be received within a month after the publication of the journal so that they can be properly considered by the Editor and the Editorial Board for the following issue.

\section{Subscriptions}

AUR is free to NTEU members on an opt-in basis. Full details at www.aur.org.au/subscriptions.

Annual subscription rates (inclusive of GST where applicable) are \$71.50 AUD (Australia and NZ), \$86.00 AUD (overseas airmail). Overseas payments should be made by credit card or bank draft in Australian currency.

\section{Advertising}

AUR is published twice a year, in February and September. The current hard copy circulation is approximately 8,000 per issue. Rates are available on application toaur@nteu.org.au .

\section{Archive}

This issue and previous issues of $A U R$ can be viewed online at www.aur.org.au.

\section{Style}

Download full Style Guide at www.aur.org.au/submissions. Use 'per cent' rather than '\%' in the text. Use '\%' in tables and figures where space is constrained.

Use 's' rather than ' $z$ ' in words such as 'organise' (analyse, recognise, etc.)

Use a single space at the end of sentences.

Use single quotation marks. Use double quotation marks for quotes within a quote. All quotes of more than 50 words should be indented and placed in a separate paragraph.

Dates thus: 30 June 2010.

Authors should ensure that the material cited in the text matches the material listed in the References.

Neither male nor female pronouns should be used to refer to groups containing persons of both sexes.

Do not use numbered sections.

Do not use underlining.

Do not use footnotes, endnotes or any headers or footers except for page numbers (bottom of page, centred).

Avoid use of abbreviations, except for well-known organisations or processes.

Tables and figures should be incorporated into the text close to where they are first referred. In general, 'tables' comprise data, and 'figures' comprise everything else (graphs, photographs, etc.)

Tables and figures should have separate numbered sequences, and titles should be above for tables, and below for figures. Figures should be prepared in black and white. Graphs with coloured bars are often illegible in black-and-white print.

\section{References}

References to be cited according to APA Publication Manual 6th edition (with minor exceptions).

References in the text should be given in the author-date style: King (2004) argues ..

or

as various authors (King, 2004; Markwell, 2007) argue ..

Two co-authors should be cited in the text as

(Smith \& Jones, 2013).

More than two authors cite as

(Jones et al., 2011).

Page references should be thus:

(King, 2004, p. 314)

Page references should be used for direct quotations.

The reference list should be placed in alphabetical order at the end of the paper, utilising the author-date system.

For a reference to a book:

Gall, M., Gall, J. \& Borg, W. (2003). Education Research: An introduction (7th ed.). New York: Allyn \& Bacon.

For a journal reference:

King, D.A. (2004). What different countries get for their research spending. Nature 430,311-316.

For a reference to a chapter in a collection:

McCollow, J. \& Knight, J. (2005). Higher Education in Australia: An Historical Overview, in M. Bella, J. McCollow \& J. Knight (Eds). Higher Education in Transition. Brisbane: University of Queensland Press.

For a web reference:

Markwell, D. (2007). The challenge of student engagement Retrieved from http://www.catl.uwa.edu.au/_data/ page/95565/Student_engagement_-_Don_Markwell___30_Jan_2007.pdf.

Do not include retrieval dates for web references unless the source material may change over time (e.g. wikis) 


\section{Australian Universities' Review}

3 Letter from the editors: Introduction to the special issue - Challenging the Privatised University

\section{Kristen Lyons, Jeremy Tager \& Louise Sales}

5 The conference: An overview and assessment

\section{Richard Hil}

Conferences come and go: some you remember, others you don't. This event, organised by the University of Queensland and Friends of the Earth, and supported by the National Tertiary Education Union (NTEU), National Alliance for Public Universities (NAPU) and the Ngara Institute, was in the former category.

\section{The Brisbane Declaration}

\section{Part 1: An analysis of problems associated with the} privatised university

9 Critiquing neoliberalism in Australian universities Jeannie Rea

While students chanting 'No cuts, No fees, No corporate universities' may be dismissed as youthful hyperbole by some, it is not as superficial a characterisation of the state of our public university system as it seems. The withdrawal of government funding and fee deregulation is the core issue for Australian higher education. It is even more stark because we have a largely government funded system.

15 The Death of Socrates: Managerialism, metrics and bureaucratisation in universities

\section{Yancey Orr \& Raymond Orr}

Neoliberalism exults the ability of unregulated markets to optimise human relations, but it is paradoxically built on rigorous systems of rules, metrics and managers. The potential transition to a marketbased tuition and research-funding model for higher education in Australia has therefore been preceded by managerialism, metrics and bureaucratisation.

26 Democratisation or management and corporate capture? Theses on the governance crisis of Australia's semi-privatised public universities

\section{Andrew $G$ Bonnell}

This paper proceeds from the view that managerial capture has already become a fundamental problem after largely untrammelled managerialism in our public universities, and that this problem is likely to be compounded by further shifts towards deregulation and de facto privatisation. This is the direction that current federal government policy is trying to take in the higher education sector.

\section{Part 2: Impacts of the privatised university}

33 Academics, the humanities and the enclosure of knowledge: the worm in the fruit

\section{Nick Riemer}

If we want to combat contemporary 'neoliberal' attacks on universities, we should start by refusing the way that their pseudorationalities already determine so many aspects of the intellectual and institutional regimes that we consider under threat.

42 Law student wellbeing: A neoliberal conundrum Margaret Thornton

The discourse around student wellness is a marked feature of the 21st century Australian legal academy. This article argues that the neo-liberalisation of higher education is invariably overlooked in the literature as a primary cause of stress, even though it is responsible for the high fees, large classes and an increasingly competitive job market.

51 Agnosis in the university workplace

\section{Andrew Whelan}

A significant challenge for the privatised university is its impedance of particular forms of effective engagement and action in teaching and research, notably with respect to inequities in the broader social context, and the position of the university within that context. In the face of significant resource constraints, several factors combine to produce a particular form of 'ignorance'.

\section{Part 3: What constitutes the good university?}

59 Learning by doing by learning: Reflections on scholar-activism with the Brisbane Free University

\section{Fern Thompsett}

As universities are swept by a near-global tide of capitalist restructuring, myriad forms of resistance are also on the rise. This paper explores the complex tensions involved in working simultaneously within the academy, and engaging in activism beyond it.

67 What are good universities?

\section{Raewyn Connell}

This paper considers how we can arrive at a concept of the good university. The best place to start in defining a good university is by considering the work universities do. This leads to issues about the conditions of the workforce as a whole, the global economy of knowledge, and the innovations bubbling up around the edges of this economy. 


\section{REVIEWS}

74 Reflections on Critical Pedagogy Leaders in Critical Pedagogy - Narratives of Understanding and Solidarity, by Brad J. Porfilio \& Derek R. Ford (Eds).

Reviewed by Thomas Klikauer

78 Be national, not global

The New Flagship University: Changing the Paradigm from Global to National Relevance, by John Aubrey Douglass (Ed.).

Reviewed by Kaycheng Soh

81 Transformation by inclusion

Diversity and Inclusion in Higher Education, Edited by Daryl G. Smith.

Reviewed by Kate White
82 Doing it UNSW-style

Improving Assessment in Higher Education: A Wholeof-Institution Approach, by Richard Henry, Stephen Marshall \& Prem Ramburuth (Eds.).

Reviewed by Dennis Bryant

83 Improving undergraduate education

The Undergraduate Experience: Focusing Institutions on What Matters Most, Peter Felten, John N. Gardner, Charles C. Schroeder, Leo M. Lambert, Betsy O. Barefoot.

Reviewed by Chris Mayer

85 An idea of union

The National Tertiary Education Union: A most unlikely union, by John Michael O'Brien.

Reviewed by Howard Guille 


\section{Letter from the editors}

\section{Introduction to the special issue - Challenging the Privatised University}

\section{Kristen Lyons, Jeremy Tager \& Louise Sales}

Universities today are defined by their commitment to private sector management, with CEOs at the helm (on salaries of \$1 million or more), and military, pharmaceutical, biotech and mining industries, amongst others, driving commercial research agendas. There is now an established body of literature demonstrating the extent to which corporate funding can corrupt science and policy making; leading to the commodification of knowledge and the commercialisation of research 'outcomes' (Mirowski, 2011). At the privatised university or the 'edu-factory' (Haiven, 2014), degrees and research are products for sale; students are consumers, and academics are entrepreneurs and service providers.

The privatisation of universities has been driven by neoliberal ideology which has led to cuts to public sector funding and a government-led push toward fee deregulation. Such developments are of course not unique to higher education. Neoliberalism has led to the commodification of both people and nature, with outcomes that fragment families and communities, and which rupture connections between people and the planet. The violence of neoliberalism is manifest in new forms of dependency, environmental destruction, exploitation, and growing public and private debt (see Springer, 2016).

The violence of the privatised university also finds expression in the hearts and minds of university staff and students: in the emphasis on performance-based learning, and in the dispiriting stress and anxiety of those who pass through this system. These experiences are exacerbated in the context of disciplinary metrics, which includes ranking systems, journal impact assessments, citation counts, competitive grants, and numerous performance evaluations. There are also clear race and gender based experiences of this violence; with white, straight men faring best, the outcome of which enables them to dominate most tenured academic positions across most fields (Haiven, 2014).
While the neoliberal cheer squad is loud and prominent, another type of university is possible. Resistance to the privatised university continues to grow. Campus-based protests against the deregulation of university fees, as well as universities' failure to divest from fossil fuels, has driven activism on many university campuses in Australia and beyond. Such acts of resistance resonate with Zapatista Education Promoter, Companera Ana Maria, who remarked, 'Power (is) trying to teach us individualism and profit ... we were not good students' (in Gahman, 2016).

New and long established movements such as slow/free universities, the multiversity and ecoversity, progressive colleges and foundations, as well as alliances, networks and unions that champion collective learning, all demonstrate that education is not simply a commodity to be traded on the open market. Unlearning is vital in this regard, as is the questioning of established neoliberal orthodoxies such as vocationalism and competition. Nor should research be available for the highest bidder or simply a matter of meeting certain commercial requirements, as the current Coalition Government insists.

Alternative approaches to universities foster collective, collaborative and inclusive research and education, as well as re-centring service and the public good as institutional mandates (Berg \& Seeber, 2016). Here, alternative values inform everyday practices and professional relations. Participatory democracy, communal decision-making, de-colonising pedagogy, learning from indigenous and local knowledges, and horizontal learning are all part of the alternative university paradigm.

In this special issue of Australian Universities' Review, 'Challenging the Privatised University', we have assembled a collection of papers that examine the ways in which neoliberal ideology, privatisation, corporate funding and influence have changed the nature of universities and, importantly, how these developments are currently being challenged. 
The issue is divided into three parts. Part A describes and analyses the problems associated with the privatised university. Articles by Jeannie Rea, Yancey and Raymond Orr, and Andrew Bonnell discuss how neoliberalism has over recent decades colonised Australian universities through managerialist practices, regulatory metrics and bureaucratisation, and the corporatisation of university management. Part B examines some of the impacts of the privatisation on the functioning of universities. Contributions from Nick Reiner, Margaret Thornton and Andrew Whelan examine the enclosure of knowledges, declining student wellbeing and bad faith amongst staff. Finally, in Part C, Fern Thompsett and Raewyn Connell explore what good universities might look like, and fascinating possibilities that flow from alternative pedagogies, practices and professional relations.

This special issue draws from papers presented at a conference organised jointly by Friends of the Earth, the Ngara Institute, the National Tertiary Education Union (NTEU) and the National Alliance for Public Universities. The conference was held at the University of Queensland in November 2015. Following this introduction, one of the conference participants, Richard Hil, provides an overview of proceedings in terms of themes and outcomes, with a particular emphasis on the Brisbane Declaration.

In presenting this volume, our intention is to encourage public debate about the current state of our universities, and how they might be reconstituted. More specifically, we encourage academics, administrators, managers, students and others to consider how universities might contribute to the public good rather than simple private interest. This volume represents our collective efforts to chart a different course for the future of Australian universities.

As part of this process the Conference has called for greater transparency from universities in order to challenge the privatisation of science research. In early 2016, a Right to Information (RTI) request was submitted to the University of Queensland's Australian Institute of Bioengineering and Nanotechnology (AIBN) seeking access to contracts struck between the AIBN and its corporate partners. Initially, the request was turned down because it was too large - over 1200 agreements with dozens of corporate partners - which in itself is an extraordinary disclosure. The request was then limited to six research contracts. The University of Queensland denied access to any documents on the grounds that it was contrary to the public interest to disclose secret agreements between a public university and a private interest. This decision, which is now the subject of external review, highlights how the most basic forms of accountability are lacking in the current system, and the problems we face more generally in challenging the privatised university.

We have little doubt about the challenges that confront us as we seek to achieve greater institutional accountability, let alone in critiquing a system that is so closely linked to governmental and commercial priorities. Nonetheless, we hope this collection of essays, and the networks of resistance we continue to forge, can in some small but significant way contribute to reimagining an education system based on civic rather than commercial values. Contributors to this special issue have demonstrated both a lively principled intellect, and courage in the face of institutional opprobrium. Following John Holloway (2010), we accept this may require us to break with the current reality in order to create something new.

\section{Kristen Lyons is Associate Professor in environment and development sociology at the University of Queensland, and recently joined the AUR editorial board.}

Contact: kristen.lyons@uq.edu.au

Jeremy Tager and Louise Sales are with the Friends of the Earth Emerging Tech Project.

\section{References}

Berg, M. \& Seeber, B. (2016). The Slow Professor: Challenging the Culture of Speed in the Academy. University of Toronto Press.

Gahman, L. (2016). Dismantling neoliberal Education: Lessons from the Zapatistas. Roar, April 4. Retrieved from https://roarmag.org/essays/neoliberaleducation-zapatista-pedagogy/.

Haiven, M. (2014). The Ivory Cage and the ghosts of the academy. Labor and Struggle in the Edu-Factory. Truth Out, 21 March. Retrieved from http://www. truth-out.org/news/item/23391-the-ivory-cage-and-the-ghosts-of-academelabor-and-struggle-in-the-edu-factory.

Holloway, J. (2010). Crack Capitalism. London: Pluto Press.

Mirowski, P. (2011). Science-Mart: Privatising American Science. Cambridge: Harvard University Press.

Springer, S. (2016). Fuck Neoliberalism. Retrieved from http://www.academia. edu/23908958/Fuck_Neoliberalism. 


\section{The conference: An overview and assessment}

\section{Richard Hil}

\section{Griffith University}

Conferences come and go: some you remember, others you don't. This event, organised by the University of Queensland and Friends of the Earth, and supported by the National Tertiary Education Union (NTEU), National Alliance for Public Universities (NAPU) and the Ngara Institute, was in the former category.

The intention of this gathering in November 2015 was to share critical reflections on various aspects of today's university system - focusing on the incursions of corporations into the tertiary sector, especially in the areas of teaching and research - but chiefly to consider alternatives to current institutional arrangements. Conference participants agreed that there was now an abundant body of critical literature on the 'neoliberal'/'cor porate'/'privatised' university, but what was now required was a public conversation about alternatives to this system and what might constitute the 'good university'.

In her introduction to proceedings, Associate Professor Kristen Lyons from the School of Social Science at the University of Queensland spoke of the 'critical spaces' and 'edge conversations' that had contributed to a radical rethinking of higher education. Lyons called for an 'action oriented agenda' aimed at identifying the core elements of a progressive public university system.

In her keynote address, NTEU National President, Jeannie Rea, argued that university education was 'too important to be left to the market' and that federal government funding, greater academic autonomy and more secure employment were vital elements of a truly public higher education system. Rea further noted how, over recent years, up-front fees from international students - who pay up to three times more than domestic students - had been used as a 'cash cow' to prop up ailing universities, and especially to cross-subsidise research.
Rea also observed that tertiary education had become a largely 'functional' process aimed mainly at producing 'job ready' graduates to serve the requirements of industry. In many instances, Rea asserted, students had been misled by university marketing hype, often ending up in unrelated, dead-end jobs following graduation. Rae also spoke of the increased exposure of universities to corporate influences while at the same time distancing themselves from local communities, illustrating the extent to which today's tertiary institutions had been 'privatised'.

Emeritus Professor Raewyn Connell from the University of Sydney took a similar line, adding that since the Dawkins reforms of the late 1980s universities had been subject to a 'managerial takeover' resulting in topdown decision-making, less academic autonomy and more casualisation, and therefore more precarious employment. Additionally, competition in teaching and research had replaced cooperation and collegiality, and academics have been 'de-professionalised' and subjected to excessive managerial regulation. These days, said Professor Connell, universities operated more like private firms than public institutions. Yet Professor Connell also cautioned us not to look to the past for exemplars of a better university, and instead urged a 'practical' program of change based on three principles. First, the opening up of intellectual spaces to accommodate multiple sources of knowledge ('epistemes') in the pursuit of truth,/ Connell also encouraged the inclusion of 'multiple expertises' in the 
context of a 'highly participatory', 'bottom-up' approach to intellectual engagement and critical pedagogy.

Second, the good university should be based on a system of 'industrial democracy' which guarantees secure employment, decent conditions, greater academic autonomy, and an environment that enables 'learning from below' through a more civically engaged approach to higher education. Third, the articulation and critical dissection of various bodies of knowledge should be considered a 'public asset' and academic 'service' valued and not rendered subordinate to the market and corporate interests.

PhD candidate and Union Environmental Officer at the University of Queensland, Amy McMahon, observed that a sizeable portion of the enrolment fees paid by students goes towards subsidising university advertising and campus beautification projects, in effect diverting funds from vital teaching and research activities. She also pointed out that the decline of student political activism could in part be attributed to hikes in university fees and attacks by governments on student unions, with many services culled following the abolition of compulsory union fees by the former Howard Government. However, McMahon noted that students' voices and indeed student dissent had not been quashed and that the Abbott Government's proposed deregulation of university fees had galvanised thousands into action, insisting that fee deregulation and other revenue-raising measures would further diminish the capacity of students to engage in the educational process.

The opening three presentations set the tone for the conference which was made up of academics, students, activists, representatives of NGOs and others. Eminent scientists like Jack Heinemann, Professor of genetic and molecular biology at the University of Canterbury, New Zealand, spoke at plenary sessions about the growing influence of private corporations in various research activities. Of particular concern for Professor Heinemann and others was the privatisation of knowledge through copyrights, patents and an assortment of licensing arrangements. As other speakers observed, such arrangements compromised the independence of universities and invariably placed commercial interests ahead of the public good.

Over the course of two days, conference participants discussed additional matters relating to the 'corporatisation of the modem university'. Plenary sessions dealt with issues such as 'the effects of corporate investment on universities, including research'; 'the role and significance of universities in commercialising emerging technologies'; 'censorship, self-censorship';'intellectual integrity and the health of dissent in Australian universities'; and whether 'universities were still fulfilling an important public role.' Discussion also focussed on 'the effects of privatisation and corporate money on students and staff - collegiality, cooperation, transparency'; and 'the integrity of science and scientists in the privatised university'.

Each of these sessions raised overlapping concerns about the impact of corporate influence on research and teaching activities, especially the control and dissemination of knowledge and its pairing with 'commercial outcomes' (as recently evidenced in the Prime Minister's innovation statement). Perhaps most concerning was the flow of corporate funding into research activities that supported private profit-seeking interests at the expense of vitally important projects contributing to the common good.

In light of all this, conference participants considered ways of building an 'academic activist culture'. Suggestions included finding ways of re-engaging with colleagues across disciplines, building collegial, democratic cultures within schools and departments, discussing corporate influence and what to do about it; encouraging colleagues to join the National Tertiary Education Union (NTEU) and the National Alliance for Public Universities (NAPU), and undertaking research for public rather than private gain.

But the clearest articulation of what might constitute the foundations of the 'good university' was contained in a public statement now referred to as 'The Brisbane Declaration'. The Declaration is intended as a watershed statement to guide future campaigns in the struggle to create a genuinely and fully funded public university system. The Declaration begins: 'Given the role of multinational corporations in contributing to the looming global environmental, social and financial crises; and their increasing influence on all forms of education, including university education, there has never been a more important time to rethink the meaning of a good university.' The Declaration proceeds to itemise the essential features of the good university:

'We believe that good universities:

- Are communities not corporations.

- Are democratic public institutions for the social good.

- Are fully funded by government.

- Are independent of corporate funding and influence.

- Are dedicated to offering free, high quality education.

- Are transparent and accountable.

- Embrace multiple ways of knowing.

- Are transformational not merely transactional.

- Nurture public intellectuals. 
- Promote the free exchange of ideas in the quest for truth.

- Actively value collegiality and collaboration.

- Uphold and support the role of student unions.

- Uphold diversity in the production of knowledge.

- Foster and develop mutual respect.

- Participate in the development of a just, democratic and sustainable society which privileges ecologies over the economy.

- Are democratically accountable to society as a whole.

- Empower students to become active citizens and not just job ready graduates.

- Explicitly incorporate an understanding of indigenous culture and history.

- Recognise and integrate bodies of knowledge from the global south.

- Recognise academic freedom as a core value.

- Produce open, available and accessible knowledge.

- Include all academic staff and students as active participants in decision-making processes and culture.

- Invite alternative, non-hierarchical and respectful forms of performance review.

- Are committed to an ethical and knowledge driven curriculum that fosters critical reflection and creativity.

The Declaration is: 'intended to spark a national conversation about the nature, role and purpose of university education in a truly socially just, democratic society.'
It is my hope, and that of conference participants, that this Declaration becomes the catalyst for an on-going public conversation about the nature, role and purpose of universities in a truly democratic society. But this is a conversation that needs to be initiated by academics themselves; those who know something about the daily constraints of a system beholden to market forces and the corporate brand. But this public deliberation should be more than an abstract critique of what is now a quintessentially neoliberal institution - it must be a commitment to re-imagining the sort of higher education we want for current and future generations. It must be a truly public system, for the public good and in the common interest.

It must be a system that takes seriosuly and responds to the interlocking social, economic and environmental crises that now confront us - all of us on this planet.These crises are radically reshaping our lives. We therefore need to consider how education in all its forms, including higher education, fits into this emerging new reality.

Richard Hil is Adjunct Associate Professor at Griffith University, Queensland, Australia.

Contact: josephgora007@gmail.com 


\section{The Brisbane Declaration}

Given the role of multinational corporations in contributing to the looming global environmental, social and financial crises; and their increasing influence on all forms of education, including university education, there has never been a more important time to rethink the meaning of a good university in Australia.

Good universities are:

- Communities not for-profit corporations;

- Democratic public institutions for the social good;

- Fully funded by government;

- Independent of corporate influence;

- Dedicated to offering free, high quality education;

- Transparent and accountable;

- Transformational not merely transactional;

- Democratically accountable to society as a whole;

- Committed to an ethical and knowledge driven curriculum that fosters critical reflection and creativity.

Good universities:

- Embrace multiple ways of knowing;

- Nurture public intellectuals;

- Promote the free exchange of ideas in the quest for truth;

- Actively value collegiality and collaboration;

- Uphold and support the role of student unions;

- Uphold diversity in the production of knowledge;

- Foster and develop mutual respect;

- Participate in the development of a just, democratic and sustainable society which privileges ecologies over the economy;

- Empower students to become active citizens and not just job ready graduates;

- Explicitly incorporate an understanding of indigenous culture and history;

- Recognise and integrate bodies of knowledge from the global south;

- Recognise academic freedom as a core value;

- Produce open, available and accessible knowledge;

- Include all academic and non-academic staff, and students as active participants in decision-making processes and culture;

- Invite alternative, non-hierarchical and respectful forms of performance review.

This declaration is intended to spark a national conversation about the nature, role and purpose of university education in a socially just, democratic society. We invite reflection, debate and dialogue in pursuit of the good university.

\section{A Selection of Declaration endorsements}

Assoc. Prof.Andrew Bonnell, University of Queensland

Professor Raewyn Connell, University of Sydney

Adjunct Assoc. Prof. Richard Hil, Griffith University

Assoc. Prof. Kristen Lyons, University of Queensland

Dr Robyn Mayes, Queensland University of Technology

Assoc. Prof. Christine Morley, Univ. of the Sunshine Coast
Jeannie Rea, National President, NTEU

Dr Carol Richards, Queensland University of Technology

Assoc. Prof.Ariel Salleh, University of Sydney

Dr Lynda Sheveller, University of Queensland

Professor Margaret Thornton,ANU

Professor Ken Udas, University of Southern Queensland 


\section{Critiquing neoliberalism in Australian universities}

\section{Jeannie Rea}

\section{National Tertiary Education Union}

While students chanting 'No cuts, No fees, No corporate universities' may be dismissed as youthful hyperbole by some, it is not as superficial a characterisation of the state of our public university system as it seems.

Keywords: fee deregulation, privatisation, commodification, governance, government funding, government policy

The withdrawal of government funding and fee deregulation is the core issue for Australian higher education. It is even more stark because we have a largely government founded system. Colonial and state governments established universities, as well as teacher training and technical institutes and further education colleges. Unlike in some countries, our tertiary institutions have historically been overwhelmingly publicly funded with staff often directly on the public service payroll. Private, including for-profit, and religious institutions have been few and catered for few students. This is unlikely to change unless governments weaken the registration requirements for universities and other providers and start handing out HECS-HELP funded (Commonwealth Supported) places to private providers, as is current Turnbull Coalition Government policy. Ironically for the free market ideologues, it would be state subsidisation that would facilitate a viable private higher education sector in competition with public institutions.

Australia's level of public investment in higher education is low compared to other industrialised economies. Deregulated international and postgraduate course fees are now a critical source of income, as government grants account for only about one third of university income. In recent times, most vice chancellors did not oppose the Coalition Government's undergraduate fee deregulation policy, despite Australian undergraduate domestic students already paying higher fees than most comparable OECD countries.

Fee deregulation compromises the integrity of our public university system, with better resourced universities able to charge higher fees. Capacity to pay rather than merit would increasingly determine access to courses and universities. The existing hierarchy of universities would be exaggerated as the wealthy filled the places at the better resourced, along with some scholarship students, while the standards and viability of other institutions would erode. No longer would a degree from any of the members of our public university system have standing locally and internationally.

Therefore, when we talk of the privatised or privatising university, it is not a discussion about private universities, it is about the process and consequences of the marketisation of public universities and the commodification of higher education learning and research.

Marketisation of our public universities is emblematic in public university vice chancellors no longer being seen as leaders of a community of scholars but re-cast as CEOs answering to university councils (which are now more akin to corporate boards of management overseeing the operation of large enterprises). Commodification is symbolised by students considered at best as clients, at worst as customers. Despite UNESCO protocols recognising our unique rights and responsibilities, as university staff we struggle to hold onto to our status 
as stakeholders. Instead, we are treated as a cost of production, a variable input from which maximum productivity is extracted.

A university is not just another enterprise, and 'education' is not a commodity to be bought and sold. A university qualification requires work by the student, not just the purchase of a service in a commercial transaction.

Instead of mass higher education democratising universities by opening up access and participation, the dead hand of neo-liberalism has entrenched much that was criticised in the pre neo-liberal age during the period of massifying higher education especially in North America and Western Europe (1960-70s). In those earlier halcyon days, the new and old student cohorts joined, utilising their learning, to slam the universities for serving the military industrial complex and for being degree factories, whilst at the same time still being ivory towers reinforcing privilege, and for being the gatekeepers to access to professions and sanctioned knowledge.

In Australia, higher education also expanded during this period, but had not become the mass expectation that it is today. It should be noted that this new expectation significantly contributed to the current mass public opposition to undergraduate fee deregulation. Australian families now expect their children to be able to go to university. Today we have a much greater diversity amongst students, although not so much amongst staff, but Australian students pay more fees than they ever did, even if it is through the deferred income contingent loans scheme (HELP).

Today's more 'accessible' and 'inclusive' university is also much more likely to have a physical fence around the campus and restricted entry to buildings. The old concept of wandering in off the street to sit up the back and listen to a lecture would now be considered weird and such a person would likely be resented as a trespasser and not a paying customer. And of course, you must be registered on the learning management system to listen online! It is not surprising the idea of MOOCs (Massive Open Online Courses) is popular. From a learner's point of view, what is there not to like about listening in on academics teaching in their areas of expertise? The issues for critics of MOOCs should not be about letting more people into the 'lecture theatre', but about homogenising education and knowledge, about another form of neo-colonialism, about a model that could further undermine the academic profession, about splitting opportunities along class lines where the wealthy have access to 'full service' education and the poor resort to anonymous online providers.
Whilst treated as consumers, today's students are denied any real agency in their own education. However, if provoked they are more likely to gang up in cyber space to take down an individual lecturer, rather than physically occupy the admin building demanding more tutors, smaller classes and assessment reforms. Treating students as customers does mean that they will behave as such, but passively. Rather than protesting the woeful generic online course evaluation surveys, students just ignore them and complain on Facebook. Fortunately, however there is evidence of greater understanding amongst student activists of their common interest with university staff in the quality of their education. They have therefore supported casually employed academics seeking greater job security and industrial action over enterprise bargaining for improved conditions and job security.

\section{The reality and consequences of fee deregulation}

Late in 2015 with the change in the Liberal Party parliamentary leadership, the Coalition's policy of domestic undergraduate fee deregulation - accompanied with a twenty per cent funding cut from the start of 2016 - was averted for a year. However, the policy remained intact at the time of writing, just before the 2 July 2016 election with Prime Minister Turnbull confirming that deregulation was still on the table for so-called 'flagship courses'. The NTEU's characterisation of the Coalition's policy as " $\$ 100,000$ degrees, delayed not ditched" remains unfortunately unchanged.

Whilst the NTEU maintains that education is too important to leave to the market, the horse has already bolted with $\$ 100,000$ plus degrees already being sold to international and postgraduate coursework students. Additionally, with the deregulation of public Vocational Education and Training (VET) and subsidisation of private providers, too many VET level courses are also nudging towards \$100,000.

\section{International student fees}

There was a time when international students largely participated in Australian universities as guests. Most famously, they were subsidised through the Colombo Plan, which had Cold War and neo-colonial motives, but was also supported as a neighbourly gesture to the developing countries of our region. When the Whitlam Labor Government abolished all fees in 1974 that included those for overseas students. They were soon reintroduced, 
as the neo-liberal ideology 'user pays' yoke started to tighten. However, at this stage the charging of fees was seen as an expenditure saver not a revenue raiser.

This all changed in the late 1990s when the Howard Coalition Government cut higher education funding and encouraged universities to pick up the slack. The Government assisted in this by also relaxing visa requirements on international students to qualify for permanent residency. To be more precise, international students were no longer neighbours, they became the new revenue stream, and now Australia's public universities are hooked on this line. The reality is that today international students are subsidising the education of domestic students as their fees are used to partially make up the funding gap.

In direct contradiction to their importance in keeping the universities afloat, the experience of international students is deteriorating. They are crammed in classes together rather than mingling with local English speaking students, lonely unless befriended by other international students or staff, uninvolved in student life, often working long underpaid hours, sometimes living in very poor conditions and constantly worrying about letting down their families. It is not at all surprising that as the pressure mounts some students are taken advantage of by those offering cheating services. As one young man recently explained on national television, it was cheaper to pay someone else to sit his exams than to fail and have to repeat. To such students, any joy of learning and achievement has evaporated; their degree is purely a commodity. Their humanity is lost as they are referred to as Australia's third biggest source of export income.

\section{Postgraduate coursework fees}

While nowhere near as lucrative as the international student' market, postgraduate coursework is an increasing source of university income and again cross subsidises undergraduate education and research. Without caps on postgraduate fees massive debts can be accumulated by students borrowing through the government loan scheme. Students who undertake postgraduate coursework soon after their undergraduate degree are increasingly accumulating debts hitting $\$ 100,000$ and more.

Where they are already in the workforce, students are saving and paying upfront for these often overpriced courses. They are subjected to massive marketing campaigns as they are promised career advancement, when often this is quite pyrrhic. Students are focused on the qualification they are purchasing particularly if required for entry or promotion, and often have little engagement with their learning, or even the quality of their course.

Before postgraduate coursework was also made tuition fee free under the Whitlam Government in 1974, there were few postgraduate diplomas or masters outside of education courses. With a contracting graduate employment market and also new areas of study and work opening up there was a flourishing of courses including, for example, in ground breaking areas like environmental, women's and Indigenous studies, as well as graduate law courses and the ubiquitous MBA. Whilst these courses were soon subject to HECS (now HELP) and then gradually deregulated altogether through the 1990s, this pattern has continued with such programs providing opportunities for education and research in newer areas, with entry privileging RPL (Recognition of Prior Learning) thus giving second chance access for the experienced but uncredentialled.

However, there are also now many such courses criticised for little rigour and little interest from the institutions except as a source of income. Casually employed academic staff, some without university teaching experience often not only teach, but also coordinate these programs. Their feedback is largely ignored and if too critical they are not employed again. Students are attracted by the status of the institution and/ or to academic staff with public profiles, even though they may never even meet them. They are consciously paying for the university name on the testamur not the quality of their education.

The intellectual and pedagogical integrity of such courses must be questioned along with the ethical propriety. Increasingly less is asked of students in less time, entry criteria are largely non-existent, there is no moderation over marking. As a result universities are arguably sullying their own 'brand' in the bid for more income. Private providers are in this market and their numbers would increase if they were handed government subsidies as is current government policy. With already diminished 'products' in many universities, private providers could readily find a niche at the expense of public universities and their students and staff.

\section{The crucifixion of public TAFE}

Even the free marketeers are now shocked by the abuse of public subsidies by profiteers in the VET sector, as scandal after scandal has been revealed through the media and parliamentary questions and inquiries. 
Thousands of people are signed up to nonsense courses so that the profiteers can grab the government funds as 'students' unknowingly also sign up to VET-FEE HELP and start incurring a debt. Others have enrolled in courses so substandard that, for example, the Victorian Government had to cancel thousands of 'qualifications' in 2015.

In a submission to a recent Senate inquiry on VET, the NTEU concluded,

The Australian experience in VET shows that deregulated tertiary education markets result in the provision of poor quality and in some cases substandard training and qualifications; forms of unethical behaviour on the part of some private providers, or their agents, driven more by the profit motive than any interest in providing education and training; state/territory governments cutting public subsidies to VET and shifting the cost on to students (NTEU Submission on VET FEE HELP Amendment Bill, 2015).

The Report of the Senate Inquiry, 'Getting your money's worth: the operation and funding of VET providers in Australia', released on 15 October 2015 found that VET FEE HELP loans in recent years have been 'wasted or milked for profit'. The National Centre for Vocational Education Research found only one in five students is likely to complete their course. A Victorian Inquiry found that 'an education leading to greater social and economic participation - the principal purpose of VET - is being undermined by commercial imperatives.' They concluded that the failed experiment in Victoria undermined the financial and educational sustainability of public Tertiary and Further Education (TAFE) because it failed to recognise 'the unique obligations of the TAFEs or the value they provide' (Quoted in NTEU submission above).

The Australian TAFE system was once envied and copied around the world as a national system that provided education and training from basic through to tertiary level for early school leavers and adults. TAFE was the site for gaining credentials for a raft of jobs across the economy at little or no cost and at sites throughout the country.

However, rather than continue to prioritise TAFE funding and deal with criticisms of poor productivity in some areas by strengthening the system, starting in Victoria Labor governments favoured the neo-liberal path of deregulation known as 'contestability.' Contestability was supposed to make public TAFE nimbler with private Registered Training Operators (RTOs) nibbling at their ankles. Anyone could set up as a RTO in Victoria and they did. The Coalition's solution was to cut funding further destroying public TAFE.

The Rudd Federal Labor Government exacerbated the problem by offering up VET FEE HELP to all RTOs with the outcome that there are VET courses costing more than higher education courses and the onus is on the students to pay for government's failure to fund education. The average fees in 2011 were $\$ 4,800$. By 2014 they had risen almost 300 per cent to $\$ 12,300$. In 2009, 19,300 people accessed VET FEE HELP, but by 2014 this figure had risen to 203,000 (Analysis by Paul Kniest in NTEU, 2015).

Some of these are genuine courses leading to job outcomes, but many are not. Public TAFE was drained and their mission to provide vocational and further education was undermined as they could not cross subsidise to provide the expensive but needed courses. Whilst the business sector continues to bemoan the gap between what is being taught in universities and TAFE, there is no acknowledgement that the free market will absolutely not improve this as for-profit providers will offer courses in fad, not necessary, areas. In Victoria it became a joke that every second person was a 'qualified' barista and personal trainer. But more seriously, thousands of particularly poor people were (and are) undertaking courses with no job outcomes.

Whilst 'contestability' has become more contested within Labor ranks, their policy still focuses upon curbing aberrant behaviour. The policy should be abandoned before more people lose their money and their hope of bettering themselves and more public money is stolen. The Victorian Labor Government at the time of writing is considering recommendations from an inquiry to put fee caps on and review the conditions under which private providers receive any public money. (Department of Education and Training, 2015)

The experience of the crucifixion of public TAFE should be reason enough for the Coalition Government to abandon extending Commonwealth supported places and therefore HECS-HELP loans to private providers in higher education. However, while the current Minister for Education, Senator Birmingham, said he was 'somewhat scarred by the mess I've been working to clean up in the poorly regulated vocational education market', he remains committed to further government subsidised privatisation of higher education (Birmingham, 2015).

\section{International privatisation and commercialisation}

Education union leaders from Argentina, The Philippines, South Africa and the global education union federation, - Education International (EI) - warned the 2015 NTEU National Council meeting about privatisation and commercialisation in the international context. 
Whilst the experience varies amongst countries, the privatisation of public higher education is resulting in division between the tertiary education available to the rich and that available to the poor. Prestigious private and state universities are increasingly the province of the elite, while the poor have to resort to the fly-by-night privateers. This has also opened up the space for transnational private providers, such as Pearson Education, to compete with and undermine public providers, particularly as public funding declines. In the Philippines higher education funding has been cut by fifty per cent (Castro quoted in Rea, 2015, p30).

The consequence is increasingly insecure employment and the loss of academic freedom and fearless informed public commentary.

Australia is a small but valuable higher education market and there should be no doubt that transnational education services companies are very interested in gaining a foothold in the Australian education market at every level.

\section{Implications for staff}

Australian universities are already outsourcing staffing to private companies. The outsourcing of whole sections, such as security or even ITS to private companies is spreading, but outsourcing is more pervasive than this. Universities use search companies for more senior jobs and job agencies for lower level roles, including fixed term and casual positions. Questions are rightly being asked about the 'business' and privacy risks associated with this outsourcing.

Already almost one in two university jobs are precarious. Eighty per cent of Full Time Equivalent (FTE) research-only positions are short term contracts and eighty per cent of FTE teaching-only positions are casual. As most casuals work only a few paid hours a week, tens of thousands of actual people are teaching in our universities, without much supervision and few opportunities for career advancement. As 'ongoing' jobs are vacated the replacements are casual or on fixed term contracts. External human resource companies continuously advise university managements to keep their staff on tenterhooks and to make more jobs insecure and assert management control.

The pervasiveness of neo-liberal ideology is nowhere better illustrated than in the effectiveness of the con job on university managements that they are better off having a 'flexible' workforce. Universities keep hiring and re-employing people in jobs they have claimed are short term or even redundant. There are casual academics and general staff who have worked for the university for well over a decade and contract research staff who have gone from contract to contract for two decades. These are lives lived in the shadows, until people abandon working in universities. While many even in management despair of this situation, there is a great reluctance to openly challenge these policies and practices, which is probably not surprising given that much of middle and senior management are also on fixed term contracts.

As a result innovation in teaching and research is really, really hard because there is little continuity, academic freedom is a joke and the wicked issues are not being tackled.The public though still expect public universities to be working for the public good.

\section{Commercialising research}

There has always been suspicion of universities accepting funds from government and private industry for research, especially in more politically sensitive and financially lucrative areas. Such collaborations, in for example the US, are notorious. With limited private sector investment in university research, in many ways Australia has had the converse problem of not finding enough external support. But there are still examples of research findings supressed and researchers steered away from controversial investigation and particularly public commentary.

Universities have consistently argued that governments should be funding the real cost of research through the competitive grants schemes because otherwise the research is not done or universities have to cross subsidise internally. Students' fee income is constantly plundered for research. This fact is largely unknown to students, whether domestic undergraduate or full fee international or postgraduate coursework participants.

However, the government remedy has been to encourage universities to find more private capital and to commercialise their research. At the end of 2015 the Turnbull Government announced that it would not only encourage and help subsidise private investment in university research commercialisation, but that it would also privilege income over academic standing in allocating competitive research grants. As Prime Minister Malcolm Turnbull is reported to have said in December 2015,'publish or perish will be replaced by collaborate or crumble' (Matchett, 2015). Minister for Innovation, Christopher Pyne described the 'changed arrangement for the support for research grants to universities' as the 'big ticket item' of the NISA. He explained that the Government is 'going 
to abolish publications as the chief reason why you attract research grants' and explained that 'we are going to change that into research impact' (Richardson, 2015).

\section{Loss of democratic governance}

Lacking in this political environment is courage from the vice-chancellors. Another characteristic of privatisation is the erosion of university governance, as university councils/senates privilege corporate experience over stakeholder interests and dispute staff and student representation. Council meetings have become reporting forums for management rather than an avenue for meaningful debate over institutional direction, and academic boards are now merely arenas to rehearse council reports.

While university councils need to prioritise financial stability, obsessions over 'salary savings' prevail at the expense of a secure workforce, facilitating investment in new initiatives and consolidating successful activities. Contracting out is favoured, even for commercial activities that could bring a return. The core 'business' of teaching is commercialised, particularly in preparatory courses. Seemingly often weighted towards the partners' interests, the value of commercial partnerships is nebulous at best, and can carry reputational risk. Partners and donors increasingly demand an ongoing say in the university and, with most decisions 'commercial in confidence', the university community can only guess at the rationale.

In a marketised higher education sector, universities relentlessly compete with one another, reducing decades of high level inquiry and life changing innovation to slogans like 'awesome'. Whilst managing constrained budgets and pushing courses online to cut costs, universities are making massive capital investments in edifices to attract students, staff and research investors. This competitive environment explains the obsession with international research rankings and the largely unsubstantiated presumption that these attract international students.

However, the 'digital natives' (local and international) are highly suspicious. Prospective students canvas opinions within their cohort and in trusted advisors like teachers and families. They are not necessarily influenced by flashy websites, 'analytics' and a new 'campus centre'. They are, however, likely to listen to a student complaining that every year over half of their tutors are employed casually and have little paid time for consultation.

The researcher who has been employed on half a dozen contracts in a decade will have trouble convincing her
PhD students to pursue an academic career.The esteemed professor might be attracted by the salary bonus offered, but may also be concerned over the job security of colleagues or in having a say in how his research is used.

Academic freedom is increasingly fleeting - academics are pulled off research that's not a university priority and fixed term researchers are cautious of creating waves or in following an interesting path that may yield unexpected results. Politicians call for cuts to research projects that do not fit in with their ideological blinkers and corporate and government funders want the answers they paid for.

Collegiality can be dismissed as an 'ivory tower' concept, conjuring up visions of white men guarding their class privilege. However, there is a mass higher education version of collegiality whereby staff and students across the university, the country and globally, share their knowledge and the immense resources of universities for the public good. But this is not the vision of the privatising university, where knowledge is guarded and resources fenced off for paying customers.

Jeannie Rea is the National President of the National Tertiary Education Union, Australia. She was previously a Deputy Dean at Victoria University, Victoria, Australia and lectured in gender studies and public relations.

Contact: jrea@nteu.org.au

A summary of this article, 'What is wrong with the privatising university', appeared in Friends of the Earth's Chain Reaction magazine, Issue 125, November 2015.

\section{References}

Birmingham, S. (2015). Reviews highlight decades of higher education funding challenges. Department of Education and Training Media Centre, 28 October. Retrieved from https://ministers.education.gov.au/birmingham/reviewshighlight-decades-higher-education-funding-challenges.

Department of Education and Training Victoria. (2015). VET Funding Response. Retrieved from http://www.education.vic.gov.au/about/department/ Pages/vetfundingresponse. aspx?Redirect $=1$.

Matchett, S. (2015). UWA cuts controversy continues. Campus Morning Mail, 11 December. Retrieved from http://campusmorningmail.com.au/503726-2/.

NTEU. (2015). NTEU Submission to Senate Education and Employment Committee Inquiry on Higher Education Support Amendment (VET FEEHELP Reform) Bill, October. Retrieved from http://www.nteu.org.au/article/ NTEU-Submission-to-Senate-Inquiry-into-VET-FEE-HELP-18177.

Rea, J. (2015). Education for Sale. Advocate, 22 (3).

Richardson, G. (Presenter). (2015). Interview with Christopher Pyne. In The Richo Program [television broadcast]. Australia: Sky News, 9 December. Senate Education and Employment Education References.

Committee. (2015). Getting your money's worth: the operation and funding of Vocational Education and Training (VET) providers in Australia, October. Retrieved from http://www.aph.gov.au/Parliamentary_Business/Committees/ Senate/Education_and_Employment/vocationaled. 


\title{
The Death of Socrates
}

\section{Managerialism, metrics and bureaucratisation in universities}

\section{Yancey Orr}

\author{
University of Queensland
}

\section{Raymond Orr}

\section{University of Melbourne}

Neoliberalism exults the ability of unregulated markets to optimise human relations. Yet, as David Graeber has recently illustrated, it is paradoxically built on rigorous systems of rules, metrics and managers. The potential transition to a market-based tuition and researchfunding model for higher education in Australia has, not surprisingly, been preceded by managerialism, metrics and bureaucratisation (rendered hereafter as 'MMB') in the internal functioning of universities in the last decade. This article explores the effects of MMB on the lives of academics, the education of students, and the culture and functioning of universities. By examining some of the labour activities of academics, work scheduling and time use, we demonstrate that MMB reduces the efficiency and quality of academic teaching, research and administration. Even more worrying, by qualitatively assessing the language, values and logic increasingly present in the academic culture of higher education in Australia, we show that MMB does not simply fail to improve universities or accurately assess academic achievement, it replaces the core values of education with hollow bureaucratic instrumentalism.

Keywords: bureaucratisation, managerialism, metrics, transvaluation of values

Then raising the cup to his lips, quite readily and cheerfully he [Socrates] drank off the poison. And hitherto most of us had been able to control our sorrow; but now when we saw him drinking, and saw too that he bad finished the draught, we could no longer forbear, and in spite of myself my own tears were flowing fast; so that I covered my face and wept, not for him, but at the thought of my own calamity in having to part from such a friend.- Plato, Phaedo

The importance of measurement and standardisation for contemporary systems of control is an enduring theme associated with modernity (Weber, 1978 [1922]; Foucault, 1990 [1976]; Scott, 1998). The rise of such regimes and mentalities has not only been understood as altering structures of power but also contributing to a loss of heterogeneous forms of value, community and imagination (Alexander, 2013; Graeber, 2001; Graeber, 2015). Perhaps most famously, Weber, writing of changes in both global spirituality (2001 [1905]) and university systems (1946 [1919]) of his own day, described the effects of such processes as 'disenchantment' (Entzauberung). The ethnological studies tracing systems of control and subsequent disenchantment in the context of religion (Eliade, 1987), economy (Polanyi, 2001 [1944]), the family (Lasch, 1995) and sex (see Robinson, 2014 on Weber) remain seminal works in 20th Century social sciences.Such transformations are no longer research questions only to be explored in the field. The rationalisation triumvirate of metrics, managerialism and bureaucratisation (MMB) now organise the educational, professional and intellectual terrain of many universities, their academics and students. 
Reflecting this general trend in humanism's response to modernity, we offer a small study within the context of the academy that explores such systems of control and the subsequent disenchantment of secular society's once sacred place.

This article presents a series of examples of what MMB can do to education, thereby providing feedback for academic administrators as well as analytical techniques for understanding MMB's effects for academic staff, with their responsibility as stewards of the university, apart from simply 'employees' of it. To these ends, our examination of MMB in the academy is divided into two sections. The first addresses labour inefficiencies through how, by its own desire to make universities more productive and legible workplaces through centralised control, MMB creates a remarkably inefficient and unclear system through excessive management. To do this, we compare the labour (defined in time, attention and personnel) to perform common tasks in what we define as managerial and non-managerial universities. The second section explores the effects of MMB. In particular, we describe the values, behaviours and mentalities now emerging within the MMB system as an illustration of what might be described as the disenchantment of academic life. We base this comparative method from our experiences in North American and Australian universities which, for the authors; represent examples of non-MMB and MMB educational institutions, respectively. Within the context of this paper, we focus our analysis on those clear accounts of the differences between these systems, in the hope of bringing greater empirical accuracy and thus more pointed criticism of such a fundamental transformation occurring in higher education.

The thematic division of this article addresses two common positions supporting MMB in the academy. To proponents of this type of broad rationalisation, such changes in the university could appear to improve the efficiency and quality of the institution. It must first be pointed out that the managerialism found in current MMB institutions is not the traditional form of administration within a university of deans, provosts, and vice-chancellors / presidents (Ginsberg 2011). In the MMB model we refer to in this paper, managerialism extends beyond the use of business managers in administrative roles. Decisions about teaching techniques, research projects, university educational philosophies and the daily activities of academics are increasingly micromanaged. In such a system, even when administrators are academics, they make decisions based on metrics rather than human judgment. Yet, this contemporary brand of MMB in education does not reflect all types of managerialism in the private sector. The type of management philosophy that academics now often face in universities that focuses on workflows and metrics is a type of Taylorism. Associated with Fredrick Taylor (1856-1915), such a philosophy reduced labour into a series of discrete elements, each regulated by a management structure. By controlling the technical aspects of production rather than the culture or satisfaction of workers, management asserts that output is increased. Coming into fashion in the early 20th century, Taylorism has, since the 1930 s, been viewed as severely flawed for industries that lack easily measured and agreed-upon tasks or outputs (Akerlof \& Kranton, 2005). Academic work is not readily measurable in the context of other industries, such as the fast-food industry, that still use Taylorist management techniques. The examples highlighting the inefficiencies of MMB in the first part of this article are to address supporters of this new system on technocratic grounds.

Other supporters of MMB in education hold the ostensibly reasonable view that universities, as part of society, change within society. In a world increasingly beset by MMB, should not universities mirror this transformation? Is 'institutional isomorphism' (see DiMaggio \& Powell, 1983) undesired in the 21st Century? To this seemingly reasonable position, we have addressed the second part of this article. It shows how such transformations alter the search for knowledge, the integrity of educators and the experiences of students. It does so through altering the values, discourse and behaviour associated with the academy. We demonstrate that the resulting culture of the university is antithetical to the venerable tradition of the advancement and dissemination of knowledge.

Before turning to our analysis, we, given the limited space within this article, will offer parsimonious definitions of the key terms to be used. We operationally define MMB as constituted from a combination of these three concepts:

Bureaucratisation: The prevalence within an institution for decisions to be made by a codified set of regulations rather than the judgments of individuals.

Metrics: The use of formal quantitative analytics rather than human judgment in evaluating the worth of individuals and actions.

Managerialism: Through the use of bureaucratic procedures and metrics, the activities of individuals and groups should be controlled by individuals not performing such activities. This is often believed to increase efficiency. 


\section{Labour inefficiencies}

In a managerial institution, bureaucratic systems seek to create rules, metrics and uniform outputs.This is one part of a trend of replacing human judgment with the impersonal rules and regulations in both the uptake of information and the control of actions. In such a system, education becomes increasingly interconnected with formal processes and procedures and thus administrative sectors. Therefore the autonomy, and, it seems, efficiency of the educator is lost within a series of relationships with administrators, support staff and policies. In this context, administrators not only tell academics what to do, but more accurately, how to interpret baroque regulation schemes and a set of operational procedures. In short, administrators can be seen as gatekeepers to an inaccessible world.

The major manifestation of this interconnectedness is the management of academic personnel's tasks through the medium of email. To illustrate MMB's increasing presence in academic work, we compared the number of emails in a single semester received by one of the authors (Y. Orr) at the University of Alberta in 2013, a non-managerial Canadian university with the number of emails he received at the University of Queensland in 2014, an Australian managerial institution. We have culled the data so that the comparison only counts the following type of emails relating to: teaching undergraduates, general employee information that must be attended to by academics (grades, employee mandatory training, scheduling of meetings, etc.). Emails that could be summarily ignored (closing of a parking structure due to inclement weather, arrival of a diplomat on campus, etc.) were not counted. Emails relating to graduate or research

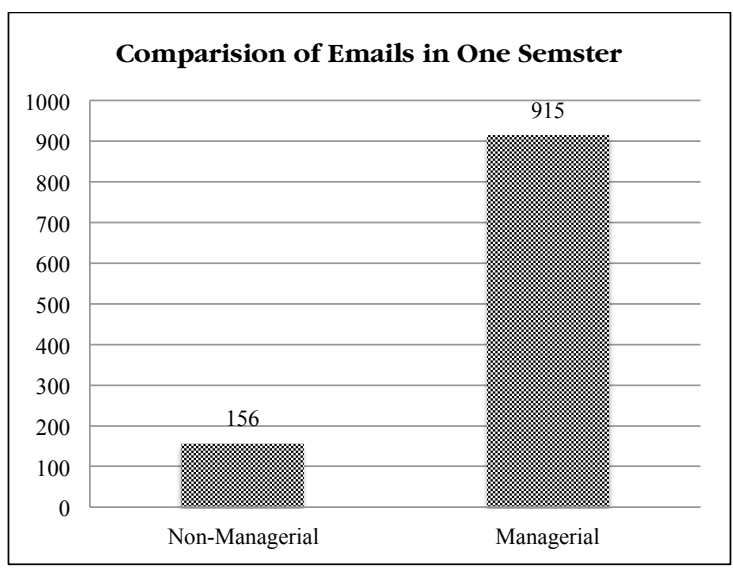

Figure 1: Number of emails in a semester between an 'efficient' managerial educational (915) and a traditional educational institution (156).

for a higher degree (RHD) student training and service were also not included as the number of these students and service responsibilities varied between universities.

An important question emerges from this comparison in Figure 1: why are there six-times as many emails in a managerial as in a non-managerial educational institution? The answer to this question may in part be found in the over-administration of academic life in managerial institutions. The volume of emails may also indicate a problem of informational clarity, whereby anything short of explicitness is distrusted, a perceived legitimate source of concern and clarification. The managerial system demonstrates a trend whereby professionalisation and trust is replaced by bureaucracy and suspicion, and a high standard of explicitness is demanded due to the suspicion of falling outside of a policy.

We posit that the greater volume of email around teaching originates from the complex administrative procedures in place in the MMB system. Based on an examination of our own emails throughout a single semester, a comparative glimpse of the managerial model (i.e. MMB) against the non-managerial model follows. The university that was labelled as 'managerial' considered itself a streamlined and efficient institution modelled and operated in accordance with contemporary business practices. This is demonstrated in its frequent use of language in emails that tout control, clarity, a series of checks and oversight. In contrast, the 'Non-Managerial' institution made little claims to efficiency of its operations.

In this case-by-case comparison we looked at five procedures common to university operations: 1 ) creation of a syllabus / electronic course profile; 2) creation of an exam; 3) student failure process due to extenuating circumstances; 4) travel authorisation; and 5) hiring of a teaching assistant / tutor. Each arrow indicates an email sent as part of an academic or professional task and is numbered in the sequence of the overall task. The key in the top describes its corresponding purpose.

So what do the integration of academic life with administrative control, the redundancies of observations, metrics, training and standardisation accomplish for an educational institution? How does this affect the education of students, the research for the academics and the efficiency and quality of the institution? The improvements for the university, education or research are minimal. Meanwhile, the negative effects for the quality of education are substantial. Before we turn to the negative consequences, let us examine the actual improvement to the education of students by looking at the example of exam creation and implementation. 
A U S T R A L I A N U N I V E R S I T I E S , R E V I E W

Managerial

1. Notification to create syllabus

2. Notification of syllabus upload

3. Notification of formatting change

4. Response to (3)

5. Notification to academic supervisor

6. Supervisor request for changes

7. Response to (6)

8. Approval Given

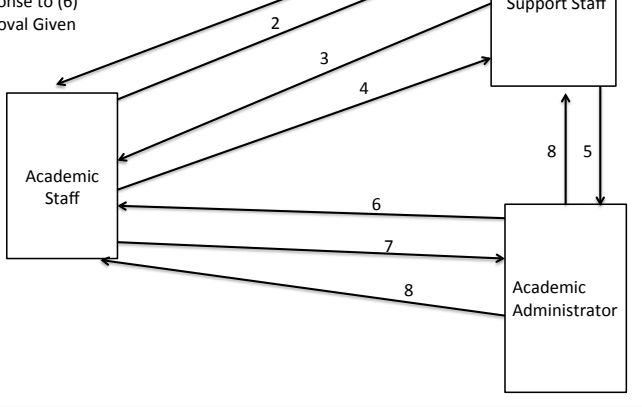

Non-Managerial

1. Request to include the university's

policy regarding recording class

lectures

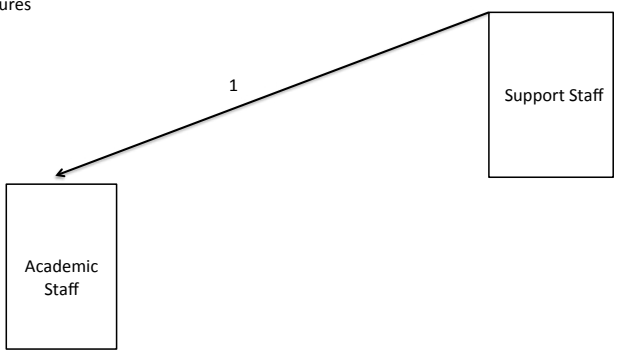

Figure 2: Creation of Course Profile / Syllabus*

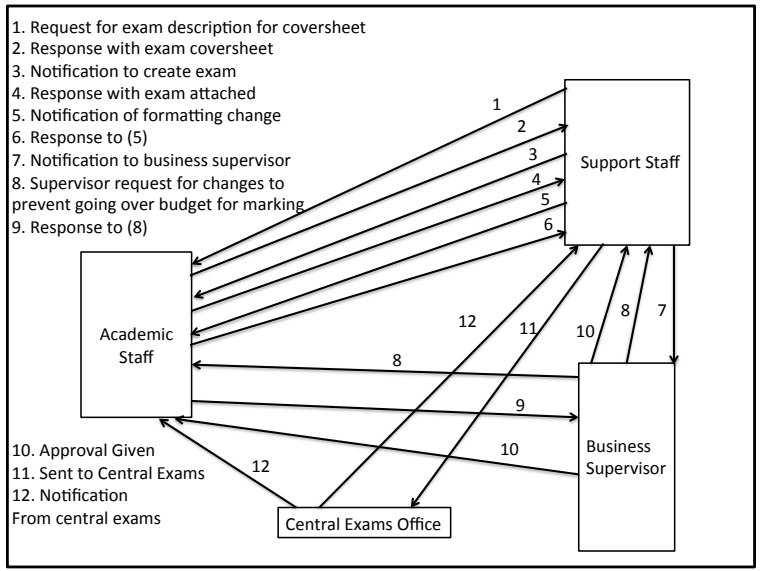

1. Sending exam to tutor (teaching assistant) to print

2. Confirmation that exams are printed

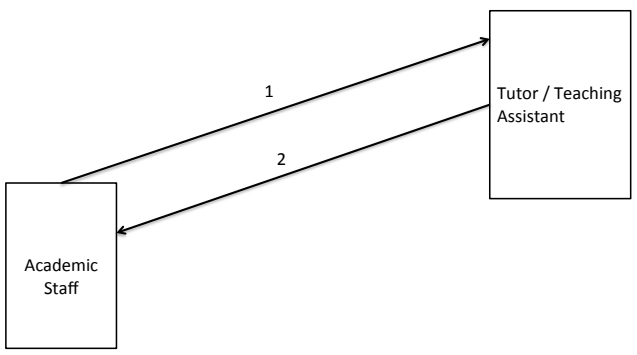

Figure 3: Creation of Exam

1. Request to student services

2. Request for information sent to Academic Staff

3. Request for information sent to tutors

4. Tutors reply

5. Forward information to Student Support Services

6. Confirmation
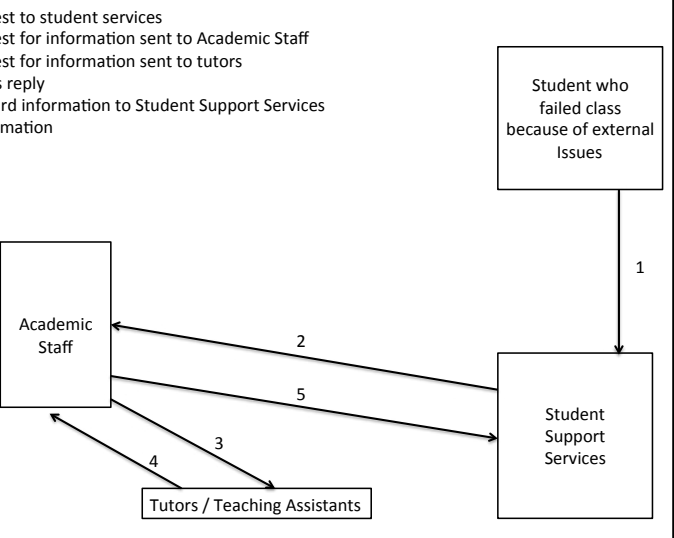

1. Request by student

2. Response by academic staff

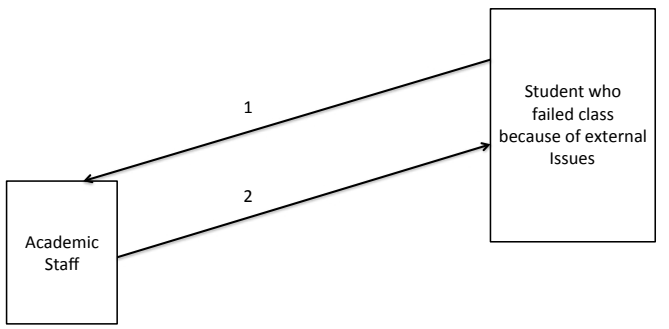

Figure 4: The process of addressing a student who failed because of mitigating external circumstances 
Managerial

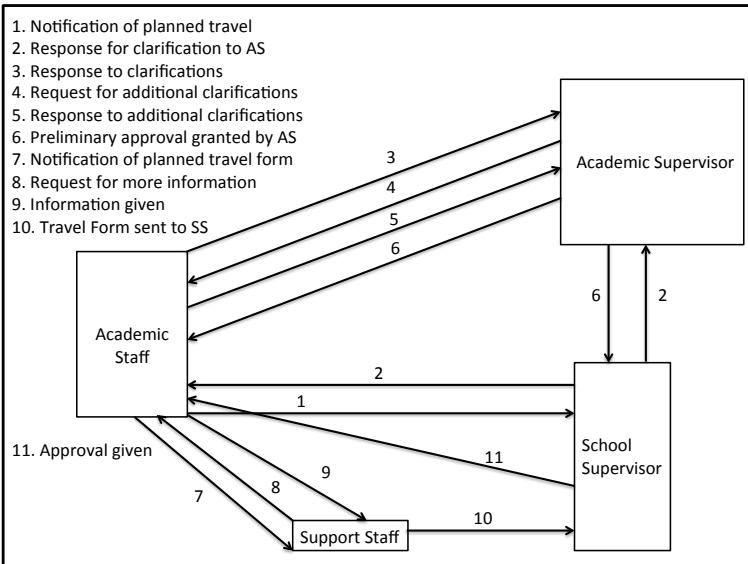

Non-Managerial

1. Human judgment: "Can I do this travel without adversely impacting my teaching, research and service responsibilities"

Figure 5: Travel Authorisation for travel outside of the semester*
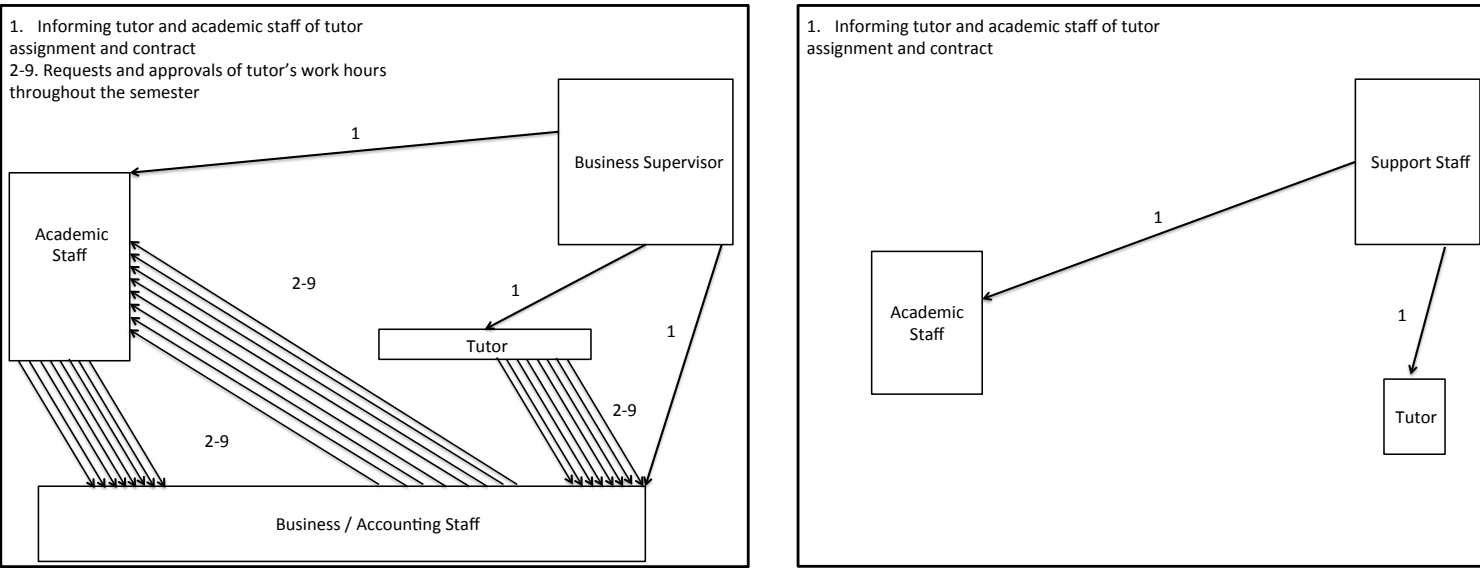

Figure 6: Tutor / Teaching Assistant Contracts Per-Tutor, Per-Class*

Note: These diagrams do not take into account the electronic forms common in managerial systems that are often part of email exchanges.

* These processes also involve completing time-consuming online forms in MMB institutions.

\section{Exam Creation}

Exams in a Taylorist managerial system must be run through a central exam service. It is unclear what the rationale for this is, but one explicit reason given is to ensure uniformity in exam formats and the administrative procedures that govern them. What this actually means is that exams are to have a uniform appearance across classes and disciplines. Each is to have a university logo atop the exam, with a certain assemblage of information giving the date, name and class of the exam. Standardising the formatting of the exam is also a significant part of this process. This may seem to be critical for writing an exam, but we would argue it is actually quite trivial. For instance, multiple-choice exams have the possible answers written in an exam as:
According to Ricardo, who ate Martin's apple pie on Saturday?
a) James
b) Gina
c) Trudy
d) Stan

The format of the 'a),b),c),d)' is supposed to be uniform throughout the exam, and ideally it should be. However, when writing an exam, an academic staff member will, occasionally, for one or two questions, write something like:
(a) James
A) James
(b) Gina
or...
B) Gina
(c) Trudy
C) Trudy
(d) Stan
D) Stan

The standard of (a), b), c), d)' has been replaced by a slightly different format for a number of questions. That such superficial regulation is the realised difference that 
centralised uniform exam systems make defies generous notions of efficiency. Such an absurdity becomes a tragedy through its substantive effects on exams. In particular, a centralised platform, using standardised exams, takes weeks to order and print. Academics, therefore, must submit exams a month before the class is over, meaning that they have to create exams based on content that they have not yet taught, circumstances which are arguably far more critical for the efficacy of assessment than the formalities of the text.

\section{Syllabus approval}

The need for control over the academic process has led to the upending of one of the more robust forms of communication in history. The ability to communicate with another can be divided into: bodily forms of communication that predate homo sapiens, verbal communication using symbolic language believed to have begun around 40,000 years ago, and written communication starting around 5,000 years before present. From the beginning of the modern university, syllabi which utilise the 5,000-year-old written form of communication, have been the method for explaining to a class what they will be learning and doing during the semester. This involves writing a schedule and listing the materials, reading and tasks with the same form of narrative found in traditional prose. Since the 1980s, this has been accomplished with the use of a word processor.

The drive to make the syllabus comply with standard formats has merged with technological advancements to produce something quite monstrous. Although, like the devil, it has many names, a syllabus in which content is input onto a website and converted into a formatted document, can be found in almost all managerial Australian universities. We will refer to it as a 'course profile'. The time to create, update, change and produce is different between the two. For instance, we timed how long it took to change a date on a syllabus compared to a course profile. Updating a traditional syllabus takes around 17 seconds, while the use of the online matrix, the number of clicks of the mouse and overall disorientation of the web-based course profile format takes 2 minutes and 40 seconds (approximately 10 times longer). This is compounded at every task for each semester. Whether or not this actually aids students in understanding the dimensions and expectations of the class is unclear, we did not find any research supporting the use of the course profile for enhanced learning. We showed students examples of a traditional syllabus and an electronic course profile and asked them which one they thought was more helpful in understanding what would happen in the class. Students preferred the clear prose and spatial orientation of the syllabus, even though almost none had seen one before.

Little captures the futility of a standardised syllabus in which the nuance of narrative prose is lost more so than the 'learning activities' section of a course profile. In this section, a set of learning skills, outlined by the instructor, are chosen based on the events in the class by date. This is intended to let the student know what type of educational activity will take place in a given class period and the types of skills or cognitive activity that they will draw on to perform these tasks. For instance, will the student be listening to an instructor or working on a project using what they had previously learned in class? This attempt to create a measurable unit, standardise it, and convey it to a student seems like a beneficial process for students to understand what happens in a class. However, because all learning is comprised of multiple forms of experience and requires innumerable forms of action and contemplation, these units do not capture many of the meaningful forms of learning that actually take place. Moreover, students surely know from reading the description of the activity in the schedule, such as 'Lecture: Plant Physiology' or 'Laboratory: Dissection of Toads,' what the activity entails. These activities are turned into a long matrix in which they are plotted out in one area following the sequence during the semester (see Figure 7). The students often express their bewilderment about these plots or 'learning activities' and none have described them as helpful. 
Perhaps the most significant critique of formalising a syllabus into a new standardised document is the questions this raises about the competency the university identifies in its own academic staff. If there is an actual need to format syllabi into a uniform document through the use of a rigid software, then questions arise as to whether the university is admitting that its academics cannot do the following tasks: (a) write in clear prose; (b) write in clear

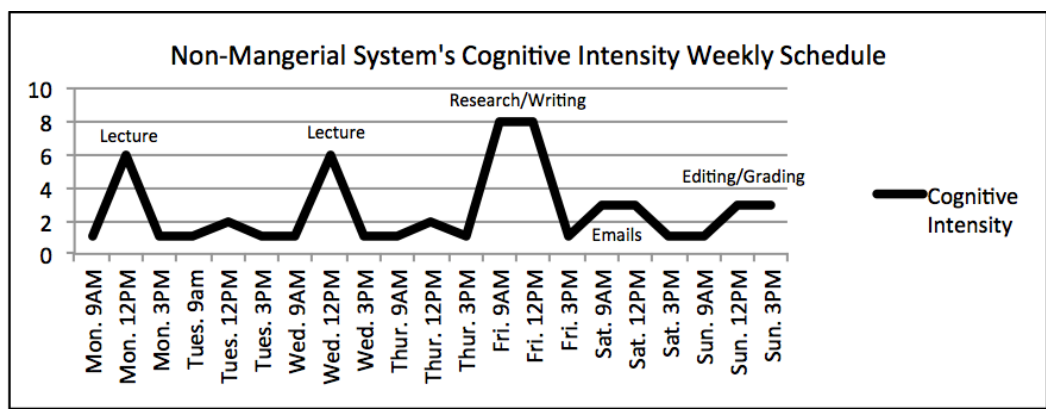

Figure 8: Impressions of cognitive intensity and activities in a traditional educational institution throughout the week

This graph is based on the author' experiences in the following non-managerial institutions: University of California at Berkeley, the University of Arizona, Yale University \& University of Alberta. prose about a class they will teach;

(c) write about a subject in which they are presumed to have expertise; and (d) write in a manner that is comprehendible to the students they teach. One must conclude that if such a system is needed, then universities have chronically hired academics who cannot perform the basic duties in their profession. Will universities admit to this? If not, then they must confess that such formatting of syllabi are not for the needs of students, teachers or education but instead for exogenous institutional rituals.

The most obvious lesson from an analysis of the emails and series of connections between educational and administrative staff is that this is a massive waste of time. Other institutions function with more competence without the regulations and structures of the Taylorist MMB model. It is unclear how to compare this unnecessary bureaucratic model with the actual labour that is invested in teaching and research. However, for those of us in a bureaucratic managerial institution, it feels as though it comprises the majority of our experience of our work and our relationship with institutions and colleagues. When we think of 'The University of So-and-so' our thoughts turn to administrative emails and not of what we learned in a recent seminar or conversation on campus. As wasteful as this system is, the effects of constant over-administration are perhaps more insidious to the quality of life and education as we will discuss next.

\section{Disenchantment}

In the first section, we have examined the inefficiencies of the managerial model. The enormous work that goes into such activities has little positive influence on the learning, research and quality of the educational institutions or the lives of those working in them. In this section, we will turn to how metrics, managerialism and bureaucratisation qualitatively change educational culture in Australian universities. An examination of subjective work experience of academics, the new values shared among colleagues and the emerging types of behaviour in MMB illustrates how little universities now look like educational institutions.

\section{Work intensity and thoughts}

Deep analysis, insight and creative production require periods of repose (Hegel 1995 [1816]; Ericsson 2006). The incessant emails stemming from numerous managerial relationships may constrain the ability for academics to achieve this intellectual space (Vostal 2016). Those entering an MMB system from a traditional academic culture often feel as though they have not only begun a new profession, but are in a entirely different industry (Ylijoki 2013). Recent studies have shown how 'fragmentation' within an academic's working day affects productivity and work satisfaction (Duncan et al 2015). To express the variance in the rhythm and quality of work, we have graphed, based on our subjective experience, the intensity of an academic's cognition throughout the week in a traditional and a managerial university. One might conclude that because an academic's job centres on the search for knowledge and its dissemination, cognitive intensity might be concentrated around these two activities. The relative importance of such punctuated episodes differs greatly in these two systems.

One notices in Figure 8 the high peaks of mental or energetic performance. Also, there are periods of 'downtime' within this schedule. Most intellectuals, artists, scientists and other members of creative fields recognise that this period of inactivity is necessary for high levels of creative output (Immordino-Yang et al 2012). It is even so for other occupations in which performance takes place in short intense bursts followed by recovery periods, such as in entertainment. This need is heightened when 


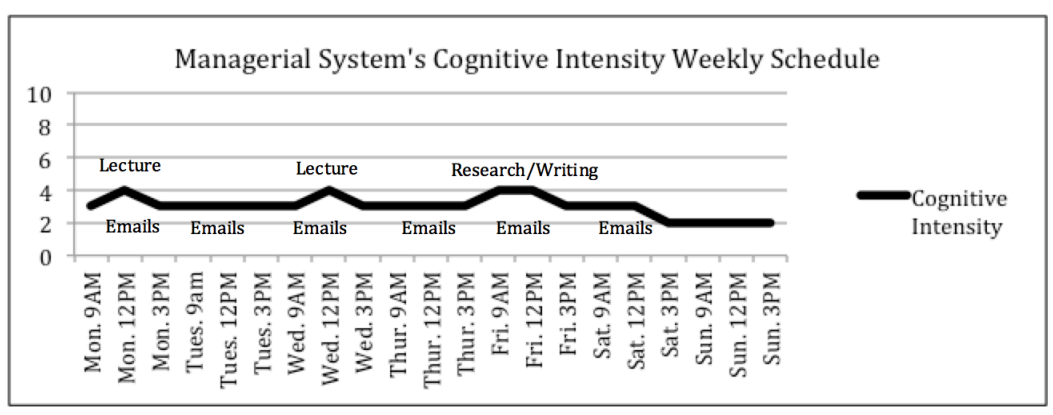

\section{Figure 9: Impressions of cognitive intensity and activities in a MMB educational institution throughout the week} The graph is based on the authors' experiences at the following managerial institutions:
the University of Melbourne and the University of Queensland. a mason or stonebreaker in-between surgeries. The effects of such work activity would be debilitating to the central activity of the profession. To carry this a step further, to ask people whose profession is to have complicated and nuanced thoughts and then expect them to constantly respond to the minutia of administrative email, would be like asking Herbert von Karajan to fix the rickety audio systems of arcade pinball machines according to the fickle needs of tone-deaf adolescents one is asked not only to perform but also to create. In a Taylorist MMB model, these blank spaces could be viewed as wasted time or an inefficiency. Whether it is a waste or if MMB models seek to 'utilise' such time is irrelevant, because the model in Figure 8 does not exist in the new system. Instead, with the ubiquity of administrative and logistical emails, the intensity of work looks more like Figure 9.

There are several key differences between these two intensity schedules reflecting common changes experiences of academics (Ylijoki \& Mäntylä 2003). Most strikingly, there is greater mental activity subsumed by emails in Figure 9. The aggregate data supporting this assertion and the rationale behind the importance of emails in the MMB system was outlined earlier. Constant emails affect the creative aspects of an academic's life in two ways (Menzies \& Newsome 2007). First, there is relatively less energy and focus given to classes, research and writing. And, second, the necessary repose needed for developing meaningful ideas, classes and writing is no longer available. Very few of us can turn from responding to an email - for example demanding the font size be changed immediately on subheadings of an exam - to a new discovery or thought with the click of a mouse. The effects of this transition on the capacity for thought are difficult to overstate.

Perhaps external responsibilities that are not directly related to a primary function of a profession are part of any job. For instance, society finds it reasonable to ask a surgeon who is required to perform intricate highstakes surgery with his hands to also teach students and administer facilities in-between surgeries. Yes, society does do this, but the analogy is subtly inaccurate. Academics are to thoughts as neurosurgeons are to mindful and controlled hand movements. It would more closely be the equivalent of asking a surgeon to work as in-between conducting performances at the Berlin Philharmonic.

\section{Values and discourses}

Beyond email's effects on the subjective experience of work intensity and the quality of education, MMB has altered the shared values of academics. Taken at their own word, metrics were intended to reflect the values associated with the production and transmission of knowledge in research, publication and teaching as part of modernity's quest for quantification (Webster 2006). Instead, they have transformed the value system itself. More than simply substituting a set of values for a proxy whereby the original values are measured using different means, it builds a value system that is qualitatively different and actually antithetical to the growth that characterises learning (see Holmstrom \& Milgrom 1991 for a formal model for such a process). Here, we illustrate several ways in which the quality of work can be communicated to a colleague as examples from which we construct a comparison between traditional and MMB systems. As an example, Figure 10 shows the various ways whereby one colleague can describe the quality of work to another about a Prof. Johnson.

One would expect that statement (a) would be the most likely and appropriate description about the quality of another colleague's work. It is our experience that under the quantitative metrics used in MMB systems, statements like (a) are nearly non-existent. Rarely do academics speak of the actual content of another's work, but instead use the MMB idioms to signal the content. In non-managerial systems, statements from (d)-(g) are likely considered extremely uncouth, while statements (f) and (g) might be considered against the spirit of the academy. Someone who would make such comments would be thought of as crass. The differences in these statements reflect 


\begin{tabular}{|c|c|c|}
\hline${ }_{0 \mathrm{~g}}^{9}$ & $\begin{array}{l}\text { (a) Prof. Johnson's research showed that hunter-gatherers have higher levels of cooperation in } \\
\text { harsher environments. } \\
\text { (b) Prof. Johnson wrote the most important work on hunter-gatherer societies. } \\
\text { (c) Prof. Johnson is the leading authority on hunter-gatherers in the world. } \\
\text { (d) Prof. Johnson published an article in "Fancy Social Science Journal X". } \\
\text { (e) Prof. Johnson published an article in an A* journal. } \\
\text { (f) Prof. Johnson published five journal articles last year. } \\
\text { (g) Prof. Johnson received a grant for } 500,000 \text { dollars last year. }\end{array}$ & 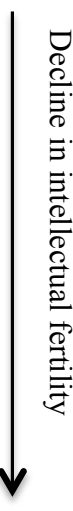 \\
\hline
\end{tabular}

Figure 10: Types of descriptions used to attest to the quality of another's work

what is understood as work, quality and the point of the educational enterprise. The metrics meant to passively gauge the 'quality of work' actually alter the values of the systems in a way that reduces academic culture into an idiom of MMB.

That this is a spectrum of different types of descriptions may occlude an even deeper consequence between saying (a) and (d)-(g). In each description a colleague learns something. However, what they learn varies. The content of the information (hunter-gatherers, journals, publishing rates, finances, etc.) is of course dissimilar but the ways in which these differences emerge into types of environments is qualitatively distinct.That 'hunter-gatherer's have higher levels of cooperation in harsher environments' is a form of knowledge about the actual subject matter of a discipline. In this way the communication structure of a culture reflects the intended goal of that culture. More critically, this type of information can be integrated into the existing knowledge of a student or academic staff member and it might prompt this person to learn more about this subject matter. A living discourse about actual knowledge of the world is at the centre of education but the discourse in higher education no longer reflects this. Put ourselves in the shoes of a mother who asks her child what he learned at school that day and the response was: 'that Mr. Johnson had more A* publications than Mr. Thomas'. What should she think of her son's school? Should she continue to send him there to get such an education? This is essentially the type of quotidian 'learning' that takes place in MMB universities. What is supposed to be the highest level of academic culture now looks to be the most superficial.

Do these values that we have described in the terms of discourse actually become manifest in the behaviour of academics? Do people make educational decisions based on these new values or is this simply a form of meaningless academic parlance? What is no longer being said (i.e. that hunter-gatherers do certain things) is a powerful indication that at least one aspect of academic culture has been negated. The growth of an individual, discipline or the academy that is lost when someone does not learn something substantive about hunter-gatherers is replaced with another type of activity-bureaucratic gamesmanship. The explicitness of measuring academic value in a managerial system with metrics allows for the advancement of knowledge to become a type of 'game' in which achievement is conceptualised in superficial and packaged forms as 'beauty' is in a pageant. With what they are learning in a MMB culture in which statements (d)-(g) reflect values, academics now make measured and concerted efforts to publish in prescribed ways. They seek out journals that are unduly ranked high by universities that also have high acceptance rates over journals more fitting for the actual work or that are more common outlets in their fields. Perhaps most alarming, academics now carry MMB to its logical conclusion by petitioning their universities to change the ranking of journals to improve the perceived quality of their research.

\section{Instrumentalism, careerism and student education}

This new mentality extends beyond publication strategies. Conferences are planned not as opportunities to share and explore ideas, but may rather be used to signal that departments are central players in a field. This is not to suggest that all academic activity was quixotic before the managerial model, but the explosion of this type of mentality is only outshone by how unashamed it appears to be of itself. Individuals no longer attempt to hide what were once distastefully superficial motives guiding instrumental behaviour. Many academics now explicitly state that they are doing a certain activity for the benefit of their careers, without realising that this might be 
considered antithetical to the academy. Pejorative terms such as 'careerist' are no longer applied because superficial work, ploys for advancement and instrumentalism are the new norms.

Perhaps most concerning, students, and more precisely their education, are now objectified resources in three ways: (a) student education is almost exclusively measured by the course evaluations of students; (b) student enrolment and not their education appears to be what is important for administrators; and, (c) student education is now viewed as raw material for impressing metrics and annual appraisals by academics. We will first examine the influence of course evaluations of students compared to traditional measurements. The oversight of courses and their quality is only measured within the managerial educational system through quantifiable and standardised metrics. This means through course evaluations. Literature shows a positive correlation between student grades and favourable course evaluations (Love \& Kotchen, 2010). Additionally, studies now show that high grade averages in classes may actually mean that students are learning less as their performance in advanced classes is below that of peers who took prerequisite courses with lower grade averages (Carrell \& West, 2010).

The problems associated with standardisation in metrics are magnified by the MMB culture that focuses on enrolment because of its link to finances (Slaughter \& Leslie 1997). This extends to actual academic staff members who have remarked that they knew a course was poorly taught and the students learned little but that the teaching evaluations came back positive and the high enrolments meant that it should not be altered. This logic is being reproduced in some ways throughout the next generation of educators early in their careers. For instance, tutors have brought-up issues about the grades that they thought were unusually low in several courses. This is not remarkable in-itself, but how they framed such cases were. They worried that low grades would impact the future enrolments in advanced courses years later. It appeared their concern was not the student's education, nor even the equitable relationship between performance and grades, but its effect on departmental finances. Along these lines, tutors' responses to academic staff requests carry the MMB mentality. Reasonable expectations, such as their attendance in lectures in classes for which they have never tutored or taken, are rebuffed by citing that their contracts state that they are not paid for attending lectures and thus are not obligated to attend. Decisions regarding the tutor's own education, and that of the students, and the responsibility they are entrusted with as teachers, appears to be now overshadowed by a bureaucratic rationale.

If standardised and quantifiable means are not the sole means for evaluating the quality of an education, how would quality teaching and, as an extension, quality education be measured? That such a question has to be asked is telling as to how far universities have moved from being primarily educational institutions. In educational institutions, the quality of other classes taught at a university is evident in the students in higher division classes in that institution. By educating students, a teacher learns about their prior educational history, including where they learned various aspects of their current knowledge and conceptual abilities. It would be like asking craftsmen in a weaving guild to rate their mentors on a scale from 1 to 10 instead of assessing the quality of the protégés' tapestries. The reason why we must judge educational quality with metrics is because universities are no longer educational institutions (or at least not enough so to tell the difference between good and bad teaching or have confidence in their ability to do so).

Perhaps the harshest critique of MMB in education can be found in what academics inflict upon their students. The managerial control over teaching may incentivise a naked careerism at the expense of student education by those entrusted to teach them. The managerial system rewards 'innovative teaching' far more than quality teaching. Yet it seems to do so in a seemingly facile and benign way. Demonstrating this, one is only able to report quality teaching (or at least the problematic metric measuring it) with numbers such as 4.66 out of 5.00 in an annual appraisal. An innovative teaching experiment fills up, at the very least, a line on an appraisal document with descriptive text. In fact, many appraisal documents have a section asking for how one has been an innovative teacher. In such sections, considerable space can be filled by explaining how dramatically innovative one's teaching method was and 'spin' how successful it was in achieving its goals. Educators now may marginalise, exploit and even destabilise student education to demonstrate pedagogic innovation for an appraisal form without necessarily any interest in showing, or being expected to show, that it produces worthwhile results.

\section{Next steps}

Socrates was put on trial and executed in Athens for impiously questioning the existence of civic gods and corrupting the youth. A martyr to free inquiry, his legacy is twofold: knowledge is valuable enough to make 
sacrifices for, and alternatives to communal norms are important for individual and social life. Universities have been the stewards of both legacies. We now watch these traditions end and share Plato's tears in losing such a friend in our own lives. The new hemlock is not made from a conscious effort to end the enriching aspects of the spirit of inquiry, intellectual growth and education. But as we have described, managerialism, metrics and bureaucratisation alter the lives of academics, the culture of the university and the mentalities of its academics to the point to which they no longer reflect Socratic values. Such a requiem should serve as a warning to others in the early stages of an MMB transformation.

So what should we do about the end of higher education? Many fatigued academic staff members say that they do their best to ignore the nuisances of managerialism and the superficiality of the new academic culture. They recommend focusing on one's own research as a strategy for surviving this system. This means that universities become dead places in which we are intellectually worse off for being a part of instead of locations of growth. In Plato we also can find how such an unresponsive approach may end. When brought his poison, Socrates asked the carrier: 'Well, my good man, you know about these things; what must I do?'The carrier replied, 'Nothing, except drink the poison and walk about till your legs feel heavy; then lie down, and the poison will take effect of itself.' Socrates's death, for something, was a beginning. Ours, because of nothing, portends an end.

\section{Acknowledgement}

The authors would like to thank David Graeber and Cheryll Alipio for their thoughtful comments during the preparation of this article.

\section{Yancey Orr is an anthropologist at the University of Queensland. His research investigates how knowledge systems emerge in complex societies.}

Contact: YanceyOrr, y.orr@uq.edu.au

\section{Raymond I. Orr is a political scientist at the University of Melbourne. His work examines Indigenous communities' political organisation.}

\section{References}

Akerlof, G. \& Kranton, R.E. (2005). Identity and the Economics of Organizations. Journal of Economic Perspectives 19(1), 9-32.

Alexander, J. (2013). The Dark Side of Modernity. New Jersey, USA: Wiley Press.
Carrell, S.E. \& West, J.E. (2010). Does Professor Quality Matter? Evidence from Random Assignment of Students to Professors. Journal of Political Economy 11 (3), 409-432.

Duncan, R., Tilbrook K. \& Krivokapic-Skoko B. (2015). Does academic work make Australian academics happy? Australian Universities' Review 57(1).

DiMaggio, P.J. \& Powell W.W. (1983). The Iron Cage Revisited: Institutional Isomorphism and Collective Rationality in Organizational Fields. American Sociological Review 48(2), 147-160.

Eliade, M. (1987). The Sacred and The Profane: The Nature of Religion. San Diego, USA: Harcourt Press.

Ericsson, K.A. (2006). The Influence of Experience and Deliberate Practice on the Development of Superior Expert Performance. The Cambridge Handbook of Expertise and Expert Performance. Cambridge: The University of Cambridge Press.

Foucault, M. (1990) [1976]. History of Sexuality: Volume 1: An Introduction. New York: Vintage Press.

Ginsberg, B. (2011) The Fall of the Faculty: The Rise of the All-Administrative University and Why it Matters. Oxford: Oxford University Press.

Graeber, D. 2001. Toward An Anthropological Theory of Value: The False Coin of Our Own Dreams. Basingstoke, UK: Palgrave.

Graeber, D. (2015). The Utopia of Rules: On Technology, Stupidity, and the Secret Joy of Bureaucracy. New York: Melville House.

Hegel, G.W.F. (1995 [1816]). Lectures on the History of Philosophy: Greek Philosophy to Plato. Lincoln and London: University of Nebraska Press.

Holmstrom, B. \& Milgrom, P. (1991). Multitask Principal-Agent Analyses: Incentive Contracts, Asset Ownership and Job Design. Journal of Law, Economics, \& Organization, 7, 24-52.

Immordino-Yang, M.H., Christodoulou, J. \& Singh, V. (2012). Rest is not Idleness: Implications of the Brain's Default Mode for Human Development and Education. Perspectives on Psychological Science, 7, 4, 352-364.

Lasch, C. (1995). Haven in a Heartless World. New York: Norton.

Love, D.A. \& Kotchen, M.J. (2010). Grades, Course Evaluations, and Academic Incentives. Eastern Economic Journal 36, 151-163.

Menzies, H. \& Newson, J. (2007). No Time to Think: Academics' life in the globally wired university. Time \& Society, 16, 1, 83-98.

Scott, J.C. (1998). Seeing Like a State: How Certain Schemes to Improve the Human Condition Have Failed. New Haven, CT: Yale Press.

Robinson, B.A. (2014). Barebacking with Weber: Re-enchanting the rational sexual order. Social Theory \& Health 12, 235-250.

Slaughter, S. \& Leslie, L. (1997). Academic capitalism. Baltimore, MD: Johns Hopkins University Press.

Vostal, F. (2016). Accelerating Academia: The Changing Structure of Academic Time. Edinburgh: University of Edinburgh Press.

Webster, F. (2006). Theories of information society. London: Routledge. Weber, M. (1978) [1922]. Economy and Society. Berkeley, USA: University of California Press.

Weber, M. (1946) [1919]. Science as a Vocation, in H.H. Gerth \& C. Wright Mills (eds, trans). Max Weber: Essays in Sociology. New York: Oxford University Press.

Weber, M. (2001) [1905]. The Protestant Ethic and the Spirit of Capitalism (T. Parsons, trans.). New York: Merchant Books.

Ylijoki, 0. (2013). Boundary-work between work and life in the high-speed university. Studies in Higher Education 38, 2, 242-255.

Ylijoki, 0. \& Mäntylä, H (2003). Conflicting Time Perspectives in Academic Work. Time and Society, 12, 1, 55-78. 


\section{Democratisation or}

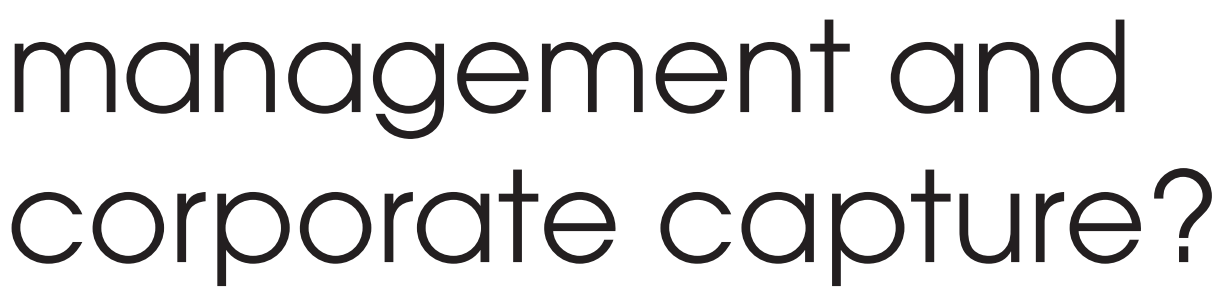

\section{Theses on the governance crisis of Australia's semi-privatised public universities}

\section{Andrew G Bonnell}

\section{University of Queensland}

This paper proceeds from the view that managerial capture has already become a fundamental problem after a couple of decades of largely untrammelled managerialism in our public universities, and that this problem is likely to be compounded by further shifts towards deregulation and de facto privatisation, which is the direction that current federal government policy is trying to take in the higher education sector. Greater managerial capture and greater susceptibility to steering by corporate interests promote greater diversion from the public good missions of public universities and increasingly dysfunctional internal governance with grave consequences for workplace culture. The paper argues that a counter-movement to democratise public universities is overdue.

Keywords: university governance, managerialism, management capture, democratisation

\section{Vice-Chancellor as CEO-Dictator}

Defenders of the managerialist status quo in Australian universities might argue that the current regime has been remarkably successful. Despite chronic funding constraints, Australian universities continue to perform very strongly on international league tables, whatever the methodological shortcomings of these may be, and continue to attract the international students who help to pay the bills. However, in part, performance on international rankings tables reflects universities' increasing shifting of resources to activities that are counted by these exercises (at the expense of other areas). University performance has also been on the back of high staff workloads and a highly casualised teaching workforce, with approximately half of the undergraduate teaching in universities being done by casual teachers.
There are, however, clear indications of the weaknesses of the current top-down managerialist model. In recent years (2011-2015), vice-chancellors at two universities have had to resign after coming under investigation by state anti-corruption commissions. At another university, two successive chancellors with business backgrounds have come under investigation by the relevant state anticorruption watchdog, and one former chancellor has since been found to have acted corruptly (Independent Commission Against Corruption, New South Wales, 2014; Hare \& Lane, 2014). Limited transparency in governance and a culture in which staff feel unable to say 'no' to a vicechancellor have been factors that contribute to facilitating ethical breaches. This problem is not unique to Australia. Benjamin Ginsberg (2011) cites a string of scandals in the United States involving corruption, insider deals, and 
academic fraud and plagiarism which, in his view, have been made possible at least in part by weak oversight on the part of boards of trustees of universities.

The existence of top-down hierarchical structures and an aggressively managerialist culture have also produced markedly sub-optimal workplace cultures in universities. Large-scale surveys periodically conducted by universities have indicated as much, despite the limitations of the survey instruments used. While staff feel a commitment to the work they carry out and a high regard for the calibre of their colleagues, there is a widespread disconnect felt by them with the university as a corporate structure. One could speak of a growing split between the university conceived of as a community of scholars, comprising staff and students, and the capital-U University as a corporate enterprise. Surveys of workplace culture also reveal a high degree of competitiveness, accompanied by behaviours of aggression on the one hand and passivity and avoidance on the other, conservatism and conformity, and suboptimal levels of constructive and cooperative behaviour. Demonstrating this, findings of a 2012 survey of over 4,300 staff members at the University of Queensland (response rate 57 per cent) included statements such as:

[the University]'s culture was also repeatedly described as akin to a feudal system: those with power and influence thrive, while others curry favour to get ahead or keep their heads down to maintain their security. [...] Power, playing politics and nepotism causes significant unhappiness and unrest within workplaces. Staff comment that the power dynamic also stifles ideas, as people are either afraid of being seen to rock the boat [...]. (Nous Group, 2013, p. 17).

Individual interviews with staff members identified 'a strong theme of mistrust and fear' (Nous Group, 2013 , p. 12). These survey results reflect hierarchical and authoritarian structures and cultures that not only have a negative human impact on the people within the institutions, but are clearly sub-optimal ways to manage the teams of highly gifted employees that make up universities' staff. The Nous Group workplace culture survey of University of Queensland states: 'Research identifies a positive correlation between predominantly constructive operating cultures and organisational outcomes' (Nous Group, 2013, p. 9), while identifying a lack of a constructive and cooperative workplace culture at that university.

Another clear indication of the failure of Australian universities' current governance model was the spectacular failure of nearly all Australian vice-chancellors to defend public higher education in the face of the Liberal-National Coalition Government's efforts to introduce a radical approach to domestic fee deregulation, coupled with stringent public funding cuts, in 2014-15 (and possibly beyond, as the issue is still unresolved and some form of deregulation is still government policy at the time of writing). This failure to defend public higher education against radical marketisation and deregulation would result in astronomical debt burdens for students who already pay substantial fees by the standards of most OECD countries' public university systems. This is all the more glaring in the light of the fact that the 'demand-driven system' of higher education enrolments has created a much higher participation rate in the Australian university system than it enjoyed previously, and thereby has created a much enlarged popular constituency for the defence of public higher education. Any strategic advantage that this enlarged constituency might have conferred on the higher education system in lobbying for better government funding was nullified by vice-chancellors' unseemly scramble for a slice of higher domestic student fees, at the expense of future generations of students. A situation in which the overwhelming majority of vicechancellors, and their peak lobby group, the hubristically and misleadingly named Universities Australia (formerly, and more accurately, called the Australian Vice-Chancellors' Committee) effectively lobbied for a 20 per cent cut in Commonwealth grants, and cuts to the public funding of the Research Training Scheme, in return for permission to charge uncapped fees to domestic undergraduate students, represented a betrayal of public higher education by the managerial elite which has gained control of universities.

\section{Universities susceptible to management capture}

Management capture has been identified in management literature for some decades now as a constant threat to good corporate governance (foundational texts here include Burnham, 1966 [1941] and Berle and Means, 1968 [1932]). The interests of a management elite in the shortterm are not necessarily identical with the long-term interests of an enterprise (Chambers \& Crowley, 2003).

Effects of management capture include: concentration of resources at the upper managerial level, often at the expense of operational levels, an increasing gap in remuneration between the top managers of an organisation and the average employee, and an increasing tendency towards hierarchical and exploitative management practices.

In the case of Australian universities, we have seen the growth of vice-chancellors' salaries to the point where 
salary packages in excess of $\$ 1$ million are not uncommon (Forsyth, 2014, p. 125; The Australian, 2015). In the 1970 s and 1980s, before the 'Dawkins revolution', ViceChancellors at the University of Queensland received no more than 150 per cent of a full professorial salary (Queensland State Archives 2009,p. 10). The remuneration packages of Australian vice-chancellors are conspicuously in excess of those received by their counterparts at leading United States or British universities, although as British universities become more corporatised, with higher student fees, there are signs of an executive salary breakout there as well.

The rising managerial caste has continually augmented its ranks in a process of management bloat. Where a university might once have had a vice-chancellor and a deputy vice-chancellor, executive groups of ten or more (like that of the current University of Queensland) are not uncommon, with a vice-chancellor (also titled president), and a senior deputy vice-chancellor (or provost) surrounded by a penumbra of deputy vicechancellors and pro-vice-chancellors, all with their own administrative entourages (see Forsyth, 2014). Deans are now assisted by numbers of associate deans or sub-deans, and deputy associate deans (or 'deanlings' or 'deanlets', as one American critic of the managerial university has called them) (Ginsberg, 2011, p. 11). Full-time heads of school are supported by senior staff whose administrative duties take up an increasing share of their time and workload allocations. The proliferation of managerial positions is creating a separate management career path for academics; instead of senior management roles being the culmination of a distinguished scholarly career, there is now a separate managerial track in which the financial rewards as well as access to internal power and influence are typically significantly larger than they are for academics who continue to devote themselves primarily to teaching and research.

\section{Deregulation or de facto privatisation?}

An aspect of deregulation that received relatively little attention in the debates over the Coalition Government's deregulation bills in 2014-15, compared with the understandable emphasis on the highly negative effects it would have on future generations of students (or aspiring students) in a material way, is the implications of deregulation for university governance. If public funding were to diminish further, the corollary would be a diminished capacity for governments to hold universities accountable for realising their public good objectives.
Indeed, such public good commitments would be likely to be submerged in the drive for revenue maximisation at the expense of students. In the late 1990s, Marginson and Considine (2000, p.20) pointed to a 'paradox' in neoliberal higher education policy in Australia, by which policies of deregulation and marketisation led to greater 'head-to-head competition' between universities and greater responsiveness to 'market signals' (or pseudomarkets), at the same time as increasing encroachment on the autonomy of individual universities. Federal governments have continued to maintain a 'national system' of higher education, ensuring standard pricing for courses for domestic students, as well as a common standards framework, and using funding levers to procure compliance with the policy objectives of the government of the day. It is foreseeable, however, that if federal funding were to further decrease, and universities gained greater independence as competitive actors in a capitalist higher education market, including setting their own prices for domestic students, the claims and capacity of governments to oblige universities to act as part of a public system of higher education would necessarily diminish.

Arms-length autonomy from governments in their internal affairs is essential for universities, but in a democracy some level of accountability is essential for universities that were founded at public expense, provided with public land, and funded for decades largely at public expense. Managerial elites in universities have essentially ceased to be accountable to internal constituencies of staff and students, as indicated by the reduction of numbers of staff members and students on governing bodies, and the weakening of the role of Academic Boards in internal governance. They still have some degree of accountability to elected governments, but this would be radically attenuated in a deregulated system.

\section{Capacity of outside senate members}

Vice-chancellors are in effect only accountable to the governing senates or councils of their institutions (nomenclature varies; in the following I will use the term 'senate'). Under the national governance protocols to which Australian universities have had to adhere for a decade now, a majority of members of these bodies must be external to the university (not current staff or students) and there must be sufficient members with expertise in business and finance. Given the extent and complexity of the finances of universities, few would question the need for some council members to have business and finance expertise, and for such members to sit on a university 
senate's Finance Committee. For example, the University of Queensland now has an annual budget in the order of $\$ 1.8$ billion. Nevertheless, some such expertise exists within the ranks of university staff, and participation by more university staff on the finance committee would be conducive to greater transparency of university budgets, which can be very opaque.

Within governing bodies, a key dimension of management capture within universities is the control of the flow of information. The capacity of university managements to limit the information received by senates is not to be underestimated. University managements are also able to exercise influence over the recruitment of external senators, by forwarding nominations to state governments for the government appointments (technically, appointments by the 'Governor in Council'),

and in some cases by exercising an influence on the selection of external senators co-opted by the existing senate.

There is some discussion in management literature about the desirability of

\section{Currently, there are too few student and staff elected members of senates. These are sometimes subjected to specious allegations of conflict of interest.}

as executive appointments and finance planning to be hived off into smaller committees. These report outcomes to the plenum of the senate, which consequently has little capacity for input.As an example,until ca.2005, the National Tertiary Education Union (NTEU) Branch President at the University of Queensland was an ex officio member of the Senate Finance Committee. This ceased when the university complied with the Howard Liberal National Coalition Government's 'National Governance Protocols', and there was no provision made thereafter for elected staff representation on the senate finance committee.This resulted in a loss of transparency in the financial affairs of the university. Staff and student representatives tend to be excluded from these inner groups, with the result that the majority of senators may have little or no meaningful input into decisions such as the selection of the next vice-

chancellor. Indeed, it would not be inaccurate to state that the majority of University of Queensland senators had no meaningful input into the appointment of the last two vice-chancellors.

Following the reduction in size of most university governing bodies that resulted from the National Governance Protocols in 2004 and separate state legislation in Victoria, there is currently a secondwave push, apparently driven by some conservative chancellors, to shrink governing bodies further, so that they more closely resemble Australian corporate boards of governance. This is likely to result in senates that have less broad community representation than some have had in the past, as well as putting further pressure on a small number of internal senators to convey to other senators knowledge specific to the institution that might be a check on what is otherwise the virtual management monopoly of information.

\section{Universities and corporate influence}

There is currently too little transparency in university budgets and in governance at the top level. To illustrate this lack of transparency: several years ago, the Academic Board of the University of Queensland, with over 120 members, of whom about 40 are elected, used to receive the same 40-page booklet of budget papers which the Senate received. The Senate also received other papers as well. By contrast, there was no budget briefing for Academic Board in 2015 and the budget briefing in 2014 was derisory in its lack of information. Members were

Currently, there are too few student and staff elected members of senates. These are sometimes subjected to specious allegations of conflict of interest (Roberts, 2016). There is also a tendency for sensitive matters such 
only told the projected EBITA (earnings before interest, taxes, and amortisation) figure for 2014 and the actual for 2013, but not the total revenue or expenditure. Staff members of a university have to wait until the appendices of the annual reports are tabled in the following year to get an accurate picture of the university's finances at the institution-wide level. On top of this, these audited accounts do not give details of the complex internal distribution of funding with its different taxes and transfers vertically and horizontally within a university. Thus it is difficult for staff to get a clear idea of the university's financial state, and external senators have little idea of the impact of changes in budgets on the level of operating units within the university.

The absence of financial transparency and the lack of transparency of governance at the top, with small senates meeting in camera, result in conditions where influence might be exerted behind the scenes. Relatively small amounts of money can be attractive to cashstrapped institutions. While large universities dispose of very considerable amounts of revenue, around 60 per cent of it tends to be committed to staffing, and much of the rest is tied up in capital maintenance, overheads, and recurrent costs. Consequently, relatively small sums can entice vice-chancellors to engage in behaviour that might have negative effects on a university's reputation among the scholarly community internationally. This was dramatically illustrated by the Abbott-led Liberal - National Coalition Government's attempt to induce a university to host a research centre on the economics of climate change which has a track record of alignment with corporate interests opposed to reduction of fossil fuel consumption. Two vice-chancellors expressed interest in lending their institution's name to such a centre.

Elsewhere, the provision of philanthropic or private funding for a specific research initiative has seen vicechancellors 'leveraging' matching funding from elsewhere in the budget to secure the outside funding. While universities have derived positive benefits from such arrangements, they illustrate the capacity for 'leverage' both ways between funding partners and universities.

Cases where members of universities' governing bodies have come into direct conflicts of interest through their activities on university senates are rare as far as we know, and there are generally protocols in place for direct conflicts to be disclosed. Of wider concern, however, is the cultural influence such senators may exercise as senates increasingly resemble corporate boards, and elected members with an intimate knowledge of higher education in general and the university in particular form a dwindling and often isolated minority. The value orientation imported from the world of private industry that can take hold at the top level of a university may not be in accord with the core function of the university, which, as Raewyn Connell reminded us in her keynote address (2015), is the advancement of knowledge and its transmission and sharing.

It is worth noting that there has never been any kind of ethical screening of the corporate backgrounds of external senators. Universities accept no money from tobacco companies for the compelling reason that this would make them ineligible for any funding from the National Health and Medical Research Council, but there is little evidence that universities exercise much ethical discrimination in other corporate relationships. It would be possible to draw up a sizable list of university senators in recent years who have come from corporations involved in ethically questionable industries (e.g. Armaments, asbestos, gambling) or from companies with ethically questionable records of conduct (e.g. bribery scandals, aggressive tax minimisation). This is not to impugn the probity of individual representatives or directors of these companies or their willingness in good faith to contribute to the governance of a university, but the cultural influence of such corporate backgrounds on the culture of university governance and management is largely under-examined. It should be noted that there is analogous work on 'regulator capture' by corporate interests and their representatives, and related conflict of interest (e.g. Nestle, 2013). The role of informal networks in the 'big end of town' or within a city's establishment elite is inherently difficult for outsiders to document or analyse, but small governing bodies are likely to be highly susceptible to insider influence through such networks.

\section{The point is to change it}

What avenues exist to democratise universities? Raewyn Connell (2015) reminds us that there was never a golden age of collegial, democratic governance in our universities. For much of their history, Australian universities were oligarchical, patriarchal, and extremely hierarchical, even feudal. 'God professors' ruled, and the gods were white, male, and often from privileged backgrounds.

Following the rapid expansion of higher education in the 1960s, in Australia as across most Western countries, and the rise of New Left student movements challenging traditional hierarchies and undemocratic structures, some openings appeared within the older formations in the academy for more democratic participation by staff 
and students, and for more collegial decision-making by a broader spectrum of academics. Clearly, some of the experiments at direct democracy in universities in the 1970 s demonstrated that very open models of direct democracy were not sustainable (D'Avigdor, 2015), even if they did play an important role at the time in advancing curriculum reform and opening up closed and hierarchical structures to a degree of wider participation by a broader spectrum of staff and students.

The Dawkins reforms of the late 1980s democratised access to higher education and diminished the status hierarchies of the binary system of higher education, but they also instigated more managerialist governance and management structures and practices to overcome institutional resistance to change and to act as a proxy for government (Forsyth, 2014). As noted above, the push towards deregulation and increased acculturation of governing bodies towards the norms and values of private industry are leading to an increasingly attenuated sense of public accountability and increasing convergence with the culture and value of capitalist enterprises.

A reform of university governance in the direction of greater democracy will not be easy, as neither university managers nor governments wedded to private sector management practice as a norm have any incentive to empower potential sources of resistance to authoritarian managerialism.

There are several potential avenues for organising democratic resistance to authoritarian managerialism. Universities retain academic boards and other residual organs of academic self-government, which tend to be dominated by appointed managers, but which still include elected staff members. There should be more purposive organisation of elected staff members on these bodies to challenge the continuing trend towards more top-down managerialism. There are usually objectively good and rational grounds for preserving and extending vestiges of collegial participation in decision-making not least being harnessing the expertise of the many highly qualified employees more directly engaged in the core work of the university than the current managerial cohort.

During the 1990s, with the onset of managerialism, the modest elements of collegial and democratic decisionmaking that existed in discipline-based departments were removed, and departments themselves were replaced by larger administrative entities subject to line-management. The negative findings of university workplace culture surveys, as well as the more advanced thinking on the successful management of groups of highly skilled and qualified people, provide grounds for reform of the grass-roots organisational levels of the universities. These should be reformed to restore collegial and participatory democratic elements at the level of the school or small organisational unit.

There needs to be greater education of relevant stakeholders and policy-makers in alternative modes of governance. The unexamined assumption that the current mode of Australian corporate governance constitutes 'world's best practice' should be challenged by publicising alternative models available internationally. Of interest is the German model of co-determination at the supervisory board level of large enterprises. Such a board is a non-executive entity with oversight of the board of management. While there are criticisms of such attempts at greater economic democracy, the model of a senate constituting a supervisory board with 50 per cent staff representation deserves careful consideration. It would not be hard to find staff supervisory board members better qualified in the field of higher education than most current external senators, and the greater level of sectorand institution-specific knowledge that such a cohort could bring to bear would provide a more effective check on the negative consequences of management capture than current arrangements. Fifty per cent external membership of the supervisory boards could ensure the necessary financial and business expertise is available to the institution, as well as allowing for some broader community representation to help ensure a university is meeting its commitments to the public good.

There are also examples of elected rectors (vicechancellors) in highly regarded universities (e.g. in Sweden, Free University of Berlin) which provide for more collegial and democratic internal governance. We need to keep questioning and challenging what the French call 'la pensée unique' - neo-liberal orthodoxy. Alternative ideas are available. If universities are not to be increasingly estranged from their core mission of advancing and transmitting knowledge, and serving the public good, alternative ideas need to be disseminated as energetically as possible, and potential reform coalitions need to be built.

Andrew G. Bonnell is an associate professor in the School of Historical and Philosophical Inquiry at the University of Queensland, Australia. He has been Branch President of the National Tertiary Education Union at the University of Queensland since 2003. From 2003 to 2013 inclusive, he was a member of the University of Queensland Senate.

Contact: a.bonnell@uq.edu.au 


\section{Acknowledgement}

I would like to acknowledge that the Queensland State Archives source was kindly brought to my attention by Howard Guille.

\section{References}

Berle, A.A. \& Means, G.C. (1968; first published 1932). The Modern Corporation and Private Property. New York: Harcourt, Brace \& World.

Burnham, J. (1966; first published 1941). The Managerial Revolution. Bloomington: Indiana University Press.

Chambers, V. \& Crowley, P. (2003). Capitalism and Accounting Reform. S.A.M. Advanced Management Journal, 68(3), Summer, 44-55.

Connell, R. (2015). Reimagining universities: what does a good uni look like? Keynote address presented at Conference on Challenging the Privatised University, University of Queensland, 23-24 November.

D'Avigdor, L. (2015). Participatory Democracy and New Left Student Movements: The University of Sydney, 1973-1979. Australian Journal of Politics and History, 61(2), June, 233-247.

Forsyth, H. (2014). A bistory of the modern Australian university. Sydney: NewSouth Publishing.

Ginsberg, B. (2011). The Fall of the Faculty. The Rise of the All-Administrative University and Why it Matters. Oxford: Oxford University Press.

Hare, J. \& Lane, B. (2014). Second UNE chancellor to face corruption watchdog. The Australian, 8 July. Retrieved from http://www.theaustralian.com.au/highereducation/second-une-chancellor-to-face-corruption-watchdog/news-story/288a c881dc53b2036b07fa6e46b1929b?=.
Hermalin, B. \& Weisbach, M. (1998). 'Endogenously Chosen Boards of Directors and their Monitoring of the CEO.' American Economic Review, 88 (1), 96-118.

Independent Commission Against Corruption, New South Wales (2014). University of New England - allegations concerning former chancellor (Operation Verdi). Findings of corrupt conduct retrieved from http://www.icac. nsw.gov.au/investigations/past-investigations/investigationdetail/204

Marginson, S. \& Considine, M. (2000). The Enterprise University. Power, Governance and Reinvention in Australia. Cambridge: Cambridge University Press.

Mitchell, S. (2015). Retailer boards short of hands-on retail experience. Australian Financial Review, 30 May. Retrieved from http://www.afr.com/ business/retailer-boards-short-of-handson-retail-experience-20150528-ghbzku

Nestle, M. (2013). 'Conflicts of Interest in the Regulation of Food Safety. A Threat to Scientific Integrity.' JAMA Intern Med., 173(22):2036-2038. doi:10.1001/jamainternmed.2013.9158.

Nous Group. (2013). Exploring Organisational Culture - Findings Report. The University of Queensland, 26 February. Retrieved from http://www.uq.edu. au/reform-program/docs/nous-group-report-032013-all-staff.pdf

Queensland State Archives. (2009). Cabinet Minutes 1978, Highlights. Released to the Public, 1 January 2009. Retrieved from http://www.archives.qld.gov.au/ Researchers/CommsDownloads/Documents/1978CabinetMinutesHighlights.pdf Roberts, S. (2016). 'NTEU UNE Branch President accused of 'conflict of interest". NTEU Advocate, 23 (1), March, p.6.

Trounson, A. (2015). Vice-chancellors' pay is on the up and up, despite fee crisis. (2015). The Australian, 17 April. 


\section{Academics, the humanities and the enclosure of knowledge: the worm in the fruit}

\section{Nick Riemer}

\section{University of Sydney \& Université Paris-Diderot}

If we want to combat contemporary 'neoliberal' attacks on universities, we should start by refusing the way that their pseudo-rationalities already determine so many aspects of the intellectual and institutional regimes that we consider under threat. This paper sketches an analysis of those aspects of the internal practices of academia that reinforce the interests at the origin of the attack on public education, and that make it possible, and indeed expected, for universities' leaders to oversee the betrayal of their institutions' very raison d'être. How have the physical and intellectual geographies of academic professionalism prepared the ground for 'neoliberal' reforms? How do the varied dispensations of modern higher education work against the ideal of open, democratic universities? How would university education, especially in the humanities, still exacerbate the privatisation and enclosure of knowledge in our societies, even if it remained public and accessible to everybody?

Keywords: academia and neoliberalism, sociology of academia, intellectuals, humanities, activism, higher-education reform

My father made your yoke heavy, and I will add to your yoke: my father also chastised you with whips, but I will chastise you with scorpions. - 1Kings 14

The Biblical Rehoboam's promise to his subjects distils the same shocking moral that years of financial discipline have inculcated into Western public universities: pleas for clemency are futile; the next regime will be stricter than the last (see Schrecker, 2010, p.162 and Collectif Acides, 2015,pp. 61-70 for details). In ancient Judaea, the ensuing backlash led to the stoning of Rehoboam's emissary and drove the king himself into flight. Universities' reactions have mostly not been so decisive. In fact, it has often been movements external to university authorities themselves, in particular students, but also unions and grassroots political actors, who have taken the lead in contesting educational austerity. Recent developments in Australia, where the government's plans to abolish caps on university fees had to be withdrawn as a result of widespread community protests, despite being supported by most vice-chancellors (Riemer 2014), are an especially clear case of how resistance to the neoliberalisation of higher education may have to be mounted against the wishes of the most senior layers of the academic hierarchy. 
Whether in Africa, Europe, the Asia-Pacific or the Americas, struggles for public higher education have gained a new lease on life amid the post-2008 convulsions agitating international capitalism. Sometimes, they have even experienced political success. But if the universally accessible higher education demanded by social movements is a necessary condition for progress towards educationally fair and democratic societies, it isn't a sufficient one. Universities must not just be opened to everyone who wants to study in them; what is taught, and how, need themselves to be critically reimagined (see Granger, 2015). While progressives are busy prising higher education from the neoliberal vice, it is therefore salutary to look more closely at exactly what the institutions are like that we're trying to save.

The exteriority of the defence of public education to the most powerful academics responsible for it should give pause. University leaders' enthusiasm in supporting, accelerating, and sometimes even instigating attacks on their own institutions has a clear entailment: higher education, and the institutions that provide it, do not 'belong' to them. Nor, can we only conclude, do they 'belong' to academics, who have often remained mute in the face of the wilful and systematic destruction being visited on their profession. Instead, it is to those who are most prepared to defend universities - students that higher education most 'belongs' and who should, as a result, participate heavily in genuinely democratic decisions over how it is set up (despite its fifty years of age, Cockburn and Blackburn, 1967, still has many useful lessons on this point).

It is for students and society themselves to tell us how universities might really serve them. But they can do this best if they know more about what universities are actually like for the people who work in them. The simplifications imposed by struggle too often lead to an insufficiently dialectical view of the politics of university reform. According to this view, 'neoliberal' forces in government, business and culture exert pressure from the outside on hapless university authorities, who are left with no choice but compliance. Such an interpretation is obviously fanciful. The most natural way of correcting it, however, risks reinstating just as unhelpful a Manichaeism, by moving the frontier between the university's educational 'inside' and neoliberal 'outside' to within the institution itself, emphasising university leaders' membership of the socio-economic and political elites responsible for the dismantling of public higher education. The old dichotomy between universities and outside forces is replaced in this interpretation by a new one between, on the one hand, the plenipotentiaries of the economic order, whether they are the presidents of Goldman Sachs or of NYU, and rank-and-file academics and students on the other.

This revised dichotomy has elements of truth: vicechancellors' and presidents' interests really do align with those of the business leaders on university councils; ordinary university workers and students really are in the firing-line of reforms, their positions ever more onerous, monitored and precarious. The problem is not in the basic characterisation of the actors, but in the way their relation is conceived.Tomorrow's vice-chancellors are drawn from today's rank-and-file academics. Bourdieu's claim (1989, p.12) that 'the dominated always contribute to their own domination' is politically counterproductive in many contexts. But, as a generalisation about the underlying mechanisms of academic cooptation by market logic, his reminder that 'the dispositions which incite complicity [...] are also the embodied effect of domination' is entirely accurate. In what follows, I hope to address some of those aspects of the internal practice of academia that make it possible, and indeed expected, for universities' leaders to oversee the betrayal of their institutions' very raison d'être. How have the physical and intellectual geographies of academic professionalism prepared the ground for 'neoliberal' reforms? How do the varied dispensations of modern higher education work against the ideal of open, democratic universities? How would university education, especially in the humanities, still exacerbate the privatisation and enclosure of knowledge in our societies, even if it did remain public and accessible to everybody?

\section{Enveloping institutions}

While governments and policy-makers exert themselves to enclose the transformative opportunities of education inside the gated communities of social privilege, enclosure of an entirely literal kind has become an even more obvious feature of universities' physical environments. Universities around the world sustain a discourse of civic engagement and celebrate - in large part for marketing purposes - their 'public intellectuals' - while, at the same time, acting against the dissemination of knowledge by intensifying the policing of their external and internal boundaries. No presence on campus without identification; no access to libraries' holdings without a student number; restricted entry to university buildings; obstacles to non-enrolled students auditing classes; encouraged or obligatory RSVPs to academic talks; paying entry to public lectures; restrictions on the use of campus 
venues for political purposes - measures like these will be well-known to anyone familiar with how modern universities work. As the built environment of higher learning is transformed into the 'hubs', 'pods', 'nodes' and 'resource' and 'engagement' centres of contemporary campus urbanism (see Coulson, Roberts and Taylor, 2015), everything in university life is closed, restricted and policed. This reaches its apogee for international students. Strict limits on the time available to complete degrees, the transfer to universities of responsibility for ensuring students not overstay visas or, in some UK universities, the use of regular fingerprinting to confirm lecture attendance, all blur the lines between education and border control.

This insistence on universities' territorial demarcations, and their integration into the national immigration apparatus, is not just about the enclosure of academic spaces with respect to the physical bodies of students, staff or members of the public. In a different register, the university takes those very bodies as sites on which its sovereignty can be asserted. The proliferation of university-branded clothing and accessories, just like

the ID cards often worn on branded 'lanyards' around staff members' necks - a distant echo of the metal collar worn by enslaved Scottish coal miners, engraved with their owner's name (Losurdo, 2013, p.82) - emblazons the university's authority onto staff and students' clothing and personal effects, symbolically subsuming individuals under the institution's identity. In the same vein, ubiquitous 'wellness' programs - offered to staff as an ideological non-solution to the problems created by structural overwork - extend institutions' authority into domains lying outside the traditionally understood ambit of professional life. Rather than fostering a neutral intellectual commons evacuated of the most overbearing insignia of market rationality, the university increasingly distinguishes itself as a 'total' - or better, an 'enveloping' (Darmon, 2015, p.84) - institution, its monopolisation of its members' lives and its omnipresent crests and logos a permanent reminder that, on campus, thought and thinkers belong to it

A single example offers, in a nutshell, an insight into the typical logic of enveloping institutions and their mechanisms The Vice-Chancellor of the University of
Sydney prefaces the University's 2015 internal discussion paper 'A culture built on our values' (University of Sydney, 2015) with the observation that the document 'introduces and explains some core values that have been proposed by our University community and describes some key mechanisms that will embed these values into our everyday behaviours.' It emerges that these values - 'courage and creativity', 'respect and integrity', 'inclusion and diversity' and 'openness and engagement' - miraculously all support the university's core commitment to 'excellence'. Despite its rhetoric of empowerment and personal flourishing, the report attempts to engineer an institutional 'culture' within an overpowering bureaucratic structure, and in the absence of any pretence of democratic organisational governance. In such a context, the purpose served is clear: the insistence on university employees' obligation to conduct themselves with 'openness', 'respect', or 'empathy' will mainly function to discourage criticism of the institution's top-down and authoritarian tendencies, precisely on the grounds that such contestation violates the respect and empathy due from staff to managers.

Accordingly, it comes as no surprise to discover, at the end of the Sydney document, that conformity with the university's 'values' - that is, 'excellence' - is to be made directly relevant to recruitment and promotion in the institution, and that, in particular, the university's 'Code of Conduct needs to be revised in light of the values that we agree as a part of this strategy process, and this code needs to be used more regularly as a resource for considering behaviour' (p.13). Culture and values, then, provide new avenues for the exertion of managerial authority and the maintenance of campuslevel social control. This outcome is exactly parallel to the way in which, at the same university, formalised antibullying provisions, which a naive observer might have expected to protect subordinates against superiors, can be used as a mechanism of managerial pressure against staff who contest management decisions (see the chapter on 'Bullying - a standard managerial practice at the University' in NTEU Sydney University Branch, 2015, pp. 15-16).

University staff have, in one way or another, if not always initiated, then regularly accepted, largely cooperated in, and sometimes welcomed developments like these, along 
with most of the other transformations that have reshaped their profession in the last several decades (see Schrecker, 2010). The worm, so it would seem, is in the fruit. Instances of contestation - strikes, attempts to break corporations' monopoly over the dissemination of research, programs aiming to increase the participation of exploited, lowincome members of society in higher education, or efforts to directly introduce wider political stakes into questions of institutional practice - are welcome, but unmistakably constitute exceptions to the norm. The fact that it is no doubt among the most exploited workers in higher education, casuals, that contestation is most obvious, tells us much about most academics' acceptance of the way we live now.

What is more, any contestation that does arise within the ranks of academia is usually seen, and understood by the actors themselves, as the mere complement of a broader compliance. Compliance with the ideological norms of the corporate university has certainly become second-nature to many. A minor example but, as an entirely unforced development, initiated by academics themselves, a telling one, is supplied by the shifting ways in which researchers are now choosing to describe the seminars and other talks at which their work is presented. The prominence of 'masterclasses', 'in conversation' sessions or 'retreats' as emerging formats for the dissemination of research does not just - or, perhaps, does not even represent a much needed attempt to diversify and open up traditional genres of academic communication; it also suggests that the dissemination of knowledge should not be promiscuously open to all comers, but confined within an already established in-group. These examples are just a small selection from the remarkable proliferation of new genres of academic communication, and new labels for old ones, that the academic world is currently generating: 'quick-fire presentations', 'brain-storms', 'idea showers', 'Q\&A sessions', 'brown bag sessions', 'elevator pitches', 'talking circles' and even 'collaborative micro-hacks' are among the evidence of the large-scale refoundation of the forms of intellectual dissemination currently underway.

It is, however, in the very bread-and-butter of universities' business - teaching - that academics' participation in the enclosure of knowledge is most apparent. Humanities disciplines - the very ones that the popular imagination strongly associates with critique and political radicalism - play a particular, and particularly disavowed, role in this enclosure. As a result, they have a distinct responsibility in combating it. It is a striking measure of the mystifying capacity of ideology that, whether in the mouths of critics or supporters of the humanities, clichés of their separation from the 'real' world and its exigencies should be so widely accepted, commanding sufficient authority in the admittedly particular - context of Japan,for instance, for the Japanese Education Minister to have called in 2015 for the closure of humanities and social science departments.This banal conviction of the humanities' intrinsic irrelevance is supremely ideological, and it has thoroughly occluded one of their major functions: the ideological preparation of the next generation of the economy's administrators, teachers, community workers and technocrats, as well as of the pool of precariously employed knowledge and creative workers responsible for safeguarding capitalism's hegemony in the public mind (cf. Paschal, 2012; see Coates and Edwards, 2009 and Association of Graduate Careers Advisory Services, 2015 for graduate employment data from Australia and the UK respectively).

Ideological preparation is, of course, a general feature of universities' role across all faculties, and before addressing the content of humanities education specifically it is worth taking a moment to reflect on it. Whatever the faculty in which they study, one important but inadequately discussed way in which universities format the next generation of workers is in the systematic disenchantment they generate by confronting often idealistic and optimistic students with the dismal realities of tertiary study. In Australia, the widespread frustration of hopes of intellectual and social blossoming that is an almost inevitable result of exposure to the marketised university classroom has been fascinatingly demonstrated by Richard Hil (2015). In their more crowded, less frequent classes, the increasing replacement of the seminar room by the online course, narrowing course options, a heavily casualised and precarious academic workforce, the absence of free time for socialising on campus, and the unmistakable atmosphere of constraint and pressure in which they learn, many students experience a disappointment and alienation that will soon be replicated on the employment market, for which the affective shock of university constitutes a rehearsal.

The severity of this alienation is moderated in those wealthier institutions which force themselves to preserve better learning conditions, for some students at least. In the Australian context, it is likely that it will be elite students - in other words, mainly those whose socio-economic circumstances allow them to achieve higher academic results, always under the ideological cover provided by discourses of academic 'merit' (cf. Bourdieu, 1989, chapter 2; Collins, 2002, p. 29) - who are most sheltered from degradation of learning conditions. Recent developments 
in the Faculty of Arts and Social Sciences at one 'leading' Australian institution (the University of Sydney) are no doubt representative. In an environment characterised by significant financial pressure on the faculty, Sydney has recently introduced a 'Faculty Scholars Program', apparently modelled on Yale's Directed Studies program and similar courses elsewhere. The program is designed to 'provide intensive small-group teaching with an expert on a topic that they are passionate about' (Arts and Social Sciences Faculty Handbook, University of Sydney). While the handful of students selected study an 'exclusive' and 'prestigious' program in small groups with the faculty's 'leading academics', the thousands of other students, and their peers elsewhere in the Australian comprehensive tertiary system, will have to make do, as best they can, with the ongoing erosion of the preconditions for a liberal education worthy of the name.

The demands of the contemporary economy mean that a proper education cannot be denied to everyone. Modern states clearly need some institutions of high quality to furnish the expertise on which administrative and technical competence depends - as long, of course, as those institutions do not seriously challenge their economic or the ideological bottom line. But not too many: many graduates clearly leave university with an educational preparation that is only just adequate for the roles they will assume as employees and citizens, and highly deficient in comparison to the fantasmagorical promises they are made by university marketing departments. This state of affairs is entirely consistent with the underlying place of higher education in a capitalist economy (see Collins, 2002 for some useful contextualisation). Just as modern manufacturing and distribution is organised on a 'just in time' basis, designed to reduce costs incurred by overproduction and unnecessary storage, so too the mass higher education industry is predicated on avoidance of costly over-education of the graduates it supplies to the labour market. Graduates must be professionally trained, but not over-trained: they mustn't be too good at their jobs when they arrive in them. Overtraining students is not just a waste of universities' limited resources, it would also supply employers with a more self-confident and capable workforce, able to fulfil the demands of their positions more easily. As a result, they would dispose of the surplus of time and, above all, mental energy necessary to press demands for greater workplace justice. Structurally negligent, just-adequate education, by contrast, weakens graduates' position vis-à-vis their employers, and restrains their availability for anything other than their immediate professional tasks.

\section{Consolations of philosophy?}

Universities have, in the last century at least, been reservoirs of dissent against capitalism. The intrinsically centrifugal nature of thought - the fact that ideas can always transcend the ideological context in which they are generated - ensures that sparks of counter-hegemonic thinking cannot fail to be struck, even within the academic furnaces of neoliberalism.

But what kind of flame are those sparks used to kindle? There is no doubt that the non-instrumental character of the humanities can, despite everything, favour the expression of critique. The pressure to increase tuition fees, to degrade the quality of the time students spend in the classroom and, on a different level, to court corporate sponsorship of research all evince the desire to place teaching and research across the university under the thumb of the market. In the same way, the continual attacks on the humanities specifically can be understood as the attempt to close off opportunities for politically transformative education in future salary-earners, and to maintain a fragmentation of social consciousness which prevents them from developing a comprehensive perspective on society as a whole' (Callinicos, 1989, p.116). Needless to say, it is the market and its masters who benefit.

There is also, however, the uncomfortable reality that in addition to this critical work, the humanities - like the pure sciences - also prepare graduates to join a large and mainly compliant labour force in sectors of the economy for which they are often significantly over-qualified. What is it, we might ask, about the forms of rationality promoted in humanities disciplines that prepare students to accept as normal post-graduation prospects that are considerably bleaker than those in other disciplines? In comparison to other graduates, Australian humanities graduates may, for instance, be less perturbed by starting salaries consistently falling at the bottom of the scale (GCA Australia, 2014). But are they really sanguine about the risk of being trapped well beyond graduation in inadequately-paid and often part-time jobs, notably in the retail and services sector (see, among other sources, Lamb, 2002, conclusions supported by more recent media reports)? Should liberal conceptions of the consolations of 'philosophy' really compensate for the slimness of its material rewards?

The Left has regularly engaged in ideological critique of the humanities, drawing attention to the political import of received ideas in many disciplines, and contesting the perpetuation, under the cover of disinterested scholarship, of diverse oppressions. But it is perhaps 
not too inaccurate a generalisation to suggest that it has characteristically been less sensitive to the ways in which, regardless of the particular content of a discipline, the habits of mind that the humanities foster in students may contribute to the social relations that support capitalist domination. As Horkheimer and Adorno put it, 'the expulsion of thought from logic ratifies in the lecture hall the reification of human beings in factory and office' (2002, p. 23). The spread of critical epistemologies and counterhegemonic theoretical currents since the 1960s has done little to reverse the trend - quite the opposite. Students' 'reification', indeed, is more likely to be acknowledged, in essentially celebratory terms, in apologias for the utility of traditional humanities subjects to the world of business - an increasingly common genre - than it is to form the basis of any comprehensive progressive critique (cf. Blackburn, 1967). In particular, the attempt to understand the humanities' ideological role has often not adequately taken up Said's call for research into 'the relationship between administrative ideas and intellectual discipline' (1977, p. 24).

Students are not just broken in for the labour market through systematic under-preparation and premonitory disenchantment. The forms in which knowledge and the activity of thinking are presented to them also play a crucial role. Education in the humanities, as elsewhere, takes the form of an elaborate disciplining of the diverse impulses of creative human intelligence - 'the servant which the master cannot control at will' (Horkheimer \& Adorno, 2002, p.29) - into a narrow, and continually shifting, bandwidth of canonical formats, recognised questions, and authorised structures of intelligibility. This channelling of the currents of thought is significantly underdetermined by any necessity inherent to rationality itself, but reflects the fundamentally contingent, historically constituted nature of academic disciplines (see Gadamer, 1960). In this situation, it is beyond a cliché to observe that the exercise of power is necessary to the creation, recognition and dissemination of knowledge.The very idea of an academic discipline, in fact, is inseparable from the structure of intellectual authority, from students to recognised experts, that governs it (see e.g. Lagasnerie, 2010, pp. 34--40).

It is not that the particular modes of reasoning and discursive practice into which students are inducted in humanities subjects are irrational or arbitrary: it is, rather, that they always represent discretionary selections from among the many forms of discursive rationality that could equally have been chosen instead. Any curriculum entails choice - of theories, emphases, authors, schools, methods, and so on. In the humanities above all, this selection is shaped in an obvious way by the ideological hegemonies at play, all grounded and justified in the classroom by the rationalising authority of the lecturer.Through assessment, students' facility in accepting this authority is made the criterion for the measure of their 'intelligence', and hence for their credentialisation for the purposes of entry into the labour market.

In this way, the humanities classroom becomes an elementary site for education in the discretionary exercise of power - the same kind of power to which students must learn to submit if they are to assume a role in the economy The practices of assessment and examination inherent to higher education, which bury students' intellectual demonstrations in often oppressive bureaucratic constraints (word-limits, formatting prescriptions, due dates, and so on) 'prepare students both to undergo and, doubtless, also to exercise and impose the modes of population administration and the practices of new [public] management', as Muriel Darmon has noted in her study of French classes préparatoires (2015, p. 308).

More abstractly, the authority invested in the lecturer to dismiss competing theoretical claims on a discretionary basis encourages an acceptance of arbitrary symbolic authority which is soon reengaged outside the lecture theatre. The discretionary theoretical authority on which their lecturers' position is based resurfaces in the discretionary material authority - the authority of the market and the state - that students confront in the outside world. The symbolic power to which young people are subject in the humanities classroom, and which they also learn to deploy for themselves, offers a foretaste of the arbitrary dispensations to which they are subject as essentially disenfranchised citizens of capitalist states or as job-seekers in employment markets. The symbolic domination exerted in the world of ideas prepares students for the material domination they endure, and exert, as graduated wage-earners.

A contingent, tradition-embedded, and 'discretionary' character is intrinsic to any discipline in which knowledge is produced creatively, and in which interpretation, especially when uninformed by strongly empirical techniques, holds pride of place. As such, while any number of reforms could be envisaged that would contribute to the democratisation of humanities disciplines, and work against their domination by intellectual elites, there can be no question of surpassing this state of affairs entirely.

Rather than fully transcending the discretionary character of humanities research, the critical task is therefore to recognise the connections between the forms 
of symbolic authority contracted and disseminated in the seminar room, and the wider forms of social and political authority in which they are embedded, and which they can simultaneously either reinforce or challenge. How far is theoretical analysis instrumentalised in the seminar room as a fundamental tool of careerism or personal advancement - lecturers' or students' - as opposed to one of social progress and collaborative emancipation? How often are hypotheses or discretionary normative judgements disguised as objective factual ones? How far are the propositions generated within disciplinary frameworks presented as fixed constraints to which students must submit, rather than as points of reference for exploring new forms of possibility? Is understanding itself conceived of as obedience (reproduction of a norm), or as response (Volosinov, 1929)? How far is the diversity of human understanding reduced to the positivities of technoscience? Is the complexifying impetus of critical rationality used to dampen or amplify the impetus to emancipation?

It is important that the manoeuvres of intellectual power and control demonstrated in the classroom not simply model the material forms of coercion on which economic exploitation rests. But the coercive tendencies latent in the basic forms of intellectual sociality are most fully expressed not in relations towards students, but in the regulation of academic professional life itself. One of the striking consequences of the recent managerialisation of academics' professional lives is that a certain sociology that emphasised the status of higher education as a total institution for the student (Bourdieu, 1989; Darmon, 2015) now has greater resonance as a description of what universities are like for staff.

There is certainly no need to observe how, in an employment market where supply vastly outstrips demand, every aspect of academics' professional activity is destabilised - or, rather, constituted - by an incessant round of assessment, evaluation and control. Teaching, research funding and 'output', as well as the 'performance' of whole departments, journals, discipline areas and institutions is analysed via managerial assessment practices fundamentally incompatible with the hermeneutic character of either education or discovery, whether within the sciences (Feyerabend, 1993) or outside them (Gadamer, 1960; Zarka, 2010; Rastier 2013). And, because power is not real unless it is arbitrary, the criteria on which this new academic phrenology is based are continually changing and, in any case, always subjective. The remark attributed to a senior administrative staff member at the University of Sydney - 'every day at work feels like a job interview' (NTEU University of Sydney, 2015, p.11) - perfectly captures the effect of these mechanisms, and applies fully to academics. The scholar has become either the beggar-supplicant, imploring, through their grant applications, the deities of funding, or the caped penitent, ritualistically submitting themselves to the latest ordeal of evaluation, their guilt already confirmed by the very necessity of the trial.

In the six years since she articulated it, the accuracy of Schrecker's (2010, p. 185) indictment has only matured:

Instead of mounting a campaign to explain what really ails higher education and how the states' dwindling support for their public colleges and universities has contributed to their perceived defects, much of the academy's official leadership is scrambling to show that it can evaluate itself. Just as administrators purged their faculties of suspected Communists in the 1950s in order to keep outsiders from doing it, they are now struggling to implement accountability procedures before trustees and politicians devise ones for them.

The problem, however, is far from confined to the 'academy's official leadership'. Ordinary academics' acquiescence to, and, often, celebration of, the tyranny of evaluation is a striking illustration of our compliance before arbitrary regimes of intellectual coercion. Academics' refusal to acknowledge this and other aspects of their profession's increasing proletarianisation has, no doubt, many sources beyond simple careerism. Middleclass professionals are unwilling to accept that they could be either dominated or, themselves, the agents of domination. Intellectuals' conviction that they maintain a monopoly over their own analysis discourages them from questioning whether their own hagiographies - Davis (2010) is a clear example - really do represent the ne plus ultra of critical reflection on their institutions. Excessive deference to the instruments of technocratic rationality dulls critique of its fundamental cardsharpery.

Less often observed perhaps, the fetish of the quantitative rests on a peculiar masochism: the tendency, widely obvious among academics, to take each tightening of the administrative screw, each subsequent degradation of working conditions, as just the next opportunity to showcase individual resilience. The willingness, through puritanical discipline, to surmount whatever punishment the institution next inflicts becomes a perverse mark of superiority in a competitive professional milieu deeply marked by Darwinian logic. The symbolic prestige still conferred by academic employment, the largely unalienated character of research work, as well as the proliferating institutional rewards for teaching, research and, no doubt, administration - the academic equivalents 
of the 'employee of the month' certificates awarded in Starbucks - supply any number of rationalisations in response to those who have the effrontery to suggest that this might not, perhaps, be the best of all possible worlds. Academia, after all, isn't a job: it's a calling, and living is something that our servants will do for us.

\section{Education: the new Greece?}

If we want to defeat the pseudo-rationalities of contemporary attacks on universities, we should start by refusing the way that their logic already determines so many aspects of the intellectual and institutional regimes that we consider under threat. Neoliberal ideologues must not be allowed to get any further in doing to education what they have already done to Greece.

But how to unscramble the egg? In seventeenth and eighteenth-century England, the enclosure movement emblem of the dispossession at the heart of the capitalist economy (Harvey, 2014; Schui, 2014) - was justified by the idea that it would greatly boost agricultural productivity. That claim wasn't just highly exaggerated: it was wholly indifferent to the injustices involved (Allen, 1992, 2004; Crawford, 2002, pp. 50-1). In the twenty-first century, there is no more urgent intellectual task for universities than resisting the market rationality that would impose a similar enclosure of knowledge on them.

As is often observed (e.g. Sievers, 2008, p.243), most academics' alienation from any recognition of their own capacity for agency is impressive. Its effect - reinforcing the status quo - is never, perhaps, more powerful than when it is enacted with that mix of complicit irony, semilucidity, and opportunistic fatalism that any institutional agitator will easily recognise in the mouths of their contradictors. The complacent reasoning, proffered with all the disabused assurance of the world-weary political sophisticate, leads to one conclusion only: nothing can be done, and especially not by us.

We cannot continue to block our nose and cover our eyes forever. Nor can we go on behaving like the audience at the very drama of which we are the actors. It is time that academics became, in Cahill and Irving's pithy (2015) formulation, not just idea makers, but idea users, and actually start working against the 'normal madness' (Sievers, 2008) of their institutions. 'In order to supersede the idea of private property, the idea of communism is enough, Marx wrote in the 1844 manuscripts. 'In order to supersede private property as it actually exists, real communist activity is necessary'. An identical conclusion follows in the battle between neoliberalism and education.
We need, however, to beware of the idea that what is mostly called for is more analysis of the kind that has been undertaken here. There is no need, in the university context, for the 'theoretical heroism' criticised by Rancière (2011) - the idea that the academic 'masses' can only make history because their 'intellectuals' have theorised it. Nothing in the foregoing analysis will come as a deep revelation to academic workers: the description of universities that has been offered here simply assembles what is already under everyone's noses. Any utility that reflections like these might have lies in something else than uncovering putatively occult truths that academics are somehow too unenlightened to grasp. The central critical task in resistance to the privatisation of knowledge is not mainly an analytical or an epistemological, but a political one. We mostly do not need to understand more about what is wrong with universities; above all, we need to make the reality that everyone understands already, but will not say, sayable - by saying it ourselves, repeatedly, and by seeking to increase the situations on campus in which others are confident enough to say it too, and then to act together to change it.

It is not just our universities that desperately need change: our economies and our societies do, too. Nothing less than the future of the environment depends on it (Tanuro, 2010). Thankfully, the road to a 'nexit' - a definitive break with 'neoliberalism' and its accompanying imperialism and war - is not paved by academics or the other ratified thinkers of the contemporary opinion bubble. It is social movements and their organic intellectuals, who are fighting the depredations of the current worldorder concretely, as well as writing about them, who will supply the ideas needed to support transformative social change, whether on campus or beyond it. It is certainly not academics who lead the struggle for a better world. But, in our own workplaces if nowhere else, we might at least participate in it.

\section{Acknowledgments}

I'm grateful to Eran Asoulin, Ben Etherington, Melissa Hardie, Evan Jones, Jacqueline Léon, James McElvenny, Briony Neilson, François Rastier and participants in an academia.edu forum for their contributions to the development of these ideas. Obviously, none of them is responsible for any of the article's faults.

Nick Riemer is a senior lecturer in the departments of English and Linguistics at the University of Sydney, Australia.

Contact: nick.riemer@sydney.edu.au 


\section{References}

Allen, R. (1992). Enclosure and the Yeoman. Oxford: Clarendon Press.

Allen, R. (2004). Agriculture during the Industrial Revolution, 1700-1850, in R. Floud \& P. Johnson (eds). The Cambridge Economic History of Modern Britain. Volume I: Industrialisation, 1700-1860. Cambridge: CUP.

Blackburn, R. (1967). A brief guide to bourgeois ideology, in A. Cockburn \& R. Blackburn (eds). Student Power. Harmondsworth: Penguin.

Bourdieu, P. (1989). La Noblesse d'état. Paris: Minuit. [English translation by L. Clough: The State Nobility. Elite Schools in the Field of Power. Stanford: Stanford University Press, 1996.]

Cahill, R. \& Irving, T. (2015). Radical Academia: Beyond The Audit Culture Treadmill. Retrieved from http://radicalsydney.blogspot.com.au/p/radicalacademia-beyond-treadmill-of.html

Callinicos, A. (1989). Against postmodernism. A Marxist critique. Cambridge: Polity.

Coates, H. \& Edwards, D. (2009). The 2008 Graduate Pathways Survey: Graduates' education and employment outcomes five years after completion of a bachelor degree at an Australian university. Australian Council for Educational Research. Retrieved from http://research.acer.edu.au/cgi/ viewcontent.cgi?article $=1011 \&$ context=higher_education

Cockburn, A. \& R. Blackburn (eds) (1967). Student Power. Harmondsworth: Penguin.

Collectif ACIDES (2015). Arrêtons les frais. Pour un enseignement supérieur gratuit et émancipateur. Paris: Raisons d'agir éditions.

Collins, R. (2002). Credential inflation and the future of universities, in S. Brint (ed.) The future of the city of intellect. The changing American university. Stanford: Stanford University Press.

Coulson, J., Roberts, P. \& Taylor, I. (2015). University Trends. Contemporary Campus Design. London and New York: Routledge.

Darmon, M. (2015). Classes préparatoires. La fabrique d'une jeunesse dominante. Paris: La Decouverte.

Davis, G. (2010). The Republic of learning: higher education transforms Australia. Pymble: HarperCollins.

de Lagasnerie, G. (2010). Logique de la création. Paris: Fayard.

Feyerabend, P. (1993). Against Method (3rd ed.). London: Verso.

Gadamer, H-G. (1960). Truth and method. (2nd ed.) (J. Weinsheimer \& D. G. Marshall, trans). London: Continuum, 2004.

AGCAS (Association of Graduate Careers Advisory Services UK) (2015). What do graduates do? 2015

GCA (Graduate Careers Australia) 2014. Gradstats. Employment and salary outcomes of recent higher education graduates. http://www.graduatecareers. com.au/wp-content/uploads/2014/12/GCA_GradStats_2014.pdf
Granger C. (2015). La destruction de l'université française. Paris: La Fabrique.

Harvey, D. (2014). Seventeen contradictions and the end of capitalism. London: Profile.

Hil, R. (2015). Selling Students Short. Sydney: Allen and Unwin.

Horkheimer, M. \& Adorno, T.W. (2002). Dialectic of Enlightenment. Philosophical Fragments (G.S. Noerr, ed., E. Jephcott, trans.). Stanford: Stanford University Press.

Lamb, S. (2001). The pathways from school to further study and work for Australian graduates. Australian Council for Educational Research. Retrieved from http://research.acer.edu.au/cgi/viewcontent. cgi?article $=1016 \&$ context=lsay_research

Losurdo, D. (2013). Contre-bistoire du libéralisme (B. Chamayou, trans.). Paris: La Découverte.

NTEU Sydney University Branch (2015). University of Sydney 2014-15: A counter-report. How the university is, and how it could be. Sydney: National Tertiary Education Union. Retrieved from http://www.nteu.org.au/sydney/article/ NTEU-Counter-report,-How-the-University-is-and-how-it-could-be'-18046

Paschal, M. (2012). Against Humanities: The Self-Consciousness of the Corporate University. Viewpoint magazine 2. Retrieved from https:// viewpointmag.com/2012/09/10/against-humanities-the-self-consciousness-ofthe-corporate-university/.

Rancière, J. (2011) [1974]. La leçon d'Althusser. Paris: La Fabrique. [English translation by Emiliano Battista: Althusser's Lesson. London, Continuum, 2011.]

Rastier, F. (2013). Apprendre pour transmettre : l'éducation contre l'idéologie managériale. Paris: PUF.

Riemer, N. (2014). University deregulation. Arena Magazine (Fitzroy, Vic) 134: 12-14 http://arena.org.au/university-deregulation-by-nick-riemer-2/.

Said, E. (1977). Orientalism. Harmondsworth: Penguin.

Schrecker, E. (2010). The lost soul of higher education: corporatization, the assault on academic freedom, and the end of the American university. New York : New Press.

Schui, F. (2014). Austerity. The Great Failure. New Haven: Yale.

Sievers, B. (2008). The psychotic university. ephemera 8: 238-257.

Tanuro, D. (2010). L'impossible capitalisme vert. Paris: La Decouverte. [English translation by Jane Ennis, Green capitalism: why it can't work. London: Merlin, 2013]

University of Sydney (2015). A culture built on our values. Discussion paper. Sydney: University of Sydney.

Vološinov, V.N. (1973) [1929]. Marxism and the philosophy of language (L. Matejka \& I.R. Titunik, trans.). New York: Seminar Press.

Zarka, Y. (2010). La destitution des intellectuels. Paris: Presses universitaires de France. 


\section{Law student wellbeing:} A neoliberal conundrum

\section{Margaret Thornton}

\section{Australian National University}

The discourse around student wellness is a marked feature of the 21st century Australian legal academy. It has resulted in various initiatives on the part of law schools, including the development of a national forum. The phenomenon relates to psychological distress reported by students through surveys. Proposed remedies tend to focus on improving the law school pedagogical experience. This article argues that the neo-liberalisation of higher education is invariably overlooked in the literature as a primary cause of stress, even though it is responsible for the high fees, large classes and an increasingly competitive job market. The ratcheting up of fees places pressure on students to vie with one another for highly remunerated employment in the corporate world. In this way, law graduates productively serve the new knowledge economy and the individualisation of their psychological distress effectively deflects attention away from the neoliberal agenda.

Keywords: neoliberalism, bigher education, law students, wellbeing; stress

\section{Stressed law students}

There are two things about the burgeoning literature on law student wellbeing in Australia that are striking. First, it is very recent, having emerged only in the $21 \mathrm{st}$ century; secondly, no explanation is postulated for the suddenness of the eruption of psychological distress. As Peterson and Peterson (2009) point out in the US context, where the discourse has a somewhat longer history, there is significant empirical data on the kinds of distress that law students experience, but little on the causes of the problem. The conundrum besetting the wellbeing phenomenon is: how can psychological distress be tempered if it emanates from unacknowledged causes?

If the wellbeing literature is to be believed, the incidence of psychological distress among Australian law students is striking. Courting the Blues, an influential study that drew attention to the issue in 2009 , found that 35 per cent of law students reported a high degree of stress compared with 13 per cent of the general community (Kelk et al., 2009). A more recent study based on a purpose-built Law Student Perceived Stress Scale (LSPSS), rather than the more common Depression, Anxiety and Stress Symptoms scale (DASS), found an even higher level of stress, with the majority of law students reporting moderate to extremely severe symptoms of depression ( 53 per cent) and anxiety ( 54 per cent) (Bergin \& Pakenham, 2015). The US study by Peterson and Peterson (2009, p. 412) also found that 53 per cent of law student respondents met the threshold for a significant level of depression. While Australian empirical studies generally reveal somewhat lower figures (O'Brien et al., 2011; Larcombe \& Fethers, 2013) the incidence is still considerably higher than that found in the general population. For the most part, disciplines other than law have received comparatively little attention (but see Larcombe et al. 2015; Leahy et al., 2010). A comparative study by Leahy et al. (2010) nevertheless found that 58 per cent of the law students were classified as psychologically distressed, followed by 52 per cent of mechanical engineering students, 44 per cent of medical students and 40 per cent of psychology 
students, but the question remains unanswered as to why law appears to engender a higher degree of stress than any other discipline in higher education. Stress is experienced by students in disciplines such as medicine and engineering, but the question remains as to why law appears to engender a higher degree of stress.

Both Australian and US studies have found that law students evinced no sign of elevated psychological distress before they entered law school and it was only during the first year that the high level of stress manifested itself (Lester et al., 2011). The suggestion is that there is something about legal education that exerts a negative effect on student wellbeing (O'Brien et al., 2011). In particular, the qualities of detachment, adversarialism and neutrality are commonly associated with 'thinking like a lawyer' (O'Brien et al., 2011, p. 56). The inculcation of values that cause students to discount their own moral values and feelings of empathy and compassion is regarded as a key source of stress and depression (Peterson \& Peterson, 2009). It is certainly alarming to find that by the time law students graduate they are found to be different people: 'more depressed, less service-oriented, and more inclined towards undesirable, superficial goals and values'(Krieger 2005, p.434). Some surveys go beyond the confines of the law school to encompass negative feelings of wellbeing, such as the difficulty of maintaining personal relationships and managing to balance work and study, although Bergin and Pakenham (2015) found that academic demands were reported to be the highest sources of stress. So influential has been the wellbeing discourse that it has been embraced by law schools, many of which have established a website dedicated to wellness (Parker, 2014).

Christine Parker (2014) has nevertheless pointed out that there are methodological limitations associated with some of the empirical studies because they are based on psychological distress scales but are cited to imply clinical conclusions. The repetition of this flaw in a number of surveys led Parker to conclude that the wellbeing 'crisis' affecting both law students and practising lawyers was an example of a contemporary 'moral panic' (Cohen, 1972). That is, the high rate of psychological distress associated with law students and the failure of law schools to effect a remedy have engendered alarm in the wider community, particularly as the incidence is linked to marked rates of depression, substance abuse and suicide in the legal profession generally (Baron, 2014; Chan et al., 2014). Parker's invocation of Cohen's thesis is compelling in light of a phenomenon that has evinced all the suddenness of Athena bursting forth from the head of Zeus. Not only does the focus on psychological wellbeing deflect attention away from what is the critical factor at its heart, namely, the neo-liberalisation of higher education, it serves to individualise and depoliticise it.

I do not wish to diminish the reality of the stress experienced by law students, but to suggest that its emergence has coincided with the neoliberal turn that has insidiously transformed higher education from a public to a private good. The impact on the discipline of law has been dramatic (Thornton, 2012; 2014). To illustrate this proposition, I overview briefly both the wellness and the neoliberal phenomena. I then consider the impact of neoliberalism on higher education, with particular regard to the legal academy in terms of what is taught and how it is taught. I conclude that law students would be better equipped to cope with the pressures of the age if law schools were more transparent about the labour market problems from the outset and if the law curriculum were diversified to prepare students for a range of employment destinations other than traditional legal practice.

\section{The wellness phenomenon}

Wendy Larcombe has conducted a number of surveys on the wellbeing of law students. She and her co-authors acknowledge the increasing costs of legal education, the proliferation of law students and the heightened competition for positions in light of the shrinking job market, but they are of the view that these problems are politically problematic and not within the power of law schools to resolve (Larcombe et al., 2013). Instead, they argue, the psychological distress of law students can be ameliorated through improved approaches to teaching and learning. The authors suggest a whole-ofschool approach that focuses on the curriculum design, assessment and wider teaching and learning environment. Nevertheless, their research found that improvements in the overall rates of course satisfaction and engagement did not result in reduced levels of depression, anxiety 
and stress (Larcombe et al., 2013). While not wishing to downplay the importance of how students are taught, I am arguing that more attention needs to be paid to what they are taught.

In terms of the shrinking job market, Larcombe and Fethers (2013) suggest that further research is needed to ascertain whether worries about future employment prospects are significantly contributing to law student distress. They found that lack of career direction was not significantly associated with high levels of stress, unlike 'worry about job prospects' and 'financial stress', which were strongly associated with both 'moderate+' and 'severe+' stress symptoms (Larcombe \& Fethers, 2013, p. 398). 'I expect to practise law after graduating' was strongly independently associated with severe+ anxiety (Larcombe \& Fethers, 2013, p. 421). Other commentators are also of the view that amelioration of the problem of law student depression lies in the realm of pedagogy, such as the creation of an 'autonomy-supportive environment' in which students are offered information and choice about how to proceed with their course (Manning, 2013; Sheldon \& Krieger, 2007).

In keeping with the psychological explanations for depression, one branch of the literature, largely centred in the US, moves away from the pedagogical model of remediation to a health model, advocating exercise, stress management and sleep, as opposed to reliance on stimulants and substance abuse (Austin 2013, 2015). The science of positive psychology involves the development of self-awareness to increase happiness, motivation, success and a healthy work/life balance (Peterson \& Peterson, 2009; James, 2011). Peterson and Peterson (2009) identify 24 character strengths, such as zest and vitality, which, if maximised, could ward off depression. An awareness of emotional intelligence is also advocated as necessary for a successful legal life (James, 2011). Emotional intelligence refers to the perception by a person of their own emotions, and how 'they use, understand and manage them to enhance their personal growth and social relations' (Mayer et al., 2001, p. 234). This might involve individuals coming out and telling their personal stories of depression and recovery (Clarke, 2015).

I now present an overview of the significant elements of the contemporary political context which I consider necessary in order to understand how neoliberalism has profoundly impacted legal education. I am not suggesting that it operates in isolation as a stressor but as an underlying causative element that cannot be disconnected from the factors identified by the empirical studies.

\section{The neo-liberalisation of higher education}

Neoliberalism defies a precise denotation, but comprises a cluster of values associated with a sharp turn to the right in politics and the sloughing off of the egalitarian values associated with social liberalism. Harvey (2005) suggests that there are too many contradictions within neoliberalism to refer to it as 'a theory'; Purcell (2008) refers to it as an ideology, and Self (2000) as 'market dogma'. What is clear is that the dominant values of neoliberalism revolve around the market, namely, commodification, competition and the maximisation of profits. Indeed, neoliberalism has been assiduous in the privatisation and deregulation of public goods (Harvey, 2005; cf. Dumenil \& Lévy, 2011). This has included utilities, transport and welfare services, but universities have also been strongly affected. While the privatisation imperative is ostensibly economic, neoliberalism has been described as primarily a political project on the basis that it is designed to restore the power of elites (Harvey, 2005).

Education is regularly a priority for the neoliberal agenda, but its goal is not to reinvigorate liberal education in order to produce critically aware citizens. It is to refocus education spending and produce a varied pool of skilled human capital to enhance competitiveness (Purcell, 2008). As primary resources and manufacturing are under threat, Australia, like other nation states, has turned to the creation of a knowledge economy for which a proliferation of trained technocrats is highly desirable. Law is expected to be the linchpin of the new knowledge economy in the facilitation of business. However, this dimension of law accords little space to social justice, the marginalisation of which is arguably a key element in the creation of law student unhappiness.

As a corollary of the marked disinvestment by the state in higher education, the cost of tuition has been largely transferred to students. Following the Dawkins reforms of 1989, fees were gradually ratcheted up, with law at the highest level. Although fees were capped for most undergraduate courses, the sector was thrown into disarray in 2014 when the Abbott Government proposed to deregulate them. This would have exerted a dramatic effect on the legal academy because it would have been viewed as an opportunity for charging ever higher fees, but the policy was put on the backburner, if not categorically reversed, when the Turnbull Government came to power in September 2015.

What is startling about the deregulation proposal is that it was at one stage supported by every Australian 
vice-chancellor except Professor Stephen Parker of the University Canberra (ABC, 2015). The VCs' support for deregulation attests to the thesis of Dumenil and Lévy (2011) that neoliberalism is a new stage of capitalism effected by an alliance between the wealthy elite and the managerial classes. If fees rise dramatically, as occurred in the US, student/customers pay a premium for the brand name of an elite university. Non-elite law schools feel that they must follow suit and increase their fees in order to appear competitive, but the consequences are disastrous for students unable to obtain well-paying jobs to service their loans (Bourne, 2011-1012).

In accordance with the deregulation imperative, it might be noted that the undergraduate LLB, the basic law degree, has been replaced or supplemented in many Australian law schools by the JD (Juris Doctor), which is nominally a postgraduate degree as it requires completion of another degree as a prerequisite to entry. The postgraduate classification enabled universities to charge full fees when undergraduate fees were capped (Cooper et al., 2011), although both Melbourne Law School and the University of Western Australia Law School, which have dispensed with the LLB altogether, have some Commonwealth-funded places. It might also be noted that Larcombe and Fethers' (2013) study revealed that a higher percentage of full fee students at the University of Melbourne suffered from elevated depressive symptoms compared with those in Commonwealth supported places. The charging of high fees is not only a source of stress for law students because of the accumulated tuition debt and the pressure to secure a well-paid position in the corporate sector, it has caused them to feel like milch cows as they know that the high fees they pay are commonly used by universities to subsidise research and other general university activities (Garber, 2015; Thornton, 2012; Allen \& Baron, 2004), rather than enhancing the law students' own educational experience. This is also the case in the US (Tamanaha, 2012).

With the cut-backs in government funding for higher education, the seemingly unstoppable demand for law places, the removal of the cap on admissions and no official body regulating the number of graduates since the Commonwealth Tertiary Education Commission (CTEC) was abolished in 1987, it is unsurprising that enrolments in law have proliferated. Fees underscore the neoliberal assumption that individuals are expected to take responsibility for their own wellbeing (Harvey, 2005). Indeed, neoliberal economic theory is of the view that if students have paid for their education, they will work harder than if the course were free (Friedman \&
Friedman, 1962). The correlative effects of stress do not figure in the theory.

The net effect of ever-increasing fees is that higher education has insidiously shifted from being a public to a private good, which emphasises the credentialing and vocational elements of the educational experience. The more altruistic values associated with public good tend to be relegated to the periphery. Of course, there is always a private benefit associated with a degree in terms of credentialism and vocationalism but, as the public good of higher education recedes into the background, the private benefit is accentuated. Hence, there is increased pressure on law schools to provide more commercially oriented subjects of the kind believed to enhance graduates' position in the labour market as job-readiness privileges 'know how', the doctrinal and the applied over the theoretical and the critical.The symbiotic relationship between law and business is a central plank of neoliberalism, but it may not accord with the social justice orientation that inspires many students to enrol in law in the first place, a dissonance that constitutes an inevitable stressor in their lives. Indeed, a survey $(n=1,400)$ by the Women Lawyers'Association of New South Wales in 2015 found that 49 per cent of women and 37 per cent of men were attracted to the study of law by an interest in social justice (Staff Reporter, Lawyers Weekly, 2015).

\section{The commodification of legal education}

The impact of the neo-liberalisation of higher education on the legal academy is dramatically illustrated by expansion in the number of law schools and law students. In the 25 years since the Dawkins reforms, the number of law schools has more than tripled - from 12 to 44 (with some institutions such as the Australian Catholic University, Deakin, James Cook and Notre Dame having more than one campus). Law was a popular choice of the new universities in the belief that it was a prestigious course with a consistently high level of demand from wellcredentialed students who could be taught cheaply. The latter assumption was based on the large lecture model of pedagogy that many pre-existing law schools had rejected in favour of small group teaching.

The exponential increase in the number of law students has emanated not only from the explosion in the number of new schools, but also from the expanded intake in established law schools - both in terms of governmentfunded and full-fee places. The result is that over 12,000 law students are now graduating per annum, representing a 50 per cent increase over a decade (Staff Reporter, 
2015). Given that the total number of lawyers in law firms in Australia is only about 60,000 (Law Council, 2015), it is clearly impossible for all graduates to be absorbed into traditional private practice. Although more than 50 per cent of graduates gravitate to a range of destinations, including business, finance, government, education and the not-for-profit sector, together with an array of positions overseas, there is heightened concern among law students regarding their job prospects. It is apparent that no regard is being paid to the possibility of even larger numbers in a deregulated market, particularly as the CTEC has not been replaced. Some law schools have doubled, tripled, quadrupled and even quintupled their enrolments since Dawkins, an impetus that has escalated since the lifting of the cap on enrolments. It is also notable that the first accredited for-profit law school opened in Sydney in 2016 (TOP Education Institute, 2015).

Competition might be said to lie at the heart of neoliberalism, which officially became government policy as a result of the Competition Reform Act 1995 (Cth). Competition between law schools is expected to make them more profitable and more efficient, which tends to encourage a lowest common denominator approach. Teaching 'more efficiently' may equate with enrolling more students and teaching them in the large lecture mode or on-line in truncated degree courses. Needless to say, this issue of competition is a major source of stress for students, both in law school and in an overcrowded and volatile labour market. In a study conducted at Monash University in 2010, the majority of 1 st year students ( 97 per cent) indicated that they were contemplating working in the law as opposed to a more generalist position (Castan et al., 2010), a statistic that clearly belies the reality.

Corporate legal practice is still regarded as the most prestigious niche within the legal labour market with its high salaries, luxurious premises and perks, such as an on-site barista and free meals when working late, but Big Law has contracted as a result of the neoliberalisation of the legal profession itself, causing the demand for traditionally trained graduates to shrink. In 2011-12 the majority of Australia's leading national firms amalgamated with super-elite London-based global firms (Thornton, 2014). In accordance with competition policy, their primary aim is geared towards maximising profits by garnering new business in Asia or other parts of the world and by securing efficiencies of scale in their operations, such as off-shoring (sending routine work to cheaper overseas jurisdictions). Rather than recruiting new graduates, it is more profitable for these firms to hire senior lawyers laterally who do not need to be trained and who come with a ready-made client base. While law graduates are equipped for multiple positions in business, the public and community sectors, as suggested, they nevertheless still generally aspire to be admitted to legal practice, even if it is only in the short term.

As graduate trainees in elite law firms are more likely to come from the elite law schools, it might be argued that high fees and deregulation are one strand of the neoliberal strategy of enhancing class power, a factor that would also seem to be somewhat at odds with the wellbeing movement. Nevertheless, there is a shadowy class factor lurking within the wellbeing studies, as one cannot help but observe that the Australian law schools where most of the empirical studies have been undertaken are Group of Eight (Go8) law schools: Adelaide, ANU, Melbourne, Monash, UNSW and UWA.The schools involved in the Brain and Mind Research Institute study (Kelk, 2009) were no doubt more diverse as that study included students from 13 law schools, although we are not told which ones. Bergin and Pakenham's study (2015) involved three law schools in South-West Queensland but, again, we are not told which ones, and no distinction is made in the analysis between students on the basis of law school attended. Class in Australian discourse invariably operates beneath the surface. Nevertheless, if students at the elite universities are experiencing high levels of stress, how much more severe is the impact of neoliberalism likely to be on students in new and regional universities where resources are often severely stretched and there is no conveyor belt between the law school and the elite law firms.

A user-pays system of higher education in a deregulated market could see a reversion to a system where the wealthiest dominate positions of power in our society. While FEE-HELP is designed to mitigate the unequal distribution of wealth, it is not altogether clear how this would work in a deregulated market. Indeed, the media outcry regarding $\$ 100,000$ degrees suggests that deregulation would have a deterrent effect in university enrolment for the less well-off who would be more hesitant than middle-class students in assuming large debts, as the latter are likely to understand it as an investment. The effect of high fees is to pressure students to compete for high-paying corporate jobs with an eye to repaying their FEE-HELP debt as soon as possible rather than pursuing a public interest position that is likely to be less highly remunerated. In this way, law students are subtly encouraged to act in accordance with the neoliberal agenda, and any stress they might suffer is attributed to their own personal inadequacies (Baron, 2013). 


\section{The transformation of the legal academy}

Between the 1970s and 1990s when social liberalism was in the ascendancy, legal education in Australia generally became more liberal, more critical and more cognisant of the social context of law (Thornton, 2001). The influential Pearce Report (1987), which was one of the last disciplinary reports to be conducted by CTEC, boosted these trends with its view that Law was replacing Arts as the preferred generalist degree.

The modernisation of the law curriculum that coincided with the Whitlam era in the early 1970 s saw a flowering of new perspectives that included poverty, social justice, discrimination, social welfare and the environment, followed by another cluster that included feminism, postcolonialism and sexuality. Social liberalism also heralded a more contextual, theoretical and critical orientation across the curriculum generally. Pedagogical practices moved away from the sage on the stage in large lecture halls, where anonymous students sat passively and imbibed frozen knowledge, in favour of small-group teaching (12 to

\section{The modernisation of the law curriculum that coincided with the Whitlam era in the early 1970s saw a flowering of new perspectives... Social liberalism also heralded a more contextual, theoretical and critical orientation across the curriculum generally.}

exams and short problems. The subjectivity of students was thereby rendered irrelevant, which led to disaffection and disengagement (Boag et al., 2010). While individual academics resisted as long as they could in holding onto the innovative pedagogies and modes of assessment they had developed, they were eventually compelled to capitulate. This was not only because of the sheer weight of numbers, but because of the increasing pressure to publish.

Productivity and performativity on the part of academics within an audit culture are facets of the neoliberalisation of higher education that have insidiously impacted on the wellbeing of students. The focus on competition between institutions, as manifested in league tables and other calculable criteria - what Burrows (2012) refers to as governance by metrics - has caused teaching to play second fiddle to research, especially as full-time academics have been encouraged to buy out teaching in favour of casuals in order to maximise the time spent on research, which their institutions value more highly. I am not suggesting that casual teachers are inferior to full-time teachers, but there are inevitable frustrations for students in 25 students) where students were recognised as active learners. The traditional end-ofyear 100 per cent exam was also jettisoned in favour of more creative forms of continuous assessment.

The Pearce Report (1987) emerged on the eve of the Dawkins reforms (1988) and, in no time at all, many of its findings and recommendations were overtaken. 'Massification' meant that small group teaching quickly became a luxury and there was a widespread reversion to lectures, which ballooned from one hour to two or three hours in the name of efficiency (Thornton, 2012). If small groups were retained, they met less frequently or were restricted to the first year. Seminars groups became larger - often 60 or 80 rather than 12 or 20 - as universities increased enrolments in an effort to meet budget shortfalls. On-line delivery suited 'massification' even better as it meant that students didn't need classrooms at all.

Instead of interrogation and critique in accordance with the tenets of active learning, the explosion in numbers encouraged a reversion to outdated pedagogical practices, such as memorising and regurgitating information. The reflective essays that fostered independent research and developed the skills of argument and critique took too long to assess. They began to be wound back in favour of terms of availability and access.

A retreat from a broader contextual approach towards the curriculum that had allowed regard to be paid to theory, context and critique also began to occur and tended to be replaced by a narrow doctrinalism. This conformed with the more applied approach that suited the demands of employers in the new knowledge economy. Critical subjects such as jurisprudence and feminist legal theory began to disappear from the curricula in favour of a commercially-oriented constellation of subjects favoured by neoliberalism that facilitated business, entrepreneurialism and profit-making (Collier 2013, 2014; Thornton, 2012; Allen \& Baron, 2004).

Is it any wonder that students become depressed and frustrated when they find themselves the passive recipients of pre-digested information that they are expected to absorb and regurgitate? They are talented people who regret the marginalisation, if not the demise altogether, of critical thinking (Boag et al., 2010), although a technocratic approach may well suit those anxious to gravitate to the corporate track as soon as possible. It is somewhat ironic that students in the wellbeing studies are now commonly suggesting that small group teaching and 
increased availability of teaching staff are measures likely to improve social connection and wellbeing (Larcombe $\boldsymbol{e t}$ al., 2013), when such practices were so recently the norm.

I suggest that the rapid transformation of the legal academy following the Dawkins reforms helps to explain the high incidence of distress found among law students. While the pessimism and adversarialism associated with 'thinking like a lawyer' are certainly not new, law student stress has been boosted by high fees, massification and increased competition. These factors impact not just on students' law school experience but also on their labour market prospects.

\section{Conclusion}

The simultaneous emergence of neoliberalism and the wellbeing movement cannot be a coincidence, although I agree with Richard Collier (2014) that a clear-cut correlation between the two cannot be made. Not only is there the elusive character of neoliberalism and the way that it has been able to insert itself insidiously into the social psyche, but wellbeing itself defies precise definition and measurement. Neoliberal subjects are expected to take responsibility for the course of their lives, despite a prevailing climate of insecurity and powerlessness (Baron, 2013; Davies, 2011). Thus, although law students may pursue their studies assiduously, they are constantly beset with stress about the future. Hilary Sommerlad (2015) has described the young London graduates unable to obtain positions as trainee lawyers as a 'professional precariat', a term that could equally apply to many Australian law graduates. The exponential increase in the number of law schools and law graduates in both the UK and Australia is a product of the neo-liberalisation of higher education, but the wellbeing discourse deflects attention away from the prevailing political economy as the underlying cause of stress. This leads students to believe that they need to resort to counselling or some other form of therapy to effect a resolution.

It is apparent that law students are depressed at the prospect of not obtaining law-related employment on graduation and that improved teaching and learning strategies alone are not the solution. Stress would undoubtedly be exacerbated if the deregulation of fees were to go ahead. In the US, about half of all law schools are private and deregulated, a context in which students from lower-ranked schools may find that they have been seduced into enrolling and paying hefty tuition fees, but then find that they are unable to service their loans because they cannot secure a sufficiently high-paying job in corporate law (Tamanaha, 2012). In Australia, some firms are taking advantage of the mismatch between the numbers of students studying law and the graduate positions available for those keen to practise by engaging graduate interns as a source of free labour or even expecting students themselves to pay the firm for a position (Harris \& Evers, 2015).

Law students are aggrieved that the high fees they pay are not connected to a superior education but to their anticipated earning capacity as graduates (Boag et al., 2010). Many are commonly working several days per week or even full-time while enrolled in a full-time law course, a factor that further accentuates their distress. Elite law schools that mandate attendance make almost no accommodation for students who have to work or have family commitments (Larcombe \& Fethers, 2013). Larcombe and Fethers found that students are expected to commit full-time to their legal education, to be on campus four days per week, to attend all classes, including lunchtime lectures and to commit to a workload that many found excessive.

While I support initiatives to boost the wellbeing of law students through positive psychology as well as teaching and learning innovations, law schools must confront the impact of neo-liberalisation and not simply slough it off as a 'political problem'. Merely endorsing the wellbeing rhetoric cannot address the fact that the first year intake in some law schools has risen to as many as 1,000 students where no form of pedagogy other than the large lecture format is feasible without a massive injection of resources.

While many dedicated teachers are doing their best in difficult circumstances - a fact attested to by the wellbeing literature - attention should be paid to the policies of neo-liberalisation to address the cynicism and despair of students. Pressure needs to be brought to bear on VCs to address the problems at the level of government policy. Rather than acquiesce and argue for deregulation in the hope of enrolling ever more students to boost their income and subsidise research in the techno-sciences, a principled stance is needed. Law schools are undoubtedly complicit in the deception of prospective law students through their on-line advertising where the assumption is that students will become lawyers on graduation provided that they enrol in that law school (Thornton \& Shannon, 2014).

Neo-liberalisation sloughs off responsibility for stress, leaving such problems to be borne by the individual or resolved through the market. As the demand for law places continues to be high, aided by the removal of caps and the quasi-deregulation of fees, the economic value of law 
students takes priority at the university level and issues of student wellbeing are consigned to the periphery. Allen and Baron (2004) warned more than a decade ago that the wellbeing problem for law students was bound to worsen as numbers of law graduates were likely to double over the ensuing decade and full fees were about to make their first appearance. Allen and Baron's prediction was prescient as the number of law graduates increased from 6,149 in 2001 to 12,742 in 2012 (Nelson 2015), but their warning has not been heeded.

As students often enter law school with high expectations of becoming lawyers when they graduate, it would be more honest for law schools to explain the labour market position to commencing students and encourage them to think about careers other than traditional metrocentric legal practice. The possibility of alternative forms of employment could also satisfy the longing of the many new law students who want to make a worthwhile contribution to social justice in the community. First, there is a shortage of lawyers in regional, rural and remote areas; secondly, most ordinary citizens cannot afford access to legal services, a problem that cries out for innovative responses and, thirdly, there is always a need for creative thinkers in government, the community sector, education, journalism and the private sector. If law schools were to turn their minds to diversifying their curricula accordingly, not just their pedagogy, rather than devoting their energies to the reproduction of competent technocrats more suited to a past age, the wellbeing of law graduates would be bound to improve dramatically.

\section{Acknowledgements}

An earlier version of this article was presented at the National Wellness for Law Forum, The Australian National University, 5-6 February 2015. I thank my colleague, Stephen Tang, for inviting me to speak.

\section{Margaret Thornton is a professor of law and public policy fellow in the ANU College of Law at The Australian National University, Canberra.}

Contact: margaret.thornton@anu.edu.au

\section{References}

ABC. (2015). Stephen Parker, the Vice-Chancellor of the University of Canberra. Sunday Profile, Radio National, presented by Richard Aedy, 26 April. Retrieved from http://www.abc.net.au/radionational/programs/sundayprofile/stephenparker/ 6416384 .

Allen, J. \& Baron, P. (2004). Buttercup goes to law school. Alternative Law Journal, 29(6), 285-288.
Austin, D.S. (2015). Drink like a lawyer: The neuroscience of substance use and its impact on cognitive wellness. Nevada Law J (forthcoming).

Austin, D.S. (2013). Killing them softly: Neuroscience reveals how brain cells die from law school stress and how neural self-hacking can optimize cognitive performance. Loyola Law Review 59, 791-859.

Baron, P. (2014). Sleight of hand: Lawyer distress and the attribution of responsibility. Griffith Law Review 23(2), 261-284.

Baron, P. (2013). A dangerous cult: Response to the effect of the market on legal education. Legal Education Review 23, 273-289.

Bergin, A. \& Pakenham, K. (2015). Law student stress: Relationships between academic demands, social isolation, career pressure, study/life imbalance and adjustment outcomes in law students' Psychiatry, Psychology and Law 22, 388-406.

Boag, A., Australian National University, \& Law School Reform Committee . (2010). Breaking the Frozen Sea: the Case for Reforming Legal Education at the Australian National University. Canberra: Law School Reform Committee, ANU Law Students' Society, Australian National University.

Bourne, R.W. (2011/2012). The coming crash in legal education: How we got here, and where we go now. Creighton Law Review 45, 291-392.

Burrows, R. (2012). Living with the H-Index: Metric assemblages in the contemporary academy. Sociological Review 6, 355-372.

Castan, M., Paterson, J., Richardson, P., Watt, H., \& Dever, M.. (2010). Early optimism? First-year law students' work expectations and aspirations. Legal Education Review 20, 1-11.

Chan, J., Poynton, S. \& Bruce, J. Lawyering stress and work culture: An Australian study. UNSW Law Journal 37(3), 1062-1102.

Clarke, B.S. (2015). Coming out in the classroom: Law professors, law students and depression. Journal of Legal Education 64, 403-415.

Cohen, S. (1972). Folk Devils and Moral Panics: The Creation of the Mods and Rockers. St Albans, Herts.: Paladin.

Collier, R. (2014). Love law, love life: Neoliberalism, wellbeing and gender in the legal profession - the case of law school. Legal Ethics 17, 202-230.

Collier, R. (2013) Privatizing the university and the new political economy of socio-legal studies: Remaking the (legal) academic subject. Journal of Law and Society 40, 450-467.

Cooper, D., Jackson, S., Mason, R., \& Toohey, M. (2011). The emergence of the JD in the Australian legal education marketplace and its impact on academic standards. Legal Education Review, 21(1), 23-48.

Davies, W. (2011). The political economy of unhappiness. New Left Review 71, September-October. Retrieved from http://newleftreview.org/II/71/william-daviesthe-political-economy-of-unhappiness.

Dawkins, Hon. J.S. (1988). Higher Education: A Policy Statement (White Paper). Canberra: Australian Government Publishing Service.

Dumenil, G. \& Lévy, D. (2011). The Crisis of Neoliberalism. Cambridge, Mass.: Harvard University Press.

Friedman, M \& Friedman, R. (1962). Free to Choose: A Personal Statement. New York: Harcourt Brace Jovanovich.

Garber, S. (2015). Law students question value of their degree. Lawyers Weekly, 4 August. Retrieved from http://www.lawyersweekly.com.au/news/16923-lawstudents-question-the-value-of-degree.

Harris, J. \& Evers, M. (2015). Law students and graduates are not cannon fodder: professional responsibility is a two-way street. Financial Review, 2 July. Retrieved from http://www.afr.com/business/legal/law-students-and-graduatesare-not-cannon-fodder-professional-responsibility-is-a-twoway-street-20150629gi0yft.

Harvey, D. (2005). A Brief History of Neoliberalism. Oxford: Oxford University Press. 
James, C. (2011). Law student wellbeing: Benefits of promoting psychological literacy and self-awareness using mindfulness, strengths theory and emotional intelligence. Legal Education Review 21, 217-233.

Kelk, N., Brain \& Mind Research Institute, \& Tristan Jepson Memorial Foundation. (2009). Courting the Blues: Attitudes towards depression in Australian law students and lawyers. Sydney: Brain and Mind Research Institute, University of Sydney.

Krieger, L.S. (2005). The inseparability of professionalism and personal satisfaction: Perspectives on values, integrity and happiness. Clinical Law Review 11, 425-445.

Larcombe, W. \& Fethers, K. (2013). Schooling the blues: An investigation of factors associated with psychological distress among law students. UNSW Law Journal 36, 390-436.

Larcombe, W., Finch, S. \& Sore, R. (2015). Who's distressed? Not only law students: Psychological distress levels in university students across diverse fields of study. Sydney Law Review 37, 243-273.

Larcombe, W., Tumbaga, L., Malkin, I., Nicholson, P., \& Tokatlidis, O. . (2013). Does an improved experience of law school protect students against depression, anxiety and stress? An empirical study of wellbeing and the law school experience of LLB and JD students. Sydney University Law Review 35, 407-432.

Law Council of Australia website. Retrieved from http://www.lawcouncil.asn.au/ lawcouncil/index.php/about-the-law-council-of-australia.

Leahy C.M., Peterson, R.F., Wilson, I.G., Newbury, J.W., Tonkin, A.L., \& Turnbull, D.. (2010). Distress levels and self-reported treatment rates for medicine, law, psychology and mechanical engineering tertiary students: Cross-sectional study. Australian and New Zealand Journal of Psychiatry 44, 608-615.

Lester, A., England, L. \& Antolak-Saper, N. (2011). Health and wellbeing in the first year: The law school experience. Alternative Law Journal 36, 47-49.

Manning, P.J. (2013). Understanding the impact of inadequate feedback: A means to reduce law student psychological distress, increase motivation, and improve learning outcomes. Cumberland Law Review 43, 325-357.

Mayer J.D., Salovey, P., Caruso, D.R., \& Sitarenios, G.. (2001). Emotional intelligence as a standard intelligence. Emotion 1, 232-242.

Nelson, F. (2015). New law school may leave grads stranded. Lawyers Weekly, 29 September. Retrieved from http://www.lawyersweekly.com.au/news/17221-newlaw-school-may-leave-grads-stranded.

O'Brien, M.T., Tang, S. \& Hall, K. (2011). No time to lose: Negative impact on law student wellbeing may begin in year one. International Journal of the First Year in Higher Education 2, 49-59.
Parker, C. (2014). The "moral panic" over psychological wellbeing in the legal profession: A personal or political ethical response? UNSW Law Journal 37, 1103-1141.

Pearce Report (1987) (Pearce, D., Campbell, E. \& Harding, D., Australian Law Schools: A Discipline Assessment for the Commonwealth Tertiary Education Commission). Canberra: Australian Government Publishing Service.

Peterson, T.D. \& Peterson, E.W. (2009). Stemming the tide of law student depression: What law schools need to learn from the science of positive psychology. Yale Journal of Health Policy, Law, and Ethics 9, 357-434.

Purcell, M. (2008). Recapturing Democracy: Neoliberalization and the Struggle for Alternative Urban Futures. New York: Routledge.

Self, P. (2000). Rolling Back the Market: Economic Dogma and Political Choice. Basingstoke, Hamp.: Macmillan.

Sheldon, K.M. \& Krieger, L.S. (2007). Understanding the negative effects of legal education on law students: A longitudinal test of self-determination theory. Personality and Social Psychology Bulletin 33, 883-897.

Sommerlad, H. (2015 forthcoming). The New 'Professionalism' in England and Wales: Talent, Diversity, and a Legal Precariat, in R. Nelson, et al. Diversity in Practice: Rhetoric and Reality.

Staff Reporter, Lawyers Weekly (2015). Law students ambivalent over legal career, 28 July. Retrieved from http://www.lawyersweekly.com.au/news/16890law-students-ambivalent-over-legal-career.

Tamanaha, B. (2012). Failing Law Schools. Chicago: Chicago University Press.

Thornton, M (2014). Hypercompetitiveness or a balanced life? Gendered discourses in the globalisation of Australian law firms. Legal Ethics 17, 153-76.

Thornton, M. (2012). Privatising the Public University: The Case of Law. Abingdon, Oxon.: Routledge.

Thornton, M. (2001). The demise of diversity in legal education: Globalisation and the new knowledge economy. International Journal of the Legal Profession $8,37-56$.

Thornton, M. \& Shannon, L. (2014). 'Selling the Dream': Law School Branding and the Illusion of Choice, in M. Thornton (ed). Through a Glass Darkly: The Social Sciences Look at the Neoliberal University. Canberra: ANU Press.

TOP Education Institute. (2015). Sydney City School of Law: Australia's Newest Law School. Retrieved from http://www.top.edu.au/home/school-of-law. 


\section{Agnosis in the university workplace}

\section{Andrew Whelan \\ University of Wollongong}

One significant, tangible and interesting challenge for the privatised university is its impedance of particular forms of effective engagement and action in teaching and research, notably with respect to inequities in the broader social context, and the position of the university within that context. In the face of significant resource constraints (themselves the outcome of complex political and economic dynamics) intersecting organisational imperatives toward competition, administrative accountability, unilateral managerial style and 'best foot forward' promotional culture combine to produce a particular lack in socio-political epistemology, referred to here as bad faith 'not-knowing', or ignorance. A central paradox is that, although the university is evidently devoted to knowledge production and dissemination, and the various issues the sector faces in Australia are well documented (notably: casualisation, ever diminishing research funding, and the implications of the massification of teaching), nonetheless, the general tendency is towards acquiescence and intensification rather than contestation of the processes that give rise to these issues. This not-knowing arises at the intersection of the dissonant and incompatible voices that frame the institution as a workplace: the top-down managerial line and its commitment to control through 'cost neutrality', the outward-facing advertorial rhetoric of excellence, and the routine snark of the embattled workforce attempting to harmonise these discrepant formulations of the organisation. It is argued that this empty space of not-knowing is recognisable to people occupying roles in other organisations, and that it represents therefore a peculiar opportunity for those interested in the future of universities as public institutions: there is more to find out about how these organisationally produced epistemic limits are recognisable and consequential across contexts, how they are imposed, and how they contain potential.

Keywords: agnotology, new public management, critical university studies, neoliberalism, organisational culture, academic labour

The following paper presents an argument assembled via observations regarding university workplaces, which will be quite recognisable to readers familiar with the Australian academic context. If the argument transpires to be an interesting one, perhaps the most interesting thing about it might be how easy it is to substantiate, and following on from that, the question as to why, given what is known and knowable about universities, they seem generally to trundle along in much the same direction. It is not likely that this latter question could be answered just here, and it may be that it is a sort of pseudoquestion. Perhaps in the limited space available we could, however, reflect on what such an answer would consist of, and what it might entail. If there is something wrong with the premises of the question, contemplating that might also prove instructive, as it would seem to invite consideration of the role played in university workplace culture by the discrepancy between public proclamation and everyday practice. As Bourdieu memorably put it: 'practice has a logic which is not that of logic' (1998, p. 82). This discrepancy or occlusion, common to many workplaces, is especially intriguing in universities, given their apparent function as institutional sites for producing knowledge and making it available.

I present this argument here for the following reasons: it might entertain readers to remember again their social and organisational context and how they might evaluate their priorities in that context; it might instantiate 
grounds for forthright consideration of the role played by commitments to scholarship, conservatively defined, and the cultural and political role of 'critique' more broadly in universities; and it might clarify how specific economic and political logics play out in academic institutions, and as such, how they relate to the policy frameworks (and the effectiveness and appropriateness of such frameworks) driving and governing formal practice in universities.

The argument in brief is that the principal challenge facing the privatised university is that its organisational culture is not really helping the people who work there to do intelligent things. On the contrary, the organisational culture of the university leads its occupants to behave in accordance with a peculiar combination of ignorance and bad faith, produced in and through the aporia mentioned above. This vocabulary of ignorance and bad faith, elaborated below, should not be understood in a dismissive or derogatory sense. The formulation is somewhat clumsy, but there does not seem to be an alternate term or phrase at hand which effectively captures the conjunction. The suggestion is that, as ever, it is interesting to think about what we don't know and how we don't know it, and interesting especially to think about what we don't know about how and why universities work, how they could work, and how we might like them to work (or how we might like to work in them).

Some commentators, as we shall see presently, are inclined to think of this production of ignorance and bad faith in a rather conspiratorial fashion, as though the system were designed by our cryptic overlords to befuddle us in the pursuit of some ... thing. Although it does indeed serve the interests of powerful people to have universities organised in this way, this unhappy accident is probably not really of much consequence to those powerful people. University personnel and their 'mission' do not pose a threat to the status quo: they play an important role in upholding it. More pertinently for the argument at hand, the conspiratorial model gives undue credit to the capacity of human intention to consciously (albeit 'remotely') steer a complex and porous social organisation like a university in a definitively meaningful way. Such steerage could however be caustically disruptive in its consequences: the argument advanced here can be considered with this speculation in mind.

In part because there is now an extensive literature in 'critical university studies' (zombieacademy, 2010), it is sensible at the outset to sketch preliminary definitions, and in that way furnish some background for what follows. The idea of 'the privatised university' does not really have a clear referent: it means different things to different people. Furthermore, the idea of the privatised university travels alongside other critical descriptions of the institution: the neoliberal university, the corporate university and so on. One or another of these frameworks for running the critique will be more appealing to some than to others. Different ways of naming 'the problem' highlight some aspects of it, but in so doing, obscure others. The critiques of interest here, as the other articles in this issue attest, are concerned with particular challenges within and for the institution, although which challenges are considered most salient varies across locations and perspectives. The specification, however, invariably implies an institution or organisation that has been through a process to get to the state it is now in (the process of privatisation, corporatisation, neoliberalisation or whatever it was). By inference, it was in some other state before this process commenced, and therefore could be in some further, unspecified or perhaps even desirable state in future. Certainly, it won't be in this state forever.

Readers will be familiar with the broader context, which has also been very well rehearsed. Some people like to use the word 'neoliberalism' as shorthand. There are usually two steps here. The opening gambit is the assertion of market fundamentalism: according to the refrain, the dominant socio-logic asserts that things are only worth doing ('investing in') if they yield an economic return. Competition guarantees efficiency, and thereby increases economic gain. Education is a private, rather than a public good (so the individual recipient should pay). Information or perhaps 'knowledge' (something seemingly relevant to universities) is rendered productive as an exchange value, rather than a use value. Individuals invest in this product to increase their own value as commodities in the labour market.

There is a picture of the world here, where an economic (really a financial) imperative has primacy and other human practices and endeavours should be subordinated to it. Economic rationalism is the ultimate sovereign, and the guarantor of 'freedom'. Of course, if one wants to weed the kale on a commune, live out in the bush or become homeless:fine (as long as there is no trespassing or leeching resources off the state). But servicing the economy is the only meaningful way to be a person. Actualisation and agency are realised through consumption. People are monadic, their behaviour is private, calculated and occurs on the basis of self-interested motivation. This perspective functions practically both as a model of rational (and morally right) action, and a disciplinary mechanism structuring institutional fields so as to entail action in accordance: rewarding action which validates and assents 
to the model, and reproving, penalising, or 'developing' action otherwise. So far, so good.

The next step, which is sometimes forgotten (and the first part is certainly entertaining), usually involves something like the following points. Firstly, the social world does not really work this way, it does not seem to have worked this way for most of human history, and people do all sorts of things that are economically deeply pointless and nonrational: having children, alcoholism, going for the St. George Illawarra Dragons and so on (Graeber, 2011). Homo economicus is a wholly imaginary creature, and an impoverished and meanspirited one at that. The dominant logic is really a kind of fantastic and impossible utopia, and tremendous energy is continuously expended to administer this world into its image:

the unanswerable logic of markets, economic necessity and bottom lines becomes a new fundamentalist religion that turns organisations into a place of darkness, where emotional brutality is commonplace and different forms of psychological violence, dehumanisation, including degradation, humiliation and intimidation, have become the norm (Gabriel, 2012, p. 1142).

Secondly, and perhaps more pertinently, the ascendance of this rhetoric of economic rationalism occurs simultaneously with an unprecedented concentration of wealth: the plutonomy of the one per cent (Hardoon, 2015; Di Muzio, 2015; Piketty, 2013). For these sorts of reasons, Brenner and Theodore refer to the process which gives rise to the problems under consideration as 'actually existing neoliberalism' (2002). It is probably safe to assume that the co-incidence of neoliberal doctrine (or however we might name that) with this concentration of wealth is not fortuitous. Keeping this bigger picture in mind can have a helpfully clarifying effect in the encounter with some of the incongruities we will presently attend to.

How then, should we approach the architecture of this challenge, which is the organisational culture of the 'actually existing' Australian university? One short answer to this question might be something like this: as a public service institution, the university is not adequately funded for the work expected of it (this is before we come to any discussion of whether we think it well suited for this sort of work, or what sort of work we think it fit for in fact). This has been the case for some time and shows no signs of reversing. Among OECD countries, Australian universities come in thirty-third out of thirty-four for government funding allocated to universities as a percentage of GDP: the Australian government would have to increase current funding by almost 50 per cent just to get to the OECD average (Tiffen, 2015).

A slightly longer answer could be that the various strategies which have emerged to deal with the problem specified in the short answer are counterproductive in fact, they have become interesting new satellite problems: the university is a kind of constellation of problems, each with its own orbit, momentum and gravitational force.

To furnish some examples: the economy of scale sought in Australian university teaching as a cost-cutting solution to that first problem seems somehow to be hitting the quality ceiling in terms of the capacity to provide a meaningful educational encounter. Studentstaff ratio only goes in one direction, and it is not the preferred one (McDonald, 2013). This has implications for teaching 'quality', and by implication, for institutional reputation and market appeal. Technological 'innovation' is presented as a pedagogical salve, although it seems to further massify and anonymise that encounter, and has also facilitated the entry of edu-tech interests, funded by speculative venture capital (Watters, 2015). The implication of this is datafication and financialisation (as with the leisure pursuits of 'social media'), which is to say, student 'engagement' with technology becomes a source of monetisable data, which in turn reconfigures what will stand as evidence of learning and teaching. Students have no part in any conversation about this.

The squeeze has also led to the casualisation of academic work. This is effectively collapsing the future of the academic profession. It is well known that most teaching in Australian universities is now conducted by an academic precariat (Rea, 2012). There is a predictable gender skew here, shot through how different kinds of university work are valued and to whom they are allocated (Lynch, 2010). Permanent employment insecurity has implications for the psychological wellbeing of the university workforce (Berg, Huijbens \& Larsen, 2016).This is a widely acknowledged institutional risk (Saltmarsh \& Randell-Moon, 2015). By head count, most academic staff, like most university staff, do not have ongoing positions (Lane \& Hare, 2014). The minority of academics who retain such positions are ageing 
(Bexley, James \& Arkoudis, 2011). The consequences of casualisation for morale and for teaching quality, and what casualisation says about the priorities for the institution and its substantive forms of work and 'outputs', are not on the agenda for public discussion. There would seem to be something of an issue with the role of university accreditation in a society purportedly committed to meritocracy where career opportunities for some of the most highly qualified people in the country are limited to sessional work.

Research is structured exclusively around hypercompetitive and continually diminishing state research grants. In formal terms successfully competing for funding is research, in that it is really the only institutionally credible assurance of recognition as 'research active' (not that such status guarantees anything intrinsically desirable). In a context otherwise subject to hearty logics of austerity, the more money a researcher can attract and spend, the better. Profligacy with research funding is the objective institutional measure of research quality. Organising research around the submission of usually unsuccessful grant applications is grossly inefficient (Graves, Barnett \& Clarke, 2011), but it is also conventionally neoliberal by the parameters briefly given above: in the absence of a natural market for research 'products', competition for grants proxies for research 'excellence' (Blommaert, 2015).

The university is constituted within Byzantine, sclerotic, and deeply antidemocratic bureaucratic processes, involving a great many administrative personnel and the ritual circulation of documents marked with the proper signatures (Ginsberg, 2011). This is said to ensure transparency and appropriate oversight. Some commentators (for example, Ernst \& Young, 2012) have implied that unsustainable administrative bloat may be what gives rise to the appearance of the short answer problem. Occasionally, the fabulous salaries of senior management are brought into this discussion (Hare, 2015).

All of these concrete and uncontroversial examples (and we could certainly enumerate further) contribute to the everyday fabric of university work, and are well documented in the literature. This is the context within which the observations to follow are situated. In a sense, this is all still simply circling around the possibly sensible question as to why, although all of this is known to be the case, everything seems to go on along just the same trajectory.

Sometimes the simplest answer to this question - that 'knowledge resistance' stymies effective 'knowledge transfer' where policy makers are driven by ideological agendas - seems like the right one (Schlesinger, 2013). Ideologues are in charge and don't care about facts: they don't listen to reason! Collini (2012) suggests that although people who produce higher education policy basically ignore criticism from academics, such criticism must nonetheless be repeated vociferously. That may be, but we can distinguish criticism from evidence and ought not conflate them, and so this is not entirely satisfactory. Moreover, in this way of thinking, it is somehow up to someone else, somewhere else, to stop doing what they are doing, or even to actually do something different altogether. Asking for somebody else to do something, or waiting for something to happen (under the increasingly implausible impression perhaps that doing so is the 'professional' thing to do), doesn't seem to have proved fruitful thus far.

A more sophisticated answer is that the neoliberal market form in universities can never be realised, and is rather applied selectively and to political ends: control, budget, the rhetoric of social inclusion and so on (Marginson, 2013). Here the ideologues aren't true ideologues, for they don't really even believe in the ideology themselves (and so those documenting how it can be debunked could perhaps be spending their time more productively). It does not work how it says it works: what is said and what is done are different: the 'meaning' of what is said should not be evaluated for what it says, but rather for what it does or what actions it permits or requires. It is not really certain whether the current situation is actually favoured by The Powers That Be, or merely a weird accidental outcome informed by this 'para-ideological' tinkering. This is interesting territory to explore and we shall return to it later.

It might be obvious, but perhaps it is worth pointing out just the same that one needs to take or be in some position to actually consider those aforementioned and well-documented realities as problems, or failures, or challenges, or as in some other way suitable for intervention from someone. For many people, these are matters of indifference, not least because they are recognisably rather humdrum iterations of the broader and generally disagreeable social context of contemporary work in corporate organisational cultures (Wilmott, 1993; Höpfl, 2005). It is not as though there is something unusual or exceptional about universities compared to other social locations: the processes of rationalisation and intensification customary to universities are ubiquitous, although they may occur with varying intensities in different locations. The concerns about university work can be understood primarily as the concerns of 
a somewhat idiosyncratic profession in the course of being deskilled, or perhaps (in the more old-fashioned vocabulary) proletarianised.

This shift in professional autonomy is a key feature of 'new public management': the suite of managerial practices originally introduced into the public sector in the 1980s, ostensibly to increase efficiency through emphasis on outputs, competitive, contract-based provision, private sector accounting techniques, and the diffusion of responsibility (not power) across the workforce hierarchy (Hood 1995). The diminished control academic workers possess over their own labour and how it is defined and assessed highlights how new public management appropriates and subverts discourses of democratisation and public accountability. 'Objective' standards, audit and externally defined and imposed measures of performance supplant trust in the professions.

Pointing out the cultural and intellectual consequences of this collapse of trust, however, is often heard rather pithily as an indulgent complaint about being required to justify one's salary (Maltby, 2008). It can be informative to compare different professions in terms of their social closure and their capacity to defend themselves from these managerial forms: doctors, lawyers, engineers and university lecturers, for example, have all fared rather differently in terms of their capacities to retain professional autonomy and control. In developing critical arguments around these issues, it can be productive to start with the widespread indifference to the conditions of university work in mind (that is to say, the extent to which this degradation is quite unremarkable to people employed in other contexts). Doing so can to some extent mitigate the potential risks of being understood as occupying or claiming a 'victim' position which, to many, does not appear congruent with possession of a $\mathrm{PhD}$, some residual occupational prestige, and a basically middle-class (though possibly downwardly mobile) status.

Descriptions of 'the university under attack' - or worse, 'the humanities' - are therefore often unhelpful, however parlous the circumstances, to the extent that they play on tacit politics of vocational identity which falsely (and perhaps somewhat disingenuously) homogenise the institution and its commitments (see, for example, Eagleton, 2015, for a particularly pompous instance of this). This is deeply alienating and antagonising to those who are unmotivated by the magical cakes of bourgeois culture and temet nosce. A sounder tack might be to better identify and articulate commonalities across organisational sites and working contexts. As is common in other workplaces, academics and others at universities seem increasingly to experience 'organisational disidentification' (Stiles, 2011, p. 6). The university is an institution with multiple incompatible identities - it is an MIO or 'multiple identity organisation' (Pratt \& Foreman, 2000), and there is no reason to assume that any one group within the organisation speaks legitimately for or to the interests of any other, or indeed that the organisation could be brought together under any one sign. This is precisely the charge often laid at the door of the managerial elite by academics, who in so doing perpetrate exactly the same identitarian manoeuvre, albeit espousing a formulation that better serves their own interests.

In a distinct idiom to that of MIOs, Cris Shore published a paper in 2010 titled 'Beyond the multiversity', riffing on Clark Kerr's coinage.The multiversity, Shore argues,

is not the death of the traditional liberal idea of the university so much as a shift to a new multi-layered conception in which universities are now expected to serve a plethora of different functions, social and symbolic as well as economic and political. Government no longer conceptualises universities primarily as sites for reproducing national culture, or educating people for citizenship or equipping individuals with a broad, critical liberal education. Rather, it expects universities to produce all of these plus its agenda for enhancing economic importance, its focus on commercialisation of knowledge, and its goals for social inclusion (2010, p. 19).

The university, the implication seems to be, cannot please all of the people all of the time. Shore's position is notable because he does not describe the imminent demise of some particular sacred totem, as though there were one, unitary, overarching logic, but rather, a kind of burying alive of this totem alongside and under a whole range of other expectations and demands. The university as MIO becomes manifest at the juncture where all these expectations and demands sediment in such a way as to produce tangible contradiction. Organisational fragmentation obviously has implications for the identity work conducted by members of the organisation, compounding the constraints the core activities of the organisation are already subject to. 
It is then not only that the university is not resourced to meet the demands placed upon it from without; it is that it is, in addition, internally incommensurable: it cannot simultaneously be the same place apparently indexed by the various activities and accounts intended for and emanating from within. The organisation talks past itself. In the interests of brevity, we can review the locus of occlusion briefly here.

At a broad or general scale, there is the relentless, asinine and sanitised hyperbole of university marketing, which is expensive but also, unfortunately, patently transparent to anyone subjected to it. This is a kind of amplified noise that tends to distort and undermine the possibilities of a more thoughtful signal of the sort people might hope to encounter from universities, an aggressive reiteration of the predictably vacuous language of 'excellence', 'impact', 'ranking' and 'world class' which is oddly both aspirational (where we are always going) and factive (kudos to us, we are already there!).

This is combined with a rigidly hierarchical, top-down managerial culture, quite incongruent with the packaging and PR, under which staff are to understand themselves as cost centres:accounting objects which consume resources, must constantly justify their presence, and can be moved around the organisation in whatever way seems most cost effective (Gabriel, 2012). Sometimes an odd commitment to the pretence of participatory governance is exhibited; with direct and generally publicly unquestioned authority softened by quaint and velvety rituals of 'consultation' and 'feedback', although essentially decision-making is vertical, slippery and opaque. Universities exhibit an admirably dogged commitment to styles of managerial control which are, according to even mainstream management theory, anathema to productive working environments (De Vita \& Case, 2014).

Running in counterpoint with these disharmonious leading voices of the institution is the back chatter and gallows humour of the staff: demoralised, silenced, tenacious, isolated, cynical, often uncertain and acutely attuned to any shift in tone from management which might harbour a threat. This is sometimes practised as a grim, passive realpolitik, as though the smartest thing to do is nothing but hope to hold on.

These discourses or ways of being (in) the organisation are not interesting because of how they line up (or don't) with particular forms of rationality or sociality or procedures for establishing meaningful statements. They are interesting because they are about practices for generating outcomes, not meanings. Imprecision, opacity, vagueness, obfuscation and obscurity are not problems to be resolved; they are resources for getting things done.

At the nexus of these irreconcilable postures is the interesting space, the space of limit or ellipsis where ignorance and bad faith are produced. Of course: 'organisations produce ignorance, and thus the possibility of mistakes, through compartmentalisation and structural secrecy' (Croissant, 2014, p. 9). But we can go further than that here. The commitment to making certain types of things exhaustively knowable about universities (and surely there is an almost morbid excellence of data capture, even if this is oriented to rather particular ends: think of block grant allocation, workload models and their costing, learning analytics, research funding administration, library acquisitions, enrolment and attrition patterns, parking requirements and revenue...) simultaneously produces certain kinds of not-knowing, certain sorts of unthinkable things: it shapes the terrain of what is worth knowing and what is worth finding out about - what will actually count as knowledge. Ferrell, for example, has gracefully described how procedures for financial acquittal and ethical oversight render particular forms of research and community practice impossible (2011; see also Hammersley \& Traianou, 2011). As Weber concisely pointed out, 'ignorance somehow agrees with the bureaucracy's interests' (1946, p. 234). In addition to this, the advertorial logic of total excellence tends to saturation, as though there were really nothing more to find out about doing something better, despite the widespread and evident burnout, boreout, soldiering, and apathy.

The space is hedged by various modalities of the turning of a blind eye: pretending-not-to-know, prefer-not-to-thinkabout-it, as-if-it-was-ok, can't-deal-with-that-right-now or choosing-not-to-acknowledge. These are routine bad faith gestures, a symptom and a further challenge of the actually existing neoliberal university. The impulse to silence is an inadvertent success of the organisation as a control system.

But there is a deeper agnosis also: a kind of dispossession of the imagination. Faber and Proops provide a helpful definition of 'closed ignorance', whereby 'we either neglect problems themselves, or do not take notice of intuitive insights, experience, information, models and methods of solution which are available inside of society' (1998, p. 117). It is a space of a kind of limit to change, to ownership, to action, and it is corrosive to the academic project overall, if that is understood to involve the articulation and development of active curiosity and the capacity to exercise it creatively and productively.

We can say that the dominant ways of framing and organising university work tend to produce ignorance 
insofar as teaching and research are cast in such a way as to foreclose alternative forms of pedagogy or community engagement which would make more widely known and therefore real the possibility of actually really doing things in different ways. To pick an example more or less at random: thinking seriously about the implications of living in the plutonomic world gestured at in the opening paragraphs, and thinking seriously about what it means to play a role in the production of graduates for work and civic engagement in a context where the state plays a generative rather than remedial role in the production of precarity, marginality and economic inequality (Slater, 2012). That is to say, we could actively query why, given what we do know about the structural production of complex social problems, everything seems to go along just the same. What is it that we don't know?

At the same time, then, this interesting space is the space of dereliction, which can be utilised to do unexpected things, because it is the sort of space nobody is really looking at, they can just feel that it is there. The what-wedon't-know is actually quite exciting, and is often one of the reasons people are drawn to research and study in the first place: it is fun to find out new things.

This article consists of an argument, for the most part uncontentious, about impediments to effectiveness in university processes, through intersecting logics that thwart creativity and lead people to refrain from full and open participation. Similar impediments can be encountered elsewhere, in other organisational contexts, where such contexts constitute the very fabric of social life. This makes it all the more important to document, investigate and contest them. I would like to conclude by alluding again to the scepticism expressed above about the possibility of steering organisations like universities effectively via the 'at a distance' policy mechanisms currently favoured by Western states. As the sociological canon reminds us again and again, institutions are emergent outcomes of patterned and above all contingent interactions, which could always go otherwise. They are always dynamic and always in flux, and thus those who attend (to) them are always actively participating and always having effects. Finally, given the asymmetric nature of knowledge and ignorance, it is perhaps also worth reflecting on Henry Kissinger's memorable quip: conventional forces of domination lose if they do not win; but all you have to do to win is not lose (1969, p. 214).

Andrew Whelan is a sociologist with the School of Humanities and Social Inquiry at the University of Wollongong, NSW.

Contact: : awbelan@uow.edu.au

\section{References}

Berg, L., Huijbens, E. \& Larsen, H. (2016). Producing Anxiety in the Neoliberal University. Forthcoming in The Canadian Geographer/le géographe canadien. Retrieved from http://www.academia.edu/19714927/Producing_Anxiety_in_ the_Neoliberal_University.

Bexley, E., James, R. \& Arkoudis, S. (2011). The Australian Academic Profession in Transition: Addressing the Challenge of Reconceptualising Academic Work and Regenerating the Academic Workforce. Melbourne: The University of Melbourne Centre for the Study of Higher Education. Retrieved from http:// www.cshe.unimelb.edu.au/people/bexley_docs/The_Academic_Profession_in_ Transition_Sept2011.pdf.

Blommaert, J. (2015). Rationalizing the unreasonable: there are no good academics in the EU. CTRL $+A L T+D E M$ : Research on alternative democratic life in Europe. Retrieved from http://alternative-democracy-research. org/2015/06/10/rationalizing-the-unreasonable-there-are-no-good-academicsin-the-eu/.

Bourdieu, P. (1998). Practical Reason: On the Theory of Action. Stanford: Stanford University Press.

Brenner, N. \& Theodore, N. (2002). Cities and the geographies of 'actually existing neoliberalism'. Antipode, 34(3), 349-379.

Collini, S. (2012). What are universities for? London: Penguin.

Croissant, J. L. (2014). Agnotology: Ignorance and Absence or Towards a Sociology of Things That Aren't There. Social Epistemology, 28(1), 4-25.

De Vita, G. \& Case, P. (2014). 'The smell of the place': Managerialist culture in contemporary UK business schools. Culture and Organization, (ahead-ofprint), 1-17.

Di Muzio, T. (2015). The 1\% and the Rest of Us: A Political Economy of Dominant Ownership. London: Zed Books.

Eagleton, T. (2015). The Slow Death of the University. The Chronicle of Higher Education. Retrieved from http://chronicle.com/article/The-Slow-Death-ofthe/228991/.

Ernst \& Young. 2012. University of the Future: A Thousand Year old Industry on the Cusp of Profound Change. Ernst \& Young. Retrieved from http://www. ey.com/Publication/vwLUAssets/University_of_the_future/\$FILE/University_of_ the_future_2012.pdf.

Faber, M. \& Proops, J. (1998). Evolution, Time, Production and the Environment. Berlin: Springer.

Ferrell, R. (2011). Income outcome: Life in the corporate university. Cultural Studies Review, 17(2), 165-82.

Gabriel, Y. (2012). Organizations in a state of darkness: Towards a theory of organizational miasma. Organization studies, 33(9), 1137-1152.

Ginsberg, B. (2011). The fall of the faculty. Oxford: Oxford University Press.

Graeber, D. (2011). On the Invention of Money - Notes on Sex, Adventure, Monomaniacal Sociopathy and the True Function of Economics. Naked Capitalism. Retrieved from http://www.nakedcapitalism.com/2011/09/davidgraeber-on-the-invention-of-money-\%E2\%80\%93-notes-on-sex-adventuremonomaniacal-sociopathy-and-the-true-function-of-economics.html.

Graves, N., Barnett, A. G. \& Clarke, P. (2011). Funding grant proposals for scientific research: retrospective analysis of scores by members of grant review panel. $B M J, 343$.

Hammersley, M. \& Traianou, A. (2011). Moralism and research ethics: a Machiavellian perspective. International Journal of Social Research Methodology, 14(5), 379-390.

Hardoon, D. (2015). Wealth: Having it all and wanting more. Oxford: Oxfam International. Retrieved from http://policy-practice.oxfam.org.uk/publications/ wealth-having-it-all-and-wanting-more-338125. 
Hare, J. (2015). Vice chancellor's salary packages on the rise. The Australian. Retrieved from http://www.theaustralian.com.au/higher-education/vicechancellors-salary-packages-on-the-rise/news-story/2fb3ceb8c375c67cc271bd4 d254f69e2.

Hood, C. (1995). The "New Public Management" in the 1980s: variations on a theme. Accounting, organizations and society, 20(2), 93-109.

Höpfl, H. (2005). The organisation and the mouth of hell. Culture and Organization, 11(3), 167-179.

Kissinger, H. (1969). The Vietnam Negotiations. Foreign Affairs, 48(2), 211-234.

Lane, B. \& Hare, J. (2014). Demand drives increase in casual staff at universities. The Australian. Retrieved from http://www.theaustralian.com.au/highereducation/demand-drives-increase-in-casual-staff-at-universities/story-effrgcjx1226817950347 ? nk=37c8937637e587af405e2ce73f940c79.

Lynch, K. (2010). Carelessness: A hidden doxa of higher education. Arts and Humanities in Higher Education, 9(1), 54-67.

Marginson, S. (2013). The impossibility of capitalist markets in higher education. Journal of Education Policy, 28(3), 353-370.

Maltby, J. (2008). There is No Such Thing as an Audit Society: A Reading of Power, M. (1994a) The Audit Society. Ephemera: Theory and Politics in Organizations, 8(4), 388-98.

McDonald, G. (2013). Does size matter? The impact of student-staff ratios. Journal of Higher Education Policy and Management, 35(6), 652-667.

Piketty, T. (2013). Capital in the Twenty-First Century (A. Goldhammer, trans.). Cambridge, MA: Harvard University Press.

Pratt, M. G. \& Foreman, P. O. (2000). Classifying managerial responses to multiple organizational identities. Academy of Management Review, 25(1), 18-42.
Rea, J. (2012). National Survey reveals a Casual Academic workforce struggling to make a living and do their job. National Tertiary Education Union. Retrieved from http://www.nteu.org.au/article/National-Survey-reveals-a-CasualAcademic-workforce-struggling-to-make-a-living-and-do-their-job-12792.

Saltmarsh, S., \& Randell-Moon, H. (2015). Managing the risky humanity of academic workers: Risk and reciprocity in university work-life balance policies. Policy Futures in Education, 1478210315579552.

Schlesinger, P. (2013). Expertise, the academy and the governance of cultural policy. Media, Culture \& Society, 35(1), 27-35.

Shore, C. (2010). Beyond the multiversity: neoliberalism and the rise of the schizophrenic university. Social Anthropology, 18(1), 15-29.

Slater, T. (2014). The myth of 'Broken Britain': welfare reform and the production of ignorance. Antipode, 46(4), 948-969.

Stiles, D. (2011). Disorganization, disidentification and ideological fragmentation: Verbal and pictorial evidence from a British business school. Culture and Organization, 17(1), 5-30.

Tiffen, R. (2015). The university rankings no government wants to talk about. Inside Story. Retrieved from http://insidestory.org.au/the-university-rankingsno-government-wants-to-talk-about.

Watters, A. (2015). Top Ed-Tech Trends of 2015: The Business of Ed-Tech. Hack Education. Retrieved from http://2015trends.hackeducation.com/business.html.

Weber, M. (1946). Bureaucracy, in H.H. Gerth \& C. Wright Mills (eds, trans). From Max Weber: Essays in Sociology. New York: Oxford University Press.

Willmott, H. (1993). Strength Is Ignorance; Slavery is Freedom: Managing Culture in Modern Organizations. Journal of Management Studies, 30(4), 515-552.

zombieacademy. (2010). 'Zombie Research.' Zombies in the Academy. Retrieved from https://zombieacademy.wordpress.com/zombie-research/. 


\title{
Learning by doing by
} learning

\section{Reflections on scholar-activism with the Brisbane Free University}

\section{Fern Thompsett}

\author{
University of Queensland \& McGill University
}

As universities are swept by a near-global tide of capitalist restructuring, myriad forms of resistance are also on the rise. While struggles that grapple directly with universities are vital, different streams of activism aim beyond them, in the form of 'prefigurative' politics—one that works to build a better world 'in the shell of the old'. This paper focuses on 'free universities', prefigurative projects that re-create university-like spaces of learning according to their own radical visions of social justice. Drawing on my own experience as a co-founder and organiser of the Brisbane Free University, as well as research conducted with 25 free universities across North America, I explore the complex tensions involved in working simultaneously within the academy, and engaging in activism beyond it. I show that most free university activists, myself included, see that it is impossible to distinguish between the inside and outside of the university, and that ultimately working across the 'divide' through prefigurative politics offers a robust means to effect substantive change.

Keywords: alternative pedagogies, prefigurative politics, activism, anti-capitalism, commodification, social justice

\section{Introduction}

This article tells the story of the Brisbane Free University (BFU), a project that organises free, public discussions, generally taking place in a semi-underground car-park on a busy inner-city street. Its story spills beyond the confines of the modest concrete box it occupies, however. Rather, it draws together threads from throughout the community in which BFU is nested, including many from 'conventional universities' (I use this term to refer to 'establishment' or 'traditional' universities, be they public or private, as opposed to free universities), and weaves them into a broader tapestry of similar movements all over the world.

Free universities form around a praxis of 'prefiguration,' meaning that rather than (or as well as) mobilising directly against the aspects of conventional universities they oppose, they step outside the university's walls to re-imagine learning on their own terms. This praxis, however, opens up complex political terrain of its own. It is often unclear to those with stakes in the academy - as well as to activists themselves - whether free universities are working to save, destroy, or replace conventional universities, or a messy combination of all three. In this context, how might we make sense of activism that lies both inside and outside of the academy, and mobilises simultaneously for, against, and beyond it?

This article uses these questions to frame my reflections on the myriad and often surprising things I have learned through organising and participating in the Brisbane Free University over three years, whilst simultaneously working 'on the inside' of a conventional university. It draws not only upon my own experiences, but also on research I conducted with around 25 different free 
university projects across the United States, Canada and Mexico in 2014. I focus on the tensions inherent to free universities' prefigurative experiments by first laying out the grounds upon which activists oppose conventional universities, including their sweeping capitulation to capitalist reforms, before turning to the complex ways in which free universities move to abandon some aspects of the university but preserve others. Finally, I consider how this might bring us to think differently about options for change, through a sort of activism that seeks to complicate, if not dismantle altogether, the very notion of 'inside versus outside' by proliferating cracks throughout conventional universities' structures in which to collectively build new ways of learning and living.

\section{The Home Front}

I would like to begin by telling my own part of the story. After graduating from university as an anthropologist, I worked for a government body before returning to what felt like my 'natural habitat' of academia as a casually-employed, part-time tutor. For me, study had never been about employability; rather, I chose a field that made me come alive with curiosity, and that seemed able to contribute towards some sort of social justice, however ill-defined was my sense of what that might mean. Like many other people, it was primarily during my undergraduate years that I developed the critical political consciousness I have since come to value. It later struck me that teaching could be a valuable way to advance these very ends, through fostering similar forms of critical thinking and political awareness amongst new generations of students. In many ways, this expectation bore fruit, and I found - and continue to find immense satisfaction in my job.

There were, however, many aspects of university work that, for me, struck discord. The bureaucratic burdens on faculty members seemed too heavy, my own position within the casual labour force too precarious, and the student cohort too preoccupied with readiness for the looming job market rather than the course material at hand - especially given that tuition fees and student debt are rising near-globally. My growing malaise happened to coincide with the eruption of Occupy encampments around the world, and the strange lovechild of these two phenomena was the Brisbane Free University.

The Brisbane Free University (BFU), founded in 2012 by three friends including myself, attempts to challenge universities' near-global 'enclosure of knowledge' (Federici, 2009) by bringing talks and discussions literally into the streets, for free. Our trio had discovered common ground in our love of some aspects of the learning we experienced at university - such as theory-based social analysis and cultural critique - but were frustrated by other aspects like hierarchical and standardising pedagogies, restrictive access policies, and a heavy focus on learning for grades, rather than for the value inherent to the content itself or the capacity to think critically about the world. Our initial idea seemed simple enough - to open a space to the public, in which anyone could learn about a variety of topics, with a focus on inclusive discussion or workshop-based pedagogies, and without any of the pressures brought by assessment or accreditation. The project has a broader purview that alternates between (or combines) fostering civic engagement with particular socio-political issues and/or voices marginalised by mainstream discourse, and encouraging 'the sheer, simple joy of learning for its own sake', all the while bringing together diverse members of the community in ways that might build solidarity (see http://brisbanefreeuniversity.org/about).

More specifically, we hold (roughly) fortnightly-tomonthly sessions with an attendance of anywhere between 20 and 200 people. Attendees come from all walks of life - from university professors to homeless people, partygoers passing by, long-time activists, mothers with their new babies, strangers and friends. Our 'campus' is a carpark under a bank in the central suburb of West End - a space that is wonderfully accessible and visible, despite its oddly grungy aesthetic - for which we have negotiated free use after business hours. Ironically, given our location, the closest BFU comes to having a 'rule' is that we operate as much as possible without any exchange of cash - no payments, grants, donations, spruiking or marketing. Putting this ideal into practice has involved its own complexities (Thompsett, 2016), but we have never had to compromise on providing free entry to our events.

Furthermore, we have always felt it important to ensure that $\mathrm{BFU}$ remains open to the ideas and participation of anyone wishing to be involved. As such, whilst many of the sessions are coordinated by the three co-founders, $\mathrm{BFU}$ is also used as a platform by other community members, whether individuals or collectives, to organise events that they feel to be of particular interest, often in other spaces or formats. Our content has ranged widely from the practical ('Vocal Workshops: Rhythm and Harmony') to the abstract ('Understanding Ethical Reasoning') to the political ('Indigenous Resistance and the State'); and from the local ('West End's Shrinking Public Realm') to the global ('Gaza in Context').

I was an active organiser with BFU from the time of its inception until I left Brisbane in late 2015. I could 
not pretend for a moment that over the course of those three years, my work with BFU was not fraught with strange tensions. I remained employed at a conventional university, and yet would spend my afterhours organising a project designed to draw attention to the more problematic aspects of the academic world in general. I used university printers to run off BFU flyers and posters, I asked faculty members if they would share their research outside the academic paywall - the vast majority of whom were only too happy to do so - and we once held a provocative panel discussion right in the centre of campus. At times, I had to wonder about the ethical defensibility of living with a foot in both camps (or campuses), so to speak, surviving as I was on the university's pay-cheques whilst running a project that contests and scavenges from it.

My position in this sense was far from unique. Although we had not initially realised it, BFU represents but another rivulet in a long and broad stream of projects that seek to subvert the status quo through study, including a good number that remain in operation as of this writing. Driven by curiosity about the world we had unwittingly stepped into, I spent the first six months of 2014 visiting about 25 similar projects across the US, Canada and Mexico, and interviewing approximately 60 organisers of and participants in free universities (shorthanded as 'activists' from here). The material I gathered during these conversations, alongside my own experiences with BFU, forms the basis for this article.

\section{Free Universities: Towards an elusive definition}

What exactly are free universities? The question is difficult to answer. One of the best descriptions I have found was penned in 1967 to mark the formation of Sydney's Free University (aka Free U), which remained in operation until 1972. As the founders wrote in their manifesto:

The idea of a Free University is this: it is free in spirit, not in cash - it will get no government grants, no scholarship scheme. It grants no degrees and offers no status. It is a small group of students and teachers who come together outside the established university system because they find that system inadequate. It ... extends its interests to issues and subject-matters frozen out of regular university courses. It is based on cooperation instead of competition; it breaks down the formal role-division of student and staff, inferior and superior; and experiments with teaching methods. Ultimately, it stands or falls by the enthusiasm of its members (Cahill et al., 1967. For more on Sydney Free U, see Irving, 2013).
Despite the nearly fifty-year gap between the launch of Sydney Free $U$ and our current moment, this description still holds for today's free universities. Although these go by a range of different names, here I use the term 'free university' to refer to projects of collective learning that are: free to attend, open to anyone, do not offer accreditation, avoid state affiliation, gather in physical spaces (i.e. offline), and include a goal of emancipation, however defined. Not all free universities use political terminology to describe themselves, but some identify as anarchist, and many are organised according to horizontalist modes of consensusbased decision-making. Many favour non-hierarchical or 'free-form' pedagogies that counter traditional teacherstudent structures by recognising that everyone can be both teacher and student, and that learning can occur effectively through egalitarian collaboration.

Within these broad criteria, however, the terrain is complex. Although many are networked with one another, each free university develops organically within its locallyspecific context, meaning that no two are alike. As several organisers were quick to point out, a 'free university' is not a franchise. Furthermore, each is internally in a state of flux. As I was told by Joe Kay, an activist with the New York-based free university for fine arts, the Bruce High Quality Foundation University (BHQFU), 'It's impossible to represent what happens here... What we do is immaterial in a way, it's hard to graft onto an object or a commodity' (personal communication, May 28, 2014). Free universities are, by definition, semi-improvised, and deliberately avoid calcifying too rigid an agenda or identity - rather, they incorporate a fluid network of spaces, organisers, and participants. This commitment to radical flexibility serves a twofold purpose - it allows projects to incorporate contributions from as many people as possible, while acting as a counterpoint to conventional educational systems' tendencies to rigidly structure learning as a linear process of ascendancy towards a pre-defined target of proficiency (Dyke \& Meyerhoff, 2013). Otherwise put, many free university organisers value fluidity not only in terms of organisational dynamics, but as an important way to defend learning for its own sake. As David Brazil, a co-founder and former organiser of the Bay Area Public School, told me: 'What are we actually doing? To some degree we don't know. And it is useful and good that we don't know' (personal communication, 30 January, 2014).

Classes, or as Wes Modes of the Free Skool Santa Cruz joked, 'post-apocalyptic revolutionary logistics training' (personal communication, 27 January, 2014), are sometimes offered by members, but more frequently by non-members of the organising group, and just about span the gamut of 
what is humanly possible to teach and learn.I heard of sessions ranging from Marxist feminism to beekeeping, self-defence, bike mechanics, immigration law, Japanese cinema, performance art, and everything in between. One of Wes Modes' 'classes' was to drive a group of people to the top of a hill at sunset, serve them tea and cookies in the back of his pick-up truck, and play them Alan Watts lectures on the car stereo. Another memorable example was 'The History of the Future', a series of role-play sessions that asked participants to imagine they were sole survivors in a post-apocalyptic world, and experiment with the sorts of socio-economic systems they would develop. As Wes commented, with a chuckle: 'Who's to say that's a class? Who's to say that's not a class?' In other words, free universities seek to broaden not only access to learning but the very ways in which we think about what learning is, and how we value various pedagogies and activities accordingly.

For all the frivolity, however, there is a serious undercurrent. The crucible in which free universities form is one of struggle. Organisers cited inspirations including Francisco Ferrer's anarchist Escuela Moderna of 1900s Spain, the Freedom Schools of the US Civil Rights Movement, Zapatista autonomous schooling, and the Free Speech movement at UC Berkeley in the 1960s, during which the term 'free university' was first coined (MezaWilson, 2012). Resistance to conventional institutions and modes of education is a constant thread across these landscapes, and remains so for free universities today.

\section{In love and rage: Against the capitalist university}

Activists' concerns about conventional universities were many and varied, but generally sketched out similar lines to those that first gave form to BFU. Many activists remain enamoured of certain ideals with which the university is associated - whether or not it has ever actually realised them - such as democratic participation, the pursuit of knowledge, rigorous research and critical thought. However, they perceive the gap between the feasibility of teaching and learning according to these ideals, and the university's actual day-to-day modes of operation, to be so vast that, as scholar-activist Alex Khasnabish surmised: 'the university is kind of an impossible place' (personal communication, 5 June, 2014).

Many activists were careful to avoid over-romanticising the university, and pointed out that universities have

Courses

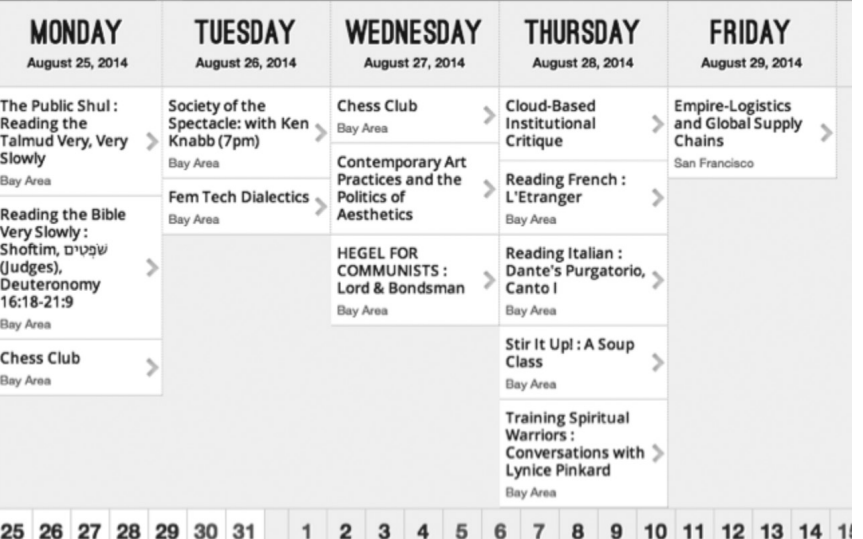

Figure 1: Example of a weekly calendar of free 'classes' offered at the Bay Area Public School, Oakland, USA.

Retrieved from bttp://thepublicschool.org/bay-area

always served to reinforce problematic power relations just as much - if not more so - as to challenge them (see also Readings, 1996; Harney \& Moten, 2013). As such, their more recent history does not represent the desertion of a formerly pure moral pedigree, but merely the capitulation to a new dominant power: capitalism. Although it is impossible to generalise about universities across the board - particularly given the fact that they have always been contested spaces subject to conflicting powers and possibilities - critical theorists such as Silvia Federici have nonetheless argued that over the last few decades, we have witnessed a global 'enclosure of knowledge', in which universities play a key gatekeeper role (2009). Importantly, universities do not only reflect shifts towards capitalism; they drive them by commodifying education, marketising research, and reframing students as consumers (Haiven 2014a, p.135). As scholar-activist Max Haiven told me, we need to recognise the university 'as a means by which capitalist social and economic relations are reproduced, by which capitalist values are stitched into the fabric of society' (personal communication, June 5, 2014).

Granted, internal resistances to these shifts are manifold - ranging from strikes and union actions to subtler, 'everyday' acts like using radical pedagogies in the classroom - and effective on many fronts. However, while power struggles 'on the inside' of conventional universities are critically important, many activists have also highlighted the potentials in engaging less traditional forms of resistance 'on the outside'. Marc Bousquet argues that struggles within the university must adopt a political inversion that drives them beyond, given that: 
the traditional hope for the University as refuge is to see it as a universal point from which to leverage anything else you want to do... Yet ... we need the fulcrum point to be someplace outside in order to leverage what's f***ed up within the University (in Bousquet, Harney \& Moten 2009, p.167).

The idea of an external fulcrum point corresponds to the praxis of prefiguration - a political orientation which, rather than aiming to overthrow or reclaim dominant structures, focuses energy on building alternatives in their interstices, or 'building the new world in the shell of the old' (Khasnabish \& Haiven 2012). This is the political terrain of free universities - projects that radically re-imagine learning outside the university walls and, more ambitiously, work to foster cracks within the stronghold of capitalism more broadly. However, this praxis raises complex questions of its own. In acting outside of the university walls, are free universities moving to abandon or to preserve the university? Where do activists draw the line between the inside and the outside of the university, and how do those with a foot in both camps, like myself, navigate those tensions?

\section{Activism on the Möbius Strip: Beyond the inside/outside divide}

Many of the activists with whom I spoke had become involved in free universities because they saw scant potential in conventional universities for the sorts of teaching and learning they value. Ryan Mitchell, speaking about Toronto's Anarchist Free University (AFU), told me: 'it was [founded] in reaction to the neoliberal university, which is so bloody and instrumental. It's run like a business, where education, or somebody actually learning something, is really quite incidental or secondary to it... We like these ideas, we like teaching, and the university is maybe not the best place for it' (personal communication, 12 June, 2014).

How, then, to think about the conventional university? At times during my research, it seemed that activists' prognoses were terminal. Consider, for example, the Edu-Factory Collective, a global network of scholaractivists that operated, until their recent disbandment, under the slogan: 'What was once the factory is now the university. In the introduction to their inaugural journal, they proclaimed:'The state university is in ruins, the mass university is in ruins, and the university as a privileged place of national culture ... is in ruins. We're not suffering from nostalgia. Quite the contrary, we vindicate the university's destruction' (The Edu-Factory Collective, 2009 , p. 1). Similarly, Max Haiven, formerly a member of the Edu-Factory collective, admitted to me: 'I don't hold out any hope whatsoever that the university is going to be 'cured' within the present socioeconomic system... The task now when it comes to education is to abolish the university as we know it' (personal communication, 5 June, 2014).

Although these statements appear hard-line in calling for us to abandon ship, more often than not, they were followed by far more nuanced political positioning. Like myself, the majority of activists I interviewed were drawn to free university projects because they continue to value certain ideals still represented by university education. Max Haiven, for instance, followed on by cautioning:

If we're going to abandon the university, we do need to think really critically both in the present and in the future about how to recreate [it]. There needs to be a space in any society for rigorous research, to take time with problems and really think through how the world works. And I don't think the university is necessarily the best place for that to happen ..., but it's worth preserving that ideal at least, in some way (personal communication, 5 June, 2014).

In fact, many activists argued that it was not only counter-productive but fundamentally false to think about universities in terms of an inside/outside binary. Far from the 'ivory tower' analogy, universities are so thoroughly permeated by interests and investments from the 'external' world, and vice versa, that we cannot realistically draw a line separating them from the rest of society. To offer an illustration by way of an anecdote, I recently attended UNIKE, a 2015 gathering in Auckland of scholar-activists from around the world, who shared a critical perspective on universities' shifts under neoliberal capitalism. In the closing exercise, a facilitator asked us to form small groups and write on a piece of paper some keywords to characterise today's universities. Instead of writing anything, our group twisted our piece of paper into a Möbius strip to symbolise our collective conclusion - that it is ultimately impossible to conceptualise of 'the university' as a monolithic institution distinct from the world outside it. 
Nevertheless, activists have complex relationships to the notion of an inside/outside division. Many saw that whilst the dividing line is indeed a fiction, it remains a useful conceptual tool by which to sketch out strategic lines of struggle. Fred Moten, for example, articulated his position thus:

I'm completely committed to a certain notion of the outside. But I guess it would be an outside which is not only not opposed to, but actually quite often manifests itself within, the inside... I'm wary of the opposition but at the same time, I'm now much more committed to the value of both terms (Bousquet, Harney \& Moten 2009, p. 168).

Building on these lines of reasoning, Alex Khasnabish argued that it would be foolish to simply abandon the conventional university, given that:

The space itself is just this accumulation of knowledge and resources and people and stuff... Why not take it back and do other things with it? ... [You can] happily subvert the kind of increasing neoliberalisation of [the university] in small ways, usually, but nevertheless important ways... I think setting up too strict a binary between the inside and outside - well, it's empirically wrong, ... but also it ... denigrates spaces that are inside that could be reclaimed and have all kinds of interesting things done with them (personal communication, 5 June, 2014).

Most of my interviewees told a similar story to my own, of having 'a foot in both camps', or what Dyke and Meyerhoff have described as an 'ambivalent educational self - ambivalent between taking critical, resistant perspectives on the education system and seeing one's life and work as bound up with the status quo' (2013, p. 268). Far from being hypocritical or politically questionable, however, this position was more often described as strategic, from which activists can leverage change in important ways. As Max Haiven told me:

I've always considered it to be one of my responsibilities to take the unjustly accumulated resources of the university and redistribute them into other spheres, and also to bring other voices and forms of knowledge - which are traditionally devalued - from outside the university into the university space, to problematise the types of knowledge valorised therein (personal communication, 5 June, 2014).

The more I spoke with free university activists, the less it made sense to think in inside/outside terms, whether in the context of material or immaterial realms of struggle. As to the former, conventional universities have an incontrovertibly real, material presence that should not be overlooked, in that they amass resources and capital, and exert substantive effects on people's lived realities.
On the one hand, working to change the university on the inside - or perhaps more accurately, to erode the 'enclosures' that the university continues to uphold - remains a critically important axis of struggle. Free university activists chip away at universities' enclosures by repurposing campus spaces to foster ideals otherwise seen as problematically absent, such as critical thinking around social justice struggles, or examining the morally questionable commercial ties held by universities themselves (see Brophy \& Tucker-Abramson, 2012; Lyons, 2014). Meanwhile, they redistribute resources beyond universities' paywalls by freely sharing knowledge and research with the broader community.

On the other hand, we can think of universities as bundles of largely immaterial practices, values and ideals that we can pull apart and sort through - some of which we discard, others we keep, others still we re-mould anew. In this sense, free universities' grounds of struggle are not only materially combative but symbolically so, in that they seek to point out how the conventional university as an institution is failing us, and to make spaces in which its spectral ideals might yet be preserved. These spaces are not intended as replacements, or sovereign utopian islands to be defended, but as hatcheries or harbours in which we can collectively re-imagine ourselves in relation to learning. Such processes of re-imagination are never confined to the spaces in which they are catalysed such as BFU's 'car-park campus' - but remain embedded in broader feedback loops that can surge back into mainstream structures - like conventional universities to effect change in various, and often more robust, ways (Haiven 2014a). This can range from gaining knowledge about how the conventional university functions within capitalism, to experimenting with alternative pedagogies. Enda Brophy, who had been a member of the Edu-Factory Collective and active with Toronto's AFU, explained:

My approach is that it should be a both/and. We should fight for change within the university, but we should also set up projects in which we try and imagine the kind of university that we would like to have outside the university... The distinction between reformism and revolution is outdated. We articulated our position as radical reform(personal communication, 7 March, 2014).

To this end, many argue that the autonomous, 'external' nature of free universities allows us to be more radically creative and daring in how we re-imagine what a university, or what learning, could be (Kanngieser 2007; DeLeon, 2008; Noterman \& Pusey 2012).

The dissolution of inside/outside dichotomies leads us to an important point, in that activists recognise 
that universities' crises are not contained within their campuses, but are symptomatic of far broader shifts. As Alex Khasnabish elaborated:

The university is one institution in the centre of this crisis maelstrom that we find ourselves in. [We need] to understand that the crisis is internal to the system that we live within - this capitalist, patriarchal, racist, colonialist system - that needs to be transformed, and so the university along with it (personal communication, 5 June, 2014).

Ultimately, the real struggle for universities lies beyond the university itself, such that by imagining universities differently, we invariably find ourselves re-imagining a different society altogether, again evoking the image of the Möbius strip (Haiven, 2014b). With a nod to the 'In Love and Rage' section of this article, activists acknowledge that their struggles must take aim at the heart of the capitalist hydra, of which the 'neoliberal university' is but one head. Few have articulated this intersection as poetically as in 'Communiqué from an Absent Future', a collectively-written statement from the student-led occupation of California state university campuses in 2009: 'We demand not a free university but a free society... All of our futures are linked, and so our movement will have to join with these others, breaching the walls of the university compounds and spilling into the streets' (Anonymous, 2009). While it is impossible to do them justice within the scope of this article, free university activists attempt to fray the broader fabric of capitalism on many fronts and in diverse ways, which form the bases for explorations elsewhere (see Kanngieser, 2007; Shantz, 2010; Thompsett, 2016).

\section{Conclusion}

I have learned a great many things through my involvement with the Brisbane Free University. I have learned about local Aboriginal politics, competing discourses around refugee rights, and vocal technique. I have also learned how to fit the greatest number of stackable chairs into the back of my station wagon, and how to organise a project in a way that remains open to the shifting desires of diverse participants. However, one of the most significant things I have learned is how I would like to learn.

In contrast to the commodified modes of education increasingly (though not always) marketed by conventional universities, I have learned that people take responsibility for their own learning if given the opportunity, and that critical enquiry can be linked, in very real ways, to ongoing social justice struggles. More importantly, I have been able to experiment with alternative pedagogies directly, as part of the shifting collective of curious-minded community members that compose BFU - overall, a sort of learning by doing by learning. This constitutes an example of something that has, for me, breached the inside/outside bounds between conventional and free universities by surging from the car-park campus of BFU back into the 'formal' classrooms in which I still teach.

This leads me to my second reflection - aside from re-learning how to learn, I have changed how I think about change. As John Holloway writes in Crack Capitalism, 'The only way to think of changing the world radically is as a multiplicity of interstitial movements running from the particular' $(2010$, p. 11) for which he proposes 'the method of the crack, ... a dialectic of misfitting' (2010, p. 9). Increasingly, I envision possibilities for change within conventional universities along similar (interstitial) lines. Indeed, in a context without borders or frontlines, as we are used to thinking about them, perhaps the 'crack' becomes the most fitting metaphor for change. Where once I might have strung my radical horizon along the lines of a full structural overhaul, I have learned that we must not underestimate the potential to act in the hereand-now, in a variety of ways, and often on a smaller scale.

Free universities will probably never pose a serious challenge to the ways in which conventional universities operate. In the majority of cases, it is not their aim to do so. They can, however, function as microcosms for developing alternative modes of learning and relating to one another, in ways that spill beyond their immediate parameters. Since organising with BFU, I have developed a habit of seeing 'the crack in everything', to evoke Leonard Cohen, and of recognising that the potential to subvert, reclaim and reform the status quo is more present than we might otherwise assume. Often this shift of perspective takes, like anything else, an everyday, unglamorous routine of practice, similar to what James Scott has called an 'anarchist calisthenics' (Scott, 2012). Furthermore, I have come to attribute greater meaning to seemingly small acts - for example, rethinking classroom pedagogy, or linking university-based learning with real social struggles, whether they involve university students and/or workers, or take place in the world beyond. If these appear to fall short of revolutionary imaginaries, perhaps this is because we are so attuned to looking for the revolutionary forest that we tend to miss the revolutionary trees.

To be clear, I am in no way arguing that we should forsake large-scale struggle to content ourselves with more piecemeal, immediate forms of change. Nor do 
I believe that we should attempt to direct our energy entirely within the university's structures, or divert it altogether outside of them, especially given the illusory nature of the inside/outside binary to begin with. Rather, my point is that if we are serious about change, we will need it all - the revolutionary and the reformist, the radical and the reactionary, the internal, external, and everything in between. In this sense, free universities are not the answer to universities' crises - no single thing can be - but they might be one important, if oddly-shaped, piece of the puzzle.

\section{Acknowledgements}

I am grateful to Federico De Musso and Maria Theresia Starzmann, who offered generous, thoughtful feedback on early drafts of this article. None of this - neither the article nor the project it describes - would have moved beyond a pipe dream without the committed labour and shared vision of my friends and BFU collaborators, Briohny Walker and Anna Carlson, to whom I offer boundless thanks, along with the many motley people whose names I may never know, but whose presence at and input into $\mathrm{BFU}$ are what gives the project life.

\section{Fern Thompsett is currently a doctoral student in anthropology at McGill University, Canada. Prior to} commencing her PhD, she studied at the University of Queensland, and was involved in a number of community projects in her hometown of Brisbane, including a community radio show on $4 \mathrm{ZZZ} \mathrm{fm}$ as well as the Brisbane Free University.

\section{Contact:f.thompsett@uq.edu.au}

\section{References}

Anonymous. (2009). Communiqué from an Absent Future: On the terminus of student life. We Want Everything. Retrieved from https://wewanteverything. wordpress.com/2009/09/24/communique-from-an-absent-future/

Bousquet, M., Harney, S. \& Moten, F. (2009). On Study: A Polygraph Roundtable Discussion with Marc Bousquet, Stefano Harney, and Fred Moten. Polygraph 21, pp. 159-175.

Brophy, E. \& Tucker-Abramson, M. (2012). Struggling Universities: Simon Fraser University and the Crisis of Canadian Public Education. TOPIA: Canadian Journal of Cultural Studies 28, 21-39.

Cahill, R., Connell, R., Freeman, B. Irving, T. \& Scribner, B. (1967). The Lost Ideal. Honi soit, 3 October. Retrieved from http://www.reasoninrevolt.net.au/ objects/pdf/a000522.pdf
DeLeon, A. (2008). Oh No, Not the "A" word! Proposing an "Anarchism" for Education. Educational Studies 44(2), 122-141.

Dyke, E. \& Meyerhoff, E. (2013). An Experiment in 'Radical' Pedagogy and Study: On the Subtle Infiltrations of 'Normal' education. Journal of Curriculum Theorizing 29(2), pp. 267-280.

Federici, S. (2009). Education and the Enclosure of Knowledge in the Global University. ACME: An International E-Journal for Critical Geographies 8(3), 454-461.

Haiven, M. (2014a). Crises of Imagination, Crises of Power: Capitalism, creativity and the commons. London: Zed Books.

Haiven, M. (2014b). The Ivory Cage and the Ghosts of the Academe: Labor and Struggle in the Edu-Factory. Truth Out. Retrieved from http://www.truth-out.org/ news/item/23391-the-ivory-cage-and-the-ghosts-of-academe-labor-and-strugglein-the-edu-factory

Harney, S. \& Moten, F. (2013) The Undercommons: Fugitive Planning \& Black Study. New York: Autonomedia.

Holloway, J. (2010). Crack Capitalism. London: Pluto Press.

Irving, T. (2013). 'The triumph of green hearts over sere': Reflections on student radicalism at Sydney University in the 1910s and 1960s. Presented at the History of University Life Seminar, University of Sydney, 23 October. Retrieved from http://radicalsydney.blogspot.ca/p/the-triumph-of-green-heartsover-sere_27.html

Kanngieser, A. (2007). It's our academy: Transforming education through self-organised autonomous universities. Originally presented as part of the RMIT Student Union event, Institutions, Capitalism and Dissent: A Rogue Education Conference, 2007. Retrieved from: https://www.academia.edu/343772/ It_s_Our_Academy_Transforming_Education_through_Self-organized_ Autonomous_Universities

Khasnabish, A. \& Haiven, M. (2012). Convoking the Radical Imagination: Social Movement Research, Dialogic Methodologies, and Scholarly Vocations. Cultural Studies $\leftrightarrow$ Critical Methodologies 12(5), 408-421.

Lyons, K. (2014). 'Partner or Perish'? The Convergence of public and private interests pose new questions for controversial university research. Chain Reaction 121,32-34.

Meza-Wilson, A. (2012). Educational Projects for Decolonization: AntiAuthoritarian Allyship and Resistance Education in the Americas. Master's Thesis, University of British Columbia.

Noterman, E. \& Pusey, A. (2012). Inside, Outside and on the Edge of the Academy: Experiments in Radical Pedagogies, in R. H. Haworth (ed.). Anarchist Pedagogies: Collective Actions, Theories and Critical Reflections on Education. Oakland, CA: PM Press.

Readings, B. (1996). The University in Ruins. Cambridge: Harvard University Press.

Shantz, J. (2010). Constructive Anarchy: Building infrastructures of resistance. Burlington, VT: Ashgate Publishing Co.

Scott, J. C. (2012). Two Cheers for Anarchism: Six easy pieces on autonomy, dignity and meaningful work and play. Princeton: Princeton University Press.

Thompsett, F. (2016). 'The University is kind of an impossible place': Universities towards and against capitalism, in L. Angosto-Ferràndez \& G. Presterudstuen (eds). Anthropologies of Value. London: Pluto Press.

The Edu-Factory Collective. (2009). Introduction: All Power to Self Education!, in The Edu-Factory Collective (ed.). Toward a Global Autonomous University. New York: Autonomedia. 


\section{What are good universities?}

\section{Raewyn Connell}

\section{University of Sydney}

This paper considers how we can arrive at a concept of the good university. It begins with ideas expressed by Australian Vice-Chancellors and in the 'league tables' for universities, which essentially reproduce existing privilege. It then considers definitions of the good university via wish lists, classic texts, horror lists, structural analysis, and shining examples from history. None of these approaches is enough by itself; but in combination they can be fruitful. The best place to start in defining a good university is by considering the work universities do. This leads to issues about the conditions of the workforce as a whole, the global economy of knowledge, and the innovations bubbling up around the edges of this economy.

Keywords: university, teaching, managerialism, workforce, higher education, democracy

\section{Dr Pangloss and the league tables}

A few years ago the Australian Vice-Chancellors' Committee (AVCC) re-badged itself as 'Universities Australia' (UA), and since then the assembled vice-chancellors have presented themselves as 'The voice of Australia's universities'. That's what their website says, and this is undoubtedly a rich mine of corporate wisdom. 'Australia's universities', the website tells us, 'offer a unique educational experience that fosters self-belief, rewards independent thought and fuels inquiring minds'. Universities Australia (2016) has a 'vision for a smarter Australia', which will be achieved if more students, grants and fees come into universities. But of course growth 'will not be at the expense of quality. Universities have, and will continue to maintain, robust internal quality assurance mechanisms and processes.'

This robust declaration is of course written by the UA's advertising people, but it undoubtedly reflects the vicechancellors' corporate view. They have excellent reasons to be pleased with progress. Their annual salaries averaged $\$ 835000$ each (including the bonuses) in 2014. If the UA's lobbying for unrestricted fee increases eventually bears fruit, they will get even more. For each current vice-chancellor, we could get a dozen tutors, research associates, and administrative officers.

A few years ago one of their number, Glyn Davis of Melbourne, delivered the ABC's Boyer Lectures, subsequently published as a book called The Republic of Learning. This is the most widely circulated Australian text ever written about higher education, so it's worth taking note. It's an excellent guide to the ruling mentality, and you can still find it in good second-hand bookshops.

In genial style, The Republic of Learning takes the listener/reader through the fascinating world of universities. Davis speaks of old and new achievements in teaching, research, and academic life, with many powerful insights: 'Much needs to be done that is new - but much needs to be preserved' [p. 29]. In universities, 'Authority is held collectively by the academic body, represented through an academic board or senate' [p. 97]. The system has dilemmas, but faces the future with confidence: Each public university, determined to make its way in the world, will invent the future that makes sense for it and its communities' [p. 123]. And so on.

Davis starts and finishes by invoking the great 16th-century scholar Erasmus of Rotterdam. It's a brave 
choice. That sardonic and embattled writer was a noted enemy of complacency, clichés and intellectual sloppiness.

Davis succeeds, through his six lectures, in conveying a truly Panglossian picture: all is for the best, in the best of all possible worlds. Trust us! It's a verbal version of the imagery now found on all Australian university websites: sunny skies and flowering jacarandas, happy students on manicured lawns, contented staff, brilliant breakthroughs in laboratories, and glimpses of wise Chancellors conferring well-earned awards.

Easy to laugh at, when you know the reality at the coal face. But the logic of misrepresentation has now been built into a technology of policymaking which has very real effects. A striking feature of the neoliberal era is the proliferation of 'metrics' for outcomes. This has grown into a system of ranking scales, informally known as league tables, that imply an unending competition of excellence - between journals, papers, individual academics, departments, and whole universities.

The system now has, in fact, an institutionalised definition of the good university. It takes the form of widely publicised international rankings, before which even vice-chancellors tremble. Every year, as the Times or the Shanghai annual world ranking comes out, there is a flurry of media releases from Australian universities, boasting of their rank or - should the overall score unhappily have slipped - finding a sub-ranking they can boast about.There is now a small industry supplying many different kinds of rankings (new universities, technical universities, regional rankings, discipline rankings, etc.) so the market can get what it wants.

And each year, to no-one's surprise, the top universities on the main global scoreboards turn out to be Harvard, MIT, Chicago, Stanford, Caltech, Cambridge... the wellknown, wealthy, highly selective, private or more-or-lessprivate, elite institutions of the global North. Basically, the metrics of excellence are measuring how far all the other universities in the world resemble the most economically, socially and politically privileged. The paradigm of the good university, the best of the best of all possible worlds, is there at the top of the table - in Harvard, MIT, Chicago...

Actually these are horrible institutions. I've spent a year each at two of them (one as a post-doc, the other as a visiting professor) and have seen how destructive their privilege and arrogance are for the engagement and trust that create real quality in higher education. Yes, the Ivy League and Friends have wonderful libraries, astonishing computers, elegant buildings, great art collections and low student/staff ratios. They have these, because they have wealth skimmed from the corporate economy that has relentlessly degraded the global environment for the rest of humanity. And their wonderful Nobel-Prizewinning research? Well, much of it depended on military or corporate funding, and these universities played a major role in the creation of atomic weapons and almost equally destructive 'conventional' armaments, not to mention the neoliberal economy itself.

The league-table definitions of excellence, nevertheless, are deeply embedded in corporate ideology and practice, and have been taken up by governments. That monument of neoliberal policy orthodoxy, the 2012 white paper Australia in the Asian Century, formulated this as a National Objective: 'By 2025, 10 of Australia's universities will be in the world's top 100'. Since no neoliberal government, Labor or Coalition, is going to put tax money into even one Australian university on a scale that would make it look much like Harvard, the real effect of the league-table rhetoric is to provide a permanent justification for the vice-chancellors to increase fees and trawl for corporate money.

\section{Defining the good: five approaches}

For those who don't swallow the official wisdom, it becomes important to find other ways of defining a good university. This is not easy to do, if we want the result to have a grip on the practical situation in universities; but let us try.There are five ways of approaching the job.

The first is to compile a wish list. That was what I did when the 2013 strike at University of Sydney showed the shocking gulf between what management was trying to do, and what universities actually needed. This is what my list looked like at the time (Connell, 2014). Good universities would be:

1. Educationally confident

2. Socially inclusive

3. Good places to work

4. Democratic as organisations

5. Epistemologically multiple

6. Modest in demeanour

7. Intellectually ambitious.

Such an exercise can be done collectively, and perhaps should be. A collective list was attempted by the 2015 conference from which this $A U R$ special issue has come, producing a Declaration that has a more generous 24 points (and included in full in this special issue). They overlap my seven, introducing new themes but also dropping a couple.

The problem with wish lists is obvious: they are arbitrary in coverage, and can be incoherent. They are not 
constrained by organisational limits, budgets, or the need to persuade constituencies. Yet the exercise is genuinely useful, especially at a time when neoliberal universities are steadily shutting down their internal forums for debate. Trying to formulate a wish list is jarring: it pushes you out of the everyday, and obliges you to think in a long time-frame. Everyone working in universities should try it - and circulate the results.

Second, there's the classic academic method: compile a reading list and study the authorities. Glyn Davis and his research team did this, finding John Henry Newman (The Idea of a University, 1852) and Clark Kerr (The Uses of the University, 1963). They did not, apparently, find the economist Thorstein Veblen's splendid and highly relevant 1918 book The Higher Learning in America: A Memorandum on the Conduct of Universities by Business Men.

From the classics we can certainly get stimulating ideas; but we always have to consider them in context. Newman, for instance, wrote his famous text when he was brought from England to Ireland to help the church set up a new Catholic university. The difficulty was that the bishops insisted on

having control, but in that case the Protestant-dominated government would not pay, so the project died. Newman's eloquent 'University Teaching Considered in Nine Discourses' was thus a design for an imaginary university. Its central concern was to justify having theology in the curriculum.

Newman had a critique of utilitarianism that applies to neoliberalism too: 'it aimed low, but it has fulfilled its aim' (ouch!). But he was utterly opposed to the model of the research university, new at the time, that was emerging from Germany. Newman declared on the first page of his preface that the object of a university

is the diffusion and extension of knowledge rather than the advancement. If its object were scientific and philosophical discovery, I do not see why a University should have students. (ix)

(Ouch again!) Research should be left to scientific academies. The proper role of universities was to be places for liberal education, gardens for 'the cultivation of the intellect'.

Newman didn't understand research, but he did know a lot about teaching. He showed how a profusion of topics or curriculum detail would distract students from deeper understanding, wrestling with principles and developing a sense of Universal Knowledge. No lectures at all would be better than too many. But this admirable idea of undergraduate life was designed for one social group: the gentry. Specifically, the gentlemen. It wouldn't meet our diversity KPI.

Nor, of course, do existing elite universities. There are some indications, indeed, that universities at the top of the international league tables have become less diverse in the last decade or so, consistent with the trend of growing social inequalities under neoliberal regimes.

This points to a third approach to defining the good university, rather more grounded than the wish lists. This is the procedure we might call the horror list: examining the ghastliest features of the University of Melbourne, and designing a good university by antithesis. (To be strictly fair, I would examine the University of Sydney too. I'm a graduate of both.)

Antitheses can readily be drawn up from the critical literature about contemporary Australian universities, to which this special issue is a contribution. On my reading, the main themes that emerge from this literature are:

1. The relentless commercialisation that has gone on since the Dawkins policy changes of the late 1980s. The re-introduction of fees was the trigger, but the effects have ramified. Lucrative teaching programs have been expanded and the least vocational areas (such as philosophy) contracted.There is growing dependence on a flow of full-fee-paying students, who demand returns on their personal or family investment. The public face of universities has been turning into a giant corporate PR exercise. The antithesis approach would define a good university as one that taught without fees; that maintained non-commercial courses; that did informative outreach with honesty.

2. The relentless centralisation of power in the hands of a managerial elite, increasingly modelled on for-profit corporate management. This trend has overwhelmed the moves towards democratisation that were made from the 1960 s to the 1980s. Most often this is pictured as a loss of autonomy by academics, but the trend has also wiped out student power, and industrial democracy involving non-academic staff. The antithesis approach would define 
a good university as a democratic workplace, devolving power rather than centralising it, and finding ways to have much wider participation in all levels of organisational decision-making.

3. In consequence of trends 1 and 2 , the flattening of university culture. Formulaic teaching is encouraged by intrusive online templates; forums for serious debate and dissent shrink, or are closed; staff and students alike are overworked and preoccupied with ticking boxes, doing tests and filling in audit statements. With this side of the critique, antithesis is less clearly defined. Broadly, however, it suggests that a good university will be a place rich in coffee-shops, with the coffee-shops rich in passionate argument, intense thought and exotic projects. It certainly implies that staff and students must have time for the passionate arguments, not to mention the coffee.

The wish-list, classics, and horror-list approaches all yield material for defining a good university. But this material lacks either coherence, or direct relevance to the situation we find ourselves in. Can we get an approach that hangs together better and speaks to what is practically possible? The two remaining approaches offer this possibility.

The fourth approach is illustrated by a remarkable text from the early days of the Dawkins policies. In 1994 Ian Lowe published a short book in the UNSW Press's 'Frontlines' series, called Our Universities are Turning Us into the 'Ignorant Country'. It was an attempt, like Glyn Davis's later effort but with a much sharper edge, to paint a broad picture of a university system in change. Lowe laughed at the attempt to impose an entrepreneurial culture, but also at the rigidities of academic culture. He diagnosed early the inequalities produced by the Hawke Government's attempt to get an expanded university system on the cheap. Positively, Lowe developed an agenda of modernisation without commercialisation. His model emphasised social knowledge and responsibility; engaged, face-to-face teaching; and a diversity of institutions of modest size (rejecting orthodox ideas about economies of scale).

A more recent attempt at synthesis is the Charter for Australia's Public Universities produced by the National Alliance for Public Universities (2014). This is based on an economic analysis emphasising that higher education and knowledge production are public goods, in constant tension with government policies of commercialisation and reinforcement of inequality. The document pictures a good university as an institution working fully in the public interest, internally pluralistic, and marked by continuous debate and negotiation among its communities. It sounds strenuous!
These two texts attempt to think about the university sector as a whole. They aim to be realistic about its everyday working, and to generate alternatives from possibilities that exist in the current situation. It may sound a little pretentious, but I'd call that a structural approach to developing ideas of the good university.

The fifth approach seems the simplest of all: find working examples of better universities. But there is a catch. The neoliberal policy regime has forced all mainstream universities to converge on the neoliberal model. The diversity that existed a generation or two ago, for instance the innovative curricula and degree structures of the greenfield universities of the 1960s and 70s (Pellew, 2014 on the UK case), has been sharply reined in.

Nevertheless, if we open the lens wider, there is a great deal of relevant thinking and experience. Progressive education in schools, for instance, has been undertaken in very difficult conditions while innovating in teaching method and curriculum. The Freedom Schools of the civil rights movement in the United States are a striking example (Perlstein, 1990).

Sometimes these initiatives led to innovation in higher education, as with Rabindranath Tagore's Patha Bhavana school and Visva-Bharati college (later university). This college rejected both top-down pedagogy and colonial control, and tried to create flexible and what we would now call multi-cultural programs.

Perhaps the most amazing story of bold thinking and action is the Flying University in Warsaw, set up under the Russian empire in the late 19th century. It was illegal, co-educational, and very seriously intellectual; called 'Flying' because it had to change location to avoid detection by the authorities. And it lasted for years, finally becoming legal. The tradition was revived under the repressive Communist regime in the 1970s (BuczynskaGarewicz, 1985).

In capitalist countries the university system is strongly shaped by social and economic exclusions, and there have been attempts to build working-class alternatives: notably, labour colleges in many countries. One offshoot is the current Global Labour University, a network backed by ILO (http://www.global-labour-university.org/341.html). Another strategy is followed by the interesting Freedom University in Atlanta, USA, which functions as a point of access to existing higher education for students, mostly from ethnic minorities, who are prevented from entering Georgia's public universities (Muñoz et al., 2014).

An important new development is online activism around universities. In response to the big publishers' use of paywalls to commodify the knowledge produced by 
university research, there have been many attempts to provide open access. The PLOS online journals are the most celebrated, though their publication model requires the authors to pay. An extraordinary website has been set up by the Russian neuroscientist Alexandra Elbakyan, apparently giving free access to millions of research papers (http://sci-hub.io/). Elsevier is taking her to court, and her response is that these publishers are breaking Article 27 of the UN Declaration on Human Rights, saying: 'everyone has the right freely to participate in the cultural life of the community, to enjoy the arts and to share in scientific advancement and its benefits'.

The history of universities, and the history of education more generally, are a source of ideas, practical examples and inspiration. But because circumstances change, this approach needs to be combined with the others to develop agendas for our own situation. A good place to start that synthesis is the work universities do.

\section{The work and the workforce}

The main practical business of universities is intellectual labour, of several kinds: teaching and learning at advanced levels, doing research, and circulating knowledge that is the product of research. I emphasise that these are forms of labour. Research is not done by magical inspiration, nor is teaching done by bolts of lightning. The university is a workplace, the people in it are a workforce, and the university gets its results by patient, time-consuming labour.

Though our cultural images of intellectual work still invoke isolated geniuses - Dr Faustus and his pentagram, Dr Freud and his cigar, Professor Einstein and his hair - the production of knowledge has become more collectivised over time. This involves more than the fact that as researchers, teachers and learners we stand on the shoulders of giants - a humbling truth we all have to recognise, as Newton did. It's also the fact that more and more of us are standing on their shoulders at the same time.

Contemporary research, with very few exceptions, now involves the coordinated effort of a variety of specialist workers - including those who supply the services (clerical, financial, technical, maintenance, transport) without which the people who have their names on the scientific papers could not operate at all. The same goes for teaching. Much of this coordination exists before any particular research team is assembled, grant received or course authorised. There has to be a library, an ICT service, a teaching space, a flow of students, a journal for the publication to go into - and other universities, where there are other researchers, other students, other libraries.
There is, in fact, a profound institutionalisation of the intellectual labour process, a collectivisation that has become the necessary condition for every performance that the metrics purport to measure.

The metrics, then, focus on what is most superficial about intellectual labour, and I think university staff sense that. Hence their usual scepticism about the ranking game that so excites university managers, publicists and Ministers of Education. But this divergence of opinion also points to an important dimension of what makes good universities. It's the well-being of the labour force as a whole, and the design of the institutions to maximise cooperation across the institutions and workers involved.

The institutionalisation of knowledge production and circulation is worldwide. There is a global economy of knowledge, with a definite structure. As the philosopher Paulin Hountondji (1997) points out, the global periphery, the majority world, mainly serves as a source of data. In fields ranging from climate change and epidemiology to gender studies and linguistics, a flood of information streams to the main world centres. In the knowledge institutions of the global North, especially the elite ones, data are accumulated, processed and theorised. Concepts, methodologies, models and causal analyses are mainly produced in the global metropole.

As a result of this structure, universities in the periphery are in a situation that has been called 'academic dependency' (Alatas, 2003). Universities Australia boasts that Australia produces nearly 3\% of the world's academic publications, punching above our weight as usual. It would have been more informative to say that we are obliged to import $97 \%$. Overwhelmingly, Australian universities import from Western Europe and the USA the theories, research paradigms and disciplinary frameworks that organise their curricula and research.

What the output calculations miss is the fact that the mainstream economy, as currently organised, excludes other knowledge formations. On a world scale, other knowledge formations are very substantial indeed. They include indigenous knowledges, very much alive (Odora Hoppers, 2002); alternative universalisms, such as the intellectual traditions of Islam; and the knowledge formations I have called 'Southern theory', generated in the colonial encounter and from the experience of postcolonial societies (Connell, 2007).

The Islamic tradition of great learning centres is at least as old as the European university tradition, and across the Muslim world are many examples of interweaving the two. Local indigenous knowledges may seem harder to combine with university teaching, but there is no 
lack of experimentation. The Kaupapa Māori project in Aotearoa/New Zealand is known internationally and has given rise to a classic text,Decolonizing Methodologies, by Linda Tuhiwai Smith (2012). The revival of indigenous culture in the Andean countries of South America is now represented in higher education by several institutions. One is the Indigenous University of Bolivia founded under the Morales Government, with three campuses, which awarded their first degrees in 2014 (http:// revista.drclas.harvard.edu/book/bolivias-indigenousuniversities).

Universities in the periphery, far more than those at the top of the international league tables, have the opportunity for a great cultural enrichment of organised knowledge and higher education. A good university will surely take such an opportunity. Australian moves so far have been timid.

Universities are expensive institutions and a university system on the modern scale involves a major commitment of social resources. The way funding is organised matters. The model of wholly private 'for-profit universities', that has aroused some excitement in neoliberal circles, is well established in the United States, Latin America and some other regions. Basically these institutions sell vocational training, with guarantees of subsequent employment; not surprisingly, they have recruited employers to help plan the curriculum (Tierney \& Hentschke, 2007). Australian universities have moved in this direction to scoop up fee-paying students. We can see the chaos and corruption implicit in this logic from the disastrous privatisation of TAFE in Australia over the last twenty years.

Any alternative to the instability and opportunism of the current funding system rests on achieving some social compact about the role, value, and resource level for the university sector.This would explicitly recognise that we cannot get a good university in isolation; we get a good university sector, or nothing.

A compact will not be easy to get, as the donnybrook around the Gonski plan for Australian schools funding shows: the privileged defend their privileges. But a compact is still something to aim for.It can shift discussion forward to questions about professional knowledge requirements, knowledge formations, and just how much glitz a university really needs. Above all, it will require us to think long-term about the knowledge workforce.

Recent university management has followed two remarkably destructive workforce strategies: outsourcing of non-academic work, and casualisation of academic work (not just in Australia: see Schwartz, 2014). The complex coordination of a differentiated labour process is best achieved when the workers know each other and can develop working relationships over considerable periods of time. Outsourcing of services, and rapid turnover, wreck this cooperation.

Further, as casualisation has become an entrenched organisational strategy, a damaging split has opened between a primary and secondary academic labour force. Tutoring, once rationalised as a limited period with the flavour of apprenticeship, is turning into a mass experience of long-term insecurity and exploitation. It is not too much to say that the long-term sustainability of the academic workforce is now under threat.

However, the generation most affected by precarious employment has been involved in a wave of imaginative alternative-university work, some of it connected with the Occupy movement. The Free University of NYC, for instance, uses public spaces through the city to conduct free educational activities, and draws on the Freedom Schools tradition (http://freeuniversitynyc. org). In Australia, there are Free U projects in Melbourne (http://www.melbournefreeuniversity.org) and Brisbane (https://brisbanefreeuniversity.org); the Brisbane project runs classes in a carpark, produces podcasts, and has a good set of links to similar projects. Many more examples can be found on the Web, such as the impressive Social Science Centre in Lincoln, a not-for-profit co-operative (www.socialsciencecentre.org.uk), or the charming but now defunct University for Strategic Optimism (www. universityforstrategicoptimism.wordpress.com).

A good university, and a good university system, will be concerned with the sustainability of its workforce. This means thinking not one budget ahead, but a generation ahead. Universities need to be places where people feel valued, find scope, aren't pushed about, and want to stay. Career structures need to offer, not spectacular rewards for a minority, but decent conditions and security for the workforce as a whole. Organisational structures need to create space for cooperation, learning and decisionmaking from below. We already know how to do this. It's not rocket science.

\section{In conclusion}

In writing this paper I did not want to define the good university by picturing my utopia. There has never been a golden age in universities and there may never be one. We will probably need a range of new types of university, as the domain of knowledge becomes more complex. We certainly need the habit of thinking for ourselves, and generating ideas from our own situations and problems. 
We should be sceptical of distant palaces, on earth or in heaven.

For all the madness of the neoliberal regime, the current workforce does a tremendous amount of good work in teaching, in administration, in research and in services. That's what keeps the universities going! And there are programs that expand the episteme with indigenous knowledge and multiple cultures; there are departments with some participatory decision-making; there are many experiments with student-directed learning. It is important to document, share and reflect on this experience.

I can't predict how that discussion will go, but I am confident about some principles. It isn't enough to imagine a good university; we need to plan a good university system. Quality doesn't come from privilege or from an elite; quality concerns a whole workforce and the working of a whole institution. Working conditions and workplace relations matter for the intellectual project. We need to think about sustainability in a much longer frame than the policymakers and managers generally do. And we have many starting-points now for doing something more intellectually exciting, more socially valuable, and more globally significant, than Australian universities have yet managed.

\section{Acknowledgments}

I'm grateful to all participants in the 'Where To, Enterprise U?' workshops during the enterprise bargaining campaign at University of Sydney in 2013. Particular thanks to Dr Nour Dados for her engagement and creative intellectual labour.

\section{Raewyn Connell is Professor Emerita, University of Sydney and a Life Member of the National Tertiary Education Union Contact: raewyn.connell@gmail.com}

\section{References}

Alatas, S. F. (2003). Academic dependency and the global division of labour in the social sciences. Current Sociology, 51(6), 599-613.

Buczynska-Garewicz, H. (1985). The Flying University in Poland, 1978-1980. Harvard Educational Review, 55(1), 20-34.

Connell, R. (2007). Southern Theory: The Global Dynamics of Knowledge in Social Science. Sydney: Allen \& Unwin.

Connell, R. (2014). Love, fear and learning in the market university. Australian Universities' Review, 56(2), 56-63.

Davis, G. (2010). The Republic of Learning: Higher Education Transforms Australia. Sydney: HarperCollins.

Hountondji, P. (ed). (1997). Endogenous Knowledge: Research Trails. Dakar: CODESRIA.

Kerr, C. (1963). The Uses of the University. Cambridge MA, Harvard University Press.

Lowe, I. (1994). Our Universities are Turning Us Into the 'Ignorant Country'. Sydney: University of New South Wales Press.

Muñoz, S, Espino, M. M. \& Antrop-González, R. (2014). Creating counter-spaces of resistance and sanctuaries of learning and teaching: An analysis of Freedom University. Teachers College Record, 116(7), 1-32.

National Alliance for Public Universities. (2014). A Charter for Australia's Public Universities. Retrieved from: https://napuaustralia.files.wordpress. com/2014/10/napu-a_charter_for_australias_public_universities.pdf. Newman, J. H. (1873) [1852]. The Idea of a University: Defined and Illustrated. London: Basil Montagu Pickering.

Odora Hoppers, C. A., ed. (2002). Indigenous Knowledge and the Integration of Knowledge Systems: Towards a Philosophy of Articulation. Claremont, New Africa Books.

Pellew, J. (2014). 'Utopian' universities: a 50-year retrospective. Past and Future (Institute of Historical Research, University of London), 15, 10-11.

Perlstein, D. (1990). Teaching freedom: SNCC and the creation of the Mississippi Freedom Schools. History of Education Quarterly, 30(3), 297-324.

Schwartz, J. M. (2014). Resisting the exploitation of contingent faculty labor in the neoliberal university: the challenge of building solidarity between tenured and non-tenured faculty. New Political Science, 36(4), 504-522.

Smith, L. T. (2012). Decolonizing Methodologies: Research and Indigenous Peoples (2nd ed.). London: Zed Books.

Tierney, W. G. \& Hentschke, G. C. (2007). New Players, Different Game: Understanding the Rise of For-Profit Colleges and Universities. Baltimore: Johns Hopkins University Press.

Universities Australia [a.k.a. Australian Vice-Chancellors' Committee]. (2016). Website at https://www.universitiesaustralia.edu.au/, accessed 12.03.16.

Veblen, T. (1957) [1918]. The Higher Learning in America: A Memorandum on the Conduct of Universities by Business Men. New York: Sagamore Press. 


\title{
Reflections on Critical Pedagogy
}

\section{Leaders in Critical Pedagogy - Narratives of Understanding and Solidarity, by Brad J. Porfilio \& Derek R. Ford (Eds).}

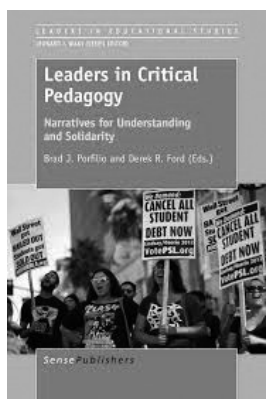

ISBN: 9463001662 (pbk.), Rotterdam: Sense Publishers, xxV+246pp., 2015.

\author{
Reviewed by Thomas Klikauer
}

Porfilio and Ford's collection is a delightful read illuminating the history and thoughts of critical pedagogy. With the International Journal of Critical Pedagogy (libjournal.uncg.edu/ijcp) and numerous academics working in and with critical pedagogy, the now well established discipline is based on an educational philosophy that focuses on emancipatory education and social movements. It combines education (Freire) with philosophy (Dewey) and elements of the Frankfurt School of critical theory. Critical pedagogy was first described by Paulo Freire (1921-1997) and developed further by American/Canadian scholar and cultural critic Henry Giroux as well as many others. It is a praxis oriented educational movement guided by the aim to assist students in developing a critical consciousness of human freedom, the recognition of domination and authoritarian tendencies as well as connecting knowledge to power while developing the ability to take constructive action for positive social change. Among its leading figures are Michael Apple, bell hooks, Joe L. Kincheloe, Peter McLaren, Henry Giroux, and Patti Lather and Shirley Steinberg. Many of these have contributed to the Porfilio/Ford edition.

With a preface by Shirley Steinberg, the volume comprises eighteen chapters and a semi-conclusion entitled 'afterword'. Each chapter presents something of a biography of the respective academic, highlighting the way they entered into the educational philosophy of critical pedagogy while outlining key themes of the discipline. In short, each chapter is a skilful mix of personal genealogy and critical pedagogy. But before getting into this, the editor's introduction states, 'this book itself performs and constitutes, in part, what scholars count as leaders' ( $p$. $\mathrm{xvi}$ ). One is tempted to argue that critical pedagogy and leaders are contradictory.

Most certainly one of critical pedagogy's origins - the
Frankfurt School of critical theory - might view 'leaders' with extreme discomfort. This is not just because the term leader translates into Führer in German but also because the Führer's henchmen - the Gestapo - knocked on Adorno's Frankfurt door and picked him up for some Gestapo-style questioning. A famous saying had it that 'when the doorbell rings at 6am, it is the milkman in Switzerland and the Gestapo in Germany'. In the wake of this very personal and very close encounter with Nazism, Adorno, Horkheimer, and the Frankfurt School migrated to the USA. As for the Frankfurt School, it has a deeply ingrained dislike of leaders and Führer. Rather than 'Leaders in Critical Pedagogy' (the book's title) the book might have been entitled 'Key Scholars in Critical Pedagogy' as critical pedagogy might reject the idea of 'being lead'. With that in mind, perhaps one of the introduction's key sentences is 'critical pedagogy seeks to understand and is concerned with the way that schools [universities, etc.] and the educational process sustain and reproduce systems and relations of oppression' ( $p$. xvi). While critical theory never developed a founding text on education or pedagogy (Murphy \& Fleming, 2010), critical pedagogy came in three waves:

a. Paulo Freire's key text - Pedagogy of the Oppressed (1970) - has set the starting point of the first wave (1970s and 1980s);

b. the second wave is associated with Henry Giroux and Ira Schor (1990s); while

c. the third wave 'returns questions of class and capitalism [and is associated with] Peter McLaren and Curry Malott' (xviii) marking the current stage of critical pedagogy.

The book's main part starts with'the education of critical consciousness becomes more difficult as hegemony becomes more entrenched' (p. 1). Unfortunately, the reason for this is never discussed - throughout the 
book. And this is despite critical pedagogy's link to critical theory and despite Adorno and Horkheimer's Culture Industry: Enlightenment as Mass Deception (1944). In short, linking education to the overwhelming powers of the global corporate mass media behemoth seems to remain elusive for critical pedagogy. There really seems to be a 'Blindspot of Western Marxism' (Smythe, 1977). It might be, at least partly, because of this that many critical educators are forced to fight a daily battle against neo-liberalism's hegemonic ideology when 'a privileged social group generalises its own interest so that they appear to be universal social goals ('what is good for General Motors...'). (p. 4; cf. Klikauer, 2015). It is this privileged group that is rather loosely organised inside a global neo-liberal ideology apparatus consisting of representatives of capital, corporate mass media, conservative/reactionary politicians, education managers, university CEOs, lobbyists, pro-capital business writers, etc. Today, they are united having become aware of their common interest. This created a global 'interest symbiosis' in support of capitalism's late 20th and 21st century ideological project of neo-liberalism colonising every eventuality of human life.

In opposition to that is critical pedagogy's 'struggle against the neo-liberal, corporate curriculum of skill, drill, and text' (p. 12) conducted by those not afraid to produce 'dangerous counter stories in the corporate academy' (p. 15; Daniels \& Porfilio, 2013). At many levels, the authors critically reflect on the ideological character of postmodernism voicing postmodernism's support of capitalism when, for example, emphasising the 'subjectivity-postmodernism-capitalism' link (p. 22; cf. Sokal \& Bricmont, 1997). Rather than postmodernist that one author found to be 'nihilistic and paralysing' (p. 94) - perhaps one should follow this: 'I took a class with Sam Bowles and Herb Gintis, just as their ground breaking book Schooling in Capitalist America (1976) was being published' (p. 43) showing not only the educational pathologies of capitalism but, to some extent at least, 'the Great Refusal à Marcuse' (p. 49).

Bowles, Gintis, Marcuse - and perhaps even more so Zizek - will make many aware that 'reality itself is increasingly structured as ideological fantasy within which other alternatives are unimaginable' (p. 55). But such alternatives may not simply be 'unimaginable'. Instead, they are deliberately given the appearance of being unimaginable - a point that already Adorno has made (Freyenhagen, 2013). Often alternative destroying ideologies are flanked by 'facts of life' hallucinations generously supported through the 'accountability machine [and the] hidden curriculum' (p. 55). One of the most entertaining and enlightening chapters comes from Curry Malott noting that

'critical pedagogies emerge as direct response to concrete material conditions and historical processes' ( $\mathrm{p}$. 61), 'the public university has always been designed to serve the interest of capital [and] today [the university] is nearly completely sold off or privatised, making the ability to engage in counter-hegemonic work...difficult' (p. 71).

One might add that those universities that are not 'yet' privatised are often governed under the silent dictatorship of managerialism (Aspromourgos, 2012). In fact, ideology has never depended on factual ownership but, more often than not, has supported those who own against those who only own their labour as an old friend of mine from the south-western German city of Trier would say (wiki/ Karl_Marx_House).

In 'Go Stupid', Gabbard argues that - perhaps at least to some level - all of us are the victims of 'institutionalised learning' (p. 105). To further institutional learning and the institutionalisation of people - cf. Adaptation to domination - 'right wing organisations with millions of dollars behind them for indoctrinating [the] American youth...offered to pay students a hundred dollars to secretly videotape or audiotape my classroom comments and fifty dollars to produce notes of statements I was making in class' (p. 133) reports Peter McLaren. But despite such attacks on critical academics, Ross emphasised that 'I had no compunction about behaving blasphemously' (p. 141) and this awareness came in a place where in the 1960s

the church demanded modesty, forbade the use of cosmetics and ornamental jewellery, and regulated hair length (no short hair for women or long hair for men). In addition, it was taboo to participate in "mixed swimming", watch movies or television, to dance or otherwise participate in ungodly amusements' (p. 142).

On top of that, one received - and still receives 'surveillance via standardised texts' (p. 143). Against that, critical pedagogy works for Dewey's educational philosophy and its 'three roots: free individual existence; solidarity with others; and choice of work and other forms of participation in society' (p. 149). These are elements existing in stark opposition to neo-liberalism's political agenda of individuals as mere servants to capitalism living in a 'de-solidaritised' society with no choices over work and no participation in society other than the frequently rehearsed media spectacle of voting for a 'hard' neo-liberal party or a 'soft' neo-liberal one. One is tempted to think 
that North Korea has one political party while we have two. Is that the difference between the dictatorship of the proletariat (or, better, a party falsely claiming to represent the proletariat) and the dictatorship of capitalism?

Set against the downgrading of democracy into a media spectacle and an instrument of rule sits Ross' concept of 'dangerous citizenship' (p. 150). It is called dangerous citizenship because 'it is dangerous to an oppressive and socially unjust status quo and to existing hierarchical structures of power' (p. 151).The concept is based on four key premises:

4. 'capitalism is incompatible with democracy;

5. teachers and curriculum have been subject to ever intensifying policy regimes that attack academic freedom and discourage critical social analysis;

6. civil disobedience is not our problem, our problem is civil disobedience [perhaps indicating that civil disobedience in-itself isn't the problem, the problem is that there is not enough of civil disobedience, TK];

7. we need new pedagogical imaginaries for teaching because traditional conceptions of democratic citizenship are bankrupt, perverted by capitalism's triumph over the interest of the public'

This links neatly to the next chapter on 'a Marxist pig farmer in Kansas' (p. 157) telling the life story of one of the author's uncles. It starts with 'I certainly had no Marxist in my family tree (I'm pretty sure they hang those types from trees in Kansas)' - a statement that, given Cohen \& Winston's 'What's the matter with Kansas?' (2010), is most likely true (p. 157). Very much in line with the aforementioned 'dangerous citizenship' is 'the oppressed worker being allowed once every few years to decide which particular representatives of the oppressing class are to represent and repress them' (p. 150). This method of domination is commonly known as 'democratic society' and 'elections' (Canfora, 2006). Ross closes with the following rather scary statement:

'I think because we spend so much of our careers criticising the system of education and the neo-liberal and corporatised institutions in which we work that we cringe at the thought of becoming 'part of the machine' or being 'institutionalised'. We don't want to 'sell out'. So we shy away from leadership and leave that 'administrative bullshit' to the neocons. But, I see this as a huge mistake' (p. 167).

Perhaps even in seemingly endless - and for many rather pointless - university meetings (TED, 2013), 'neoliberalism represents an ideology that humiliates and denies our humanity' (p. 179). But fighting against neocons, neo-liberalism, etc. Always means a fight that is risk taking conceivably because of Paulo Freire's statement that 'life in its totality taught me a great lesson that it is impossible to embrace it without taking risks. This is how life is' (p. 180). Hence critical pedagogy always involves 'education and power' as well as challenging 'official knowledge' (p. 189). Official knowledge and its ideology comes from a powerful new hegemonic bloc consisting of multiple fractions of capital who are committed to neo-liberal marketised solutions to educational problems, neo-conservative intellectuals who want a 'return' to higher standards and a 'common culture', authoritarian populist religious fundamentalists [particularly in the USA, TK] who are deeply worried about secularity and the preservation of their own traditions, and particular fractions of the professionally oriented middle class who are committed to the ideology and techniques of accountability, and management' (p. 190). These authoritarian populist religious fundamentalists appear to be a particular USA problem but can also be encountered elsewhere (Dawkins, 2015). While all this is correct, the aforementioned 'blind spot' still remains.

But there are also other blind spots such as the one that Suoranta shows us on the case of the education system in Finland that has been held up as 'the' model for all to emulate (Kalb, 2015). How inward looking and isolated Finland's education system really is might be signified by the fact that it took 35 years to translate the key work on critical pedagogy - 'Pedagogy of the Oppressed' ( $p$. 202). Porfilio and Ford's collection closes by highlighting 'the corporate-federal-industrial complex' (p. 236) in a reminiscence on Eisenhower's 'military-industrial complex'. But rather than 'the death-by-bureaucracy of public education' (p. 236), the world has moved on exposing higher education to 'death-by-Managerialism' (Locke \& Spender, 2011). At times, Managerialism even mutates into 'The Systemic Pathologies of University 'Managerialism'، (West, 2015). With its reference to the corporate-education link, the book brings to a close some of the most enjoyable chapters on the issue of critical pedagogy written by many who - I am sure - would like to be known as 'experts', if anything, rather than 'Leaders in Critical Pedagogy'.

\footnotetext{
Thomas Klikauer teaches MBA students at the Sydney Graduate School of Management at Western Sydney University, Australia when not spending his time reading 'critical pedagogy' and writing on his next book entitled 'Management Education - From Managerialism to Emancipation' to be published sometime in 2016.
}

Contact:T.Klikauer@westernsydney.edu.au 


\section{A U S T R A L I A N U N I V E R S I T I E S , R E V I E W}

\section{References}

Adorno, T. W. \& Horkheimer, M. (1944). The Culture Industry: Enlightenment as Mass Deception, Transcribed by Andy Blunden 1998; proofed and corrected Feb. 2005, web-download: www.marxists.org/reference.

Aspromourgos, T. (2012). The Managerialist University: An Economic Interpretation, Australian Universities' Review, 54(2), 44-49.

Bowles, S. \& Gintis, H. (1976). Schooling in Capitalist America: Educational Reform and the Contradictions of Economic Life, New York: Basic Books.

Canfora, L. (2006). Democracy in Europe - A History of an Ideology, London: Blackwell.

Cohen, L. \& Winston, J. (2010). What's the matter with Kansas? (a film, 1 videodisc, $90 \mathrm{~min}$.): sd., col.; $433 / 4 \mathrm{~cm}$ ), Chicago: Tallgrass Productions.

Daniels, E. A. \& Porfilio, B. J. (eds.) (2013). Dangerous Counterstories in the Corporate Academy: Narrating for Understanding, Solidarity, Resistance, and Community in the Age of Neoliberalism, Charlotte: Information Age Pub.

Dawkins, R. (2015). Love Letters to Richard Dawkins, youtube.com/ watch? $\mathrm{v}=\mathrm{gW} 7607 \mathrm{YiBs}$.

Dewey, J. (1916). Democracy and education: an introduction to the philosophy of education, New York, The Macmillan company.
Freire, P. (1970). Pedagogy of the Oppressed (transl. by Myra Bergman Ramos), New York: Continuum.

Freyenhagen, F. (2013). Adorno's practical philosophy: living less wrongly, New York: Cambridge University Press.

Kalb, I. (2015). Finland Is Turning a Big Negative Into a Bigger Positive, www. buffingtonpost.com (22 Dec. 2015).

Klikauer, T. (2015). Ideology, Anarchy \& Society - A Review Essay, Capital \& Class, 39, 3, p. 550-554.

Locke, R. R. \& Spender, J. C. (2011). Confronting Managerialism: How the Business Elite and their Schools threw our Lives out of Balance, London: Zed Books.

Murphy, M. \& Fleming, T. (eds.) (2010). Habermas, Critical Theory and Education, London: Routledge.

Smythe, D.W. (1977). Communications: Blindspot of Western Marxism, Canadian Journal of Political and Society Theory, 1, 3: pp. 1-28.

Sokal, A. \& Bricmont, J. (1997). Intellectual Impostures, London: Profile Books. Ted (2013) David Grady on 'Bad Meetings' (www.ted.com/talks).

West, D. (2015). The systemic pathologies of university 'managerialism', Canberra Times (1 Nov. 2015). Retrieved from www.canberratimes.com.au. 


\title{
Be national, not global
}

\section{The New Flagship University: Changing the Paradigm from Global to National Relevance, by John Aubrey Douglass (Ed.).}

ISBN: 978-1-137-50048-9, Palgrave Macmillan US, xxi+217pp, 2016.

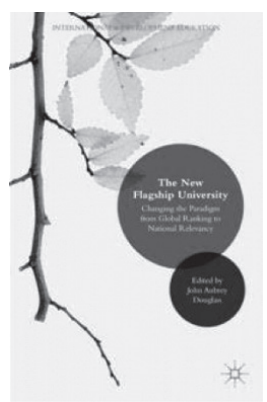

\author{
Reviewed by Kaycheng Soh
}

A naval fleet's main ship, the vessel bearing the fleet's flag and commander, is its flagship. Analogically, a state's leading university is its flagship university. There is, however, no official definition of a flagship university. Typically, in the US, it is the state's land-grant institution with the highest research profile and the most doctoral programs and the oldest and largest university with the best endowment. It has the prestigious membership of the Association of American Universities and NCAA Division I athletics is a must. That is a flagship university in the American context.

Surprisingly, the designation of a university as a flagship can be controversial. For instance, in February 2012, the University of Idaho was stripped of its flagship status by the Idaho State Board of Education to discourage competition among the state's universities but to encourage inter-institutional cooperation. Equally surprising, the University defied the governing board by posting a detailed argument against the decision and asserting that it is the state's flagship university. The University cited that it is the state's first university, its land-grant university, its leading research university, and its primary doctoral degree-granting university (Olson, 2012).

The concept of a flagship higher education institution has recently been modified, expanded, and uplifted from the national to the global level by Douglass (2016) in the monograph, The New Flagship University. It is in essence a reaction to the tyranny of world university rankings and the ambiguous concept of 'world-class university'. On a positive note, the new flagship university is a move away from the meaningless annual caucus race and a move towards taking on greater responsibility for social development and economic relevance of a university to its supporting environment. It is a move beyond the pure and narrow academic domain. In short, the new model explores pathways for universities to re-shape their missions and operational features to expand their relevance in the societies that gave them life and purpose.
In the first four chapters, Douglass advocates the idea of replacing the current world university rankings with flagship universities. Chapter 1, How Rankings Came to Determine World Class, traces the emergence and subsequent proliferation of world university rankings and points out the limitation of rankings involving small sets of indicators, the subjectivity of reputational data, and the domination by the top 25 universities, a group comprised largely of universities of American origin in the three classic rankings: Academic Ranking of World Universities, QS World University Rankings, and THE World University Rankings. However, Douglass considers the rankings an exercise evoking the bell (normal) curve and this is in fact not the case, as the ranking agencies have never made reference to this statistical phenomenon nor other more refined statistical concepts. Moreover, the discussion of the methodological and conceptual weaknesses remains at the verbal level of discourse and misses out on several critical statistical issues uncovered in the more recent years such as spurious precision, weight discrepancy, and multicollinearity and hence indicator redundancy. (See for example, Soh, 2013; 2016 forthcoming). Nevertheless, Chapter 1 provides a launching pad for the introduction of the modern adaptations of the concept of flagship universities, to be elaborated in the next chapter.

Chapter 2, The Origin of the Flagship Idea and Modern Adaptations, is basically a historical account of the concept of the flagship university, beginning with the USA and England. As documented therein, the concepts have spread in various forms to countries such as the South Korea, Hungary, Norway, and even sub-Saharan Africa. Douglass is quick to point out that the term flagship university has different meanings in different countries due to different national contexts. Such diversity is aptly illustrated in subsequent chapters of 'national reports' in Chapters 5 to 8 .

Chapter 3 is by far the longest of the nine of this monograph, taking up about 80 of the 200 pages of text. It is in this chapter, Profiling the New Flagship Model, 
that the idea is operationalised in great detail, framing the tripartite mission of research-intensive universities, namely, teaching and learning, research and knowledge generation, and social service. In a very real sense, this is putting old wine in a new bottle. However, Douglass points out that the three traditional functions of the universities have expanded and are more varied in modern times, and there are nations with different environments reflecting the differences in their national cultures, politics, aspirations, and socioeconomic realities.

The chapter lists some universal conditions of the new flagship university and these include mission differentiation (i.e., highly selective yet broadly accessible admission and academic teaching, research, and public service), comprehensive academic programs, adequate academic core, and institutional quality assurance. For Profile I, which puts the flagship university in the national system of higher education, Douglass emphasises thus,

[it] is in fact vital there exists a subgroup of leading national universities that can help nations most effectively pursue economic development, improve socioeconomic mobility, proving measures of academic quality and support for other educational institutions, and produce political and economic leaders and good citizens (p. 44).

The list obviously does not deviate much from commonly held expectations for higher education institutions in general and the emphasis highlights the leadership of the lead university and smacks somewhat of elitism.

Profile II focuses on the academic functions of teaching/ learning and research. For the former function, Douglass stresses the need and importance of engaged learning for the first-degree students with the aim of producing innovative and creative students who are ambitious and talented. He then lists no fewer than 11 opportunities by which this aim can be attained, including inquirybased learning, collaborative learning, digital literacy, etc. The need for the different approaches is further underlined by the student diversity in socioeconomic background, mental health, support systems and a host of other personal conditions. There is also a call for curriculum engagement (with many illustrative examples from various campuses) and undergraduate research engagement, with consideration of co-curricular activities and social life and conditions. The calls for a more studentoriented approach may appear new in higher education but they have been going on at the level below, in schools. This perhaps reflects, albeit indirectly, the inertia of the tradition of higher education where transmission of knowledge seems to be the paramount goal and where those who are learned preside.

As for postgraduate education and research, Douglass highlights the fact that undergraduate study is no longer an end but has become a preparation for further study. He also stresses the social and socioeconomic nature of research in contrast with the conventional notion of blue sky academic research. Going along this line of argument, the demarcation between undergraduate and postgraduate education will become very thin in times to come and expanded undergraduate programs are conceivable and, perhaps, are needed.

Profile III deals with the functions of social service and economic engagement of the new flagship university. The functions of the university are thus expanded and diversified with the concept of scholarship re-defined. Such words as public issues, community issues, local community are repeatedly found in the discourse. Mention is also made of continuing education and cooperative extension. Thus, all in all, the new flagship university, as Douglass advocates, is an institution of higher learning beyond the traditional campus bounds and involves close interaction with its supporting community and farther. In other words, the university is a far cry from the exclusive ivory tower with its own life but a socially integrative and economically productive organisation

Profile IV outlines the managerial aspects of the new flagship university, emphasising the need for autonomy and decentralisation (from ministerial control) accompanied by accountability. Examples of Japan, Singapore, and France are cited in support. The three principles of academic autonomy, fiduciary autonomy, and public accountability are stressed, particularly the first. However, how accountability can or should be actualised is not given much treatment.

Chapter 4, Considering National Context and other Variables, is indeed a 'miscellaneous' chapter. It first contrasts the university as an isolated village and as a growing city. Besides reiterating the relevance of the new flagship university and economic development, readers are reminded that it is a flexible and aspirational but not a prescriptive concept. The chapter sums up by saying that the new flagship university is a holistic model, applicable to some subgroups of major universities.

The remaining chapters present case studies of efforts and problems in moving in the direction of the new flagship universities in Asia, Latin America and Scandinavia, and the Soviet model. These chapters discuss the diverse efforts and problems of massification of higher education and the lack of trustworthiness of the current rankings. 
These are stories worthy of careful reading, although the present review has chosen to focus on the chapters most directly related to the concept and advocacy of the new flagship university.

In the space of four chapters making up half of the monograph, Douglass has expounded the concept of 'new flagship university' as a total contrary reaction to the chase for 'world-class' inherent in the current rankings. In a real sense, this is not only critical but prophetic - a vision of a different kind of higher education institution which integrates itself into the surrounding and supporting environment and in its turn, enriches this environment. This is to be achieved through entrusted autonomy, endowment, and self-management, with accountability as a mechanism of responsible self-control.

Since the new flagship university is suggested as a way to supplant the ranking-based world-class university, a pertinent question to ask is whether the replacement will eventually be actualised. The guess is that the answer is 'no', going by the current obsession with ranking built up over more than a decade. World university rankings, as currently practised, provide a single-numeric measure for comparison, or rather competition. This is simple though simplistic, fitting well the competitive milieu of the day and naïve administrative convenience. Although the process of rankings has conceptual and statistical flaws, ranking agencies and rank-consumers alike are either oblivious to these or prefer an 'ostrich' approach to reading ranking results.

By comparison, the concept of the new flagship university is much more complicated than that of the world-class university, although the emphasis on four profiles is a move in the right direction. Rank-consumers may find it cumbersome to deal with four rather than one numeric measure when making decisions. The emphasis of the new flagship university's relations with the local (be it regional or national) social and socioeconomic conditions causes another methodological problem of how to equalise the inherent differences to provide a common ground for valid comparison when comparison is needed. Even if rankings are not provided (like in U-MultiRank), rank-consumers are most likely to do their own rankings out of administrative need and convenience as well as the (bad) habit of thinking. In other words, the non-competitive approach advocated for the new flagship university will work if universities (or their nations) do not have to compete. Unfortunately, this is an unlikely event, in view of the world culture today.

On a positive note, the concept of new flagship university sounds like a much-needed alarm that higher education institutions are too complex to be reduced to half a dozen indicator scores which are then summed in rank-order to compile league tables. However, ranking agencies may have to consider seriously how to expand and modify their methodologically simplistic and statistically flawed approach of weight-and-sum to include some of the conditions or characteristics advocated for the new flagship university. Going by current attitudes and practice, this is not likely to happen, sad to say.

Kaycheng Soh is currently Research Consultant at the Singapore Centre for Chinese Language. Contact: sobkaycheng@botmail.com

\section{References}

Olson, G.A. (2012, 15 March). Standing out from the Crow. The Chronicle of Higher Education. http://chronicle.com/article/article-content/131141/

Soh, K. (2016, under review). Seven statistical sins in world university ranking. Journal of Higher Education Policy and Management.

Soh, K. (2013). Social and Educational Rankings: Problems and Prospects. New York: Untested Ideas Research Centre. 


\title{
Transformation by inclusion
}

\section{Diversity and Inclusion in Higher Education, Edited by Daryl G. Smith.}

ISBN-13: 978-0415529181, London: Routledge, 198pp., 2014.

\author{
Reviewed by Kate White
}

What role do diversity and equity have in transforming higher education institutions? This edited volume explores the historical and contemporary context for diversity; how diversity is framed at a national and institutional level and the strategies and policies for engaging diversity; the role of special purpose institutions; and the indicators used to monitor progress. It examines institutional transformation and diversity in higher education in South Africa, the United Kingdom, the United States and Brazil, and has an additional chapter comparing indigenous higher education in the United States and New Zealand.

The Introduction sets the context for the study and outlines the key issues to be explored. Then follows the country-specific chapters. Jonathan D. Jansen's chapter is an engaging and passionate account of transformation in his university. He took over as the first black ViceChancellor of the University of the Free State, originally a state Afrikaans university, soon after it attempted racial integration in not only the classrooms, but also the halls of residence. Following a much publicised incident of racism that 'tore campus and country apart in a firestorm of racial anger, angst and accusation' (P. 34), the university's leaders became 'a constant presence in the residences clarifying policy and requiring decency in human interactions' (P. 35). Jansen says that while there was no question that for any university leader after a long period of colonialism and apartheid 'we have a serious responsibility to accelerate access to higher education' (p. 40) for black students and to build the number of black professors, what was 'less often talked about and even less practised, is a conscious effort to pursue redress, reconstruction and redistribution while at the same time promoting racial reconciliation and social cohesion within the same institutions' (p. 40).

Heather Eggins' chapter reminds us that higher education in the UK is a very diverse system. Features include the concentration of students with the highest qualifications at elite universities, the dominance of rankings, including student experience rankings, governance of institutions that is concerned with identification and management of risk, and an Equality Act (2010) the implementation of which in higher education is hampered by severe funding cuts.

Yolanda T. Moses' chapter on the United States focuses on leadership for change and emphasises that institutional missions and their commitment to diversity are closely aligned. She argues that to achieve diversity and inclusion 'requires informed and sustained leadership, institutional will, intentionality, the alignment of diversity values with other values and the capacity, skills, and expertise to pull it off' (p. 95).

Daryl G. Smith's concluding chapter notes that transformation in higher education still seems to be at the margins of national policy and institutional decisionmaking. It argues that two parallel forces are pushing change: work to ensure access and success of historically underrepresented groups and increasing recognition of the value of mass higher education for healthy societies; and the more general movement for greater equity in societies that support diversity and inclusion.

This edited volume makes an important contribution to the debate on diversity and inclusion. It encourages university decision-makers to ensure that diversity and inclusion underpin institutional policies. It similarly encourages fields of study in every area of higher education policy and research to frame research in ways that put diversity and inclusion at the centre of higher education.The book is a welcome addition to the literature on diversity and inclusion in higher education, and will be a useful reference for institutional leaders, researchers in the field and equity practitioners in universities.

Kate White is an adjunct associate professor at Federation University Australia, Ballarat, and Co-Director of the WHEM (Women in Higher Education Management).

Contact: kate.white@federation.edu.au 


\title{
Doing it UNSW-style
}

\section{Improving Assessment in Higher Education: A Whole- of-Institution Approach, by Richard Henry, Stephen Marshall \& Prem Ramburuth (Eds.).}

\author{
ISBN: 978-1-742-23400-7 (paperback), 978-1-742-24662-8 (ePDF), Sydney: \\ NewSouth Publishing, xvi + 368 pp., 2013.
}

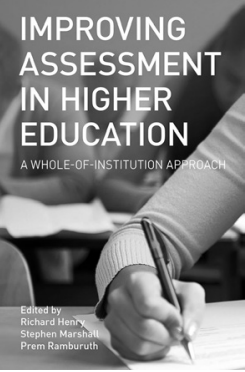

Reviewed by Dennis Bryant

The phrase 'Whole-of-Institution' in the title of this print book caught my attention. This phrase seemed to be a statement of intent, impressive in its daring, which in turn inferred meaningful action across at least one higher education arena, the University of New South Wales' (UNSW) Faculties. Perhaps they even presaged an injection of inspiration into the long flow of published articles on assessment. I read on.

This book is structured in the usual way of having a Part 1 (with three introductory chapters which are effectively literature review chapters, and which flow rather well, meaning that they should be appreciated by all, and were written by the editors in collaboration); a Part 2 (with nine case studies, one for each of UNSW's Faculties, each revealing the implementation of this project); and, a Part 3 (containing three concluding chapters).

Normally, you could expect to skim Part 1, fly on to Part 3 where you again skim but this time for confirmation, and finally settle into the heart of the project's case studies in Part 2. However, this approach would miss two critical items. In the Foreword, Professor Frederick Hilmer equates current assessment to a 'cottage industry' and confirms a need for change. The second point of note is the tone, which is carried from the Foreword on into Parts 1 and beyond. Unlike previous higher education publications, the tone in this book is coming from the strength of a vantage point, and it is no surprise to find therein that UNSW has taken responsibility for assessment by setting up internal standards, in preference to the plethora of new governmental quality assurance agencies' directives.

The implication in taking responsibility, as admirable as it is, was not entirely altruistic, nor does it seem driven in the main by long-standing research by authors such as Biggs (1999, 2001) whose comments on the role of assessment in a university's vision are well-known. However, the objective of driving down lecturer costs in performing assessment and providing feedback to students is still seen to create an increase in the quality of student outcomes, and this is two-edged efficiency. I read on into the Faculty case studies.

The case studies were written by up to four authors, each as specialists in one of the nine Faculties. While some Faculties were better prepared for change than others, Faculty responses were positive, and this positive reaction to growth opportunities was captured in the concepts that they used. Some commonly found concepts were: Lecturer workload reduction across courses and programs; TESTA (Transforming the Experience of Students Through Assessment); AOL (Assurance Of Learning); QI (Quality Improvement); Curriculum review and redesign; Efficiency outcomes - to mention a few.

In summary, I found this UNSW initiative to be groundbreaking, in the same sense that institutional initiatives at Sydney University propelled forward lecturer certification in higher education teaching (Brew \& Ginns, 2008). Is there a better accommodation than the areas of student assessment and assessment costs? This book is not merely a good read, but it would function also as a good guide to universal academic re-invigoration.

Dennis Bryant is at home designing modest but realistic metrics on student learning success, and failure. In this regard, he has an abiding interest in the success of institutional initiatives that assist students, and staff.

Contact: drdennisbryant@gmail.com

\section{References}

Biggs, J. (1999). What the Student Does: teaching for enhanced learning. Higher Education Research \& Development, 18(1), 57-75.

Biggs, J. (2001). The reflective institution: Assuring and enhancing the quality of teaching and learning. Higher Education, 41(3), 221-238.

Brew, A., \& Ginns, P., (2008). The Relationship between Engagement in the Scholarship of Teaching and Learning and Students' Course Experiences. Assessment \& Evaluation in Higher Education, 33(5), 535-45. 


\section{Improving undergraduate education}

\section{The Undergraduate Experience: Focusing Institutions on What Matters Most, Peter Felten, John N. Gardner, Charles C. Schroeder, Leo M. Lambert, Betsy O. Barefoot.}

ISBN: 9781119050742 (hb.), San Francisco: Wiley, xx+247pp., 2016.

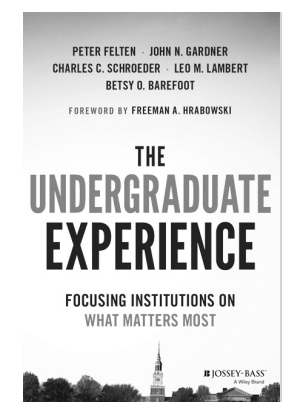

Reviewed by Chris Mayer

The Undergraduate Experience: Focusing Institutions on What Matters Most identifies successful practices in undergraduate education worthy of adoption by others. The foreword, written by Freeman A. Hrabowski III, President of University of Maryland, Baltimore County, highlights two overarching ideas that serve as the foundation for the book's six themes. The first is that successful institutions have a culture of 'positive restlessness', which is a concept discussed by George Kuh and his co-authors in Student Success in College: Creating Conditions that Matter. Hrabowski describes institutions with positive restlessness as those that are 'constantly seeking and striving to improve, determined not to be satisfied' (p. viii). The second overarching idea is 'optimism at a time when we need it more than ever' due to the challenges facing higher education (p. viii). While the authors acknowledge the existence of obstacles that make success difficult, they still believe it is possible to achieve excellence.

The introduction begins with a reference to Transforming a College: The Story of a Little-Known College's Strategic Climb to National Distinction by George Keller. In this book, Keller presents the strategy Elon University used to transform itself (p. xvii). While they praise Keller's study of Elon, the authors distinguish their work from Keller's through their focus on successful practices at multiple institutions instead of just one as well as their articulation of the two questions below that they have written the book to address.

'What matters most in the undergraduate experience?' 'What is possible when colleges and universities focus on what matters most' (p. xviii)?

The book employs the positive deviant approach to discover those who have achieved success despite facing challenges so that others with similar challenges may adapt these successful practices to their situation. For those unfamiliar with it, the positive deviant approach is described and applied in detail in Pascale, Sternin, and
Sternin (2010), and Heath and Heath (2010) develop a modified version of it with their focus on 'bright spots'. From their study of 'positive deviants', the authors propose the following six themes as essential for creating successful undergraduate experiences: Learning matters, Relationships matter, Expectations matter, Alignment matters, Improvement matters, Leadership matters.

Each of the six themes has its own chapter, and each of these chapters includes action principles illustrated by multiple examples. One action principle for the chapter on learning is to 'help students integrate learning opportunities', and it is exemplified by Carlton College's approach to curricular integration through integrative projects that 'focus on transfer and synthesis across the disciplines' (p. 35). The authors note that this curricular effort promoted collaborative course planning and led to academics and staff taking ownership for institutional learning goals (pp. 35-36).

Another theme is that relationships matter. One example that highlights relationship building is Elon University's weekly College Coffee events that occur for 40 minutes at a time when no classes are scheduled. These weekly gatherings allow academics, other staff, and students to interact, and their success provides support for the action principle of 'encouraging everyone on campus to cultivate relationships' (p. 60). Another example is Duke University's FLUNCH Program (Faculty Lunch) that funds 'opportunities for students to invite faculty members for one-on-one lunches' (p. 46). The FLUNCH Program is complemented by the FINvite Program (Faculty Invitation), which allows academics to invite students to dinner, with the University providing catered food and transportation for students (p. 46). These types of programs are not common across American higher education, but the authors argue that they should be because they strengthen relationships across the campuses in which they are used. 
When describing the theme of institutional alignment, the authors describe how Christopher Newport University (CNU) calibrated course schedules, enhanced academic advising, provided early and frequent feedback on student performance, and created a comprehensive early-alert system (pp. 100-102). All of these academic programs and campus practices were aligned to achieve the institutional mission, which resulted in a 10 per cent increase in retention and a 20 per cent increase in sixyear graduation rates (p. 103). Although the authors do not always identify quantifiable results associated with the practices in the book, in the case of CNU these results validate the action principle to 'align academic programs and campus practices'.

In the chapter on improvement, the authors describe the Harvard Assessment Seminar initiated by Richard Light over 30 years ago (p. 118). These seminars were held over dinner each month and included academics and staff from other institutions. At each seminar, participants would 'identify a question about students' collegiate experiences and then create a plan to gather and analyse relevant evidence' (p. 118). Participants discussed the results of their inquiry and used these results to inform efforts to improve student learning. While many academics bristle at the thought of assessment, the collegial research-oriented engagement described by Light presents an approach worthy of consideration.

The authors highlight the importance of leadership for those institutions seeking to improve. In exemplifying the principle of 'articulating clear, aspirational goals linked to institutional mission and values', readers return to $\mathrm{CNU}$ where the president, Paul Trimble, led a transformation of the institution. To accomplish this transformation, CNU 'sharpened its focus on the undergraduate experience and the arts and sciences, eliminated professional programs not in keeping with that vision, increased rigor of academic programs, and committed to a student-centred institutional culture' (p. 143). This led to a 500 per cent increase in the number of applicants in ten years and a significant increase in applicant standardised test scores (p. 143).

The authors end the book by highlighting the importance of culture, especially 'positive restlessness' and the development and implementation of a strategic plan (pp. 166-167). Another important component of successfully implementing the ideas in the book, they argue, is breaking down silos within institutions so that academics and other staff can collaborate to improve the undergraduate student experience (p. 172).

While the title includes the qualifier 'American' higher education, the book is relevant to Australian higher education, and its cases actually include non-American institutions. Those looking for in-depth case studies with rigorous application of theoretical perspectives will be disappointed. While the authors do employ some theoretical work, and actually rely on a significant list of references, their focus is on providing multiple successful examples in undergraduate education rather than focusing on just one or two. This makes the book of great use to practitioners (academics, staff, and administrators). The examples it provides are powerful, and the book would be very useful for an institution in the process of strategic planning. Because there is no discussion of criticism of the practices it presents or advice for implementation, those reading the book should consider it a launching point for further research and discussion of the successful practices it highlights. The book would also be an excellent read for an institution-wide professional development program focused on improving an institution's undergraduate experience.

Chris Mayer is Associate Dean for Strategy, Policy and Assessment and an Assistant Professor of Philosophy at the United States Military Academy (West Point).

\section{References}

Heath, C. \& Heath, D. (2010). Switch: How to Change Things When Change Is Hard, New York: Broadway Books.

Keller, G. (2014). Transforming a College: The Story of a Little-Known College's Strategic Climb to National Distinction, Baltimore: Johns Hopkins University Press.

Kuh, G., Kinzie, J., Schuh, J. \& Whitt, E. (2010). Student Success in College: Creating Conditions that Matter, San Francisco: Wiley.

Pascale, R., Sternin, J. \& Sternin, M. (2010). The Power of Positive Deviance: How Unlikely Innovators Solve the World's Toughest Problems, Boston: Harvard Business Press. 


\title{
An idea of union
}

\section{The National Tertiary Education Union: A most unlikely union, by John Michael O'Brien.}

ISBN 9781742234588, NewSouth Publishing, 368pp., 2015.

\author{
Reviewed by Howard Guille
}

Bradon Ellem (1988) wrote that 'People often imagine that writing a sponsored history must be like being one of Rupert Murdoch's employees'. John O'Brien has avoided the Rupert trap. He has done the National Tertiary Education Union (NTEU) proud by writing his account of its first twenty years. He writes as an insider but aware of the need to be analytical not partisan (p. 4). His last three sentences of the book capture its overall tone.

There is no reason why it (the NTEU) cannot have another twenty years of success. It will be a struggle. It was ever thus! (p. 296).

The emphasis on contestation and struggle are worth the admission price. John's achievement is no mean feat given that most of the dramatis persona he encounters and lists in the appendix are alive and kicking. They are not beyond seeking the limelight and polishing, if not embellishing, their part in any story. As one of them, I will try to desist doing so in this review.

The book is impressive and admirable. The introduction describes the five organisations that formed the NTEU on 1 October 1993. The union amalgamation is put into the context of the unified system of higher education formed in the late 1980 s with a series of institutional amalgamations and re-designations out of the binary system of the 1960s-1970s. This exposed the strains in the policy of 'equal but different' between universities and colleges of advanced education. It also put the unions for college and university academics into competition as institutes of technology became, in name at least, universities of technology. Coincidentally, the ACTU launched its policy of union consolidation and amalgamation into predominately industry-based organisations. The aim was to reduce some 300 unions into around 20 'super-unions'. It also coincided with what the ACTU (undated) says was its 'drive to reform the Australian education and training system'.

Chapter 1 is a very nuanced and informed account of the period.It would make easy reading for anyone wanting an account of where our current universities came from. Actions by some state governments and some institutions were important but John Dawkins - the Federal ALP
Minister - was pivotal. He took direct Ministerial power over the allocation of funding of all universities and colleges and used it to 'massify' the system including forcing the formation of fewer, larger institutions. In particular, the already large metropolitan colleges of advanced education were dismembered and recombined with existing universities or with Institutes of Technology being rebadged as universities. To give an example, parts of Brisbane College of Advanced Education (CAE) went into Queensland University of Technology (QUT) which was the rebadged Queensland Institute of Technology. Griffith University, a 'new university' of the 1970s was reformed by amalgamation with the Gold Coast CAE, Mt Gravatt campus of Brisbane CAE, the Conservatorium of Music (in the CAE sector) and the Queensland College of Art (degree granting but administratively part of TAFE). It went from one to five campuses; the additions were larger in student numbers than the former Griffith University. The metropolitan CAEs had been formed by a previous Commonwealth intervention less than ten years earlier. This had contributed to the stronger industrial orientation and militancy of the college academics union.

Chapter 2 covers the amalgamation process and the 'unlikely union'. The nuptials were between the unions covering, respectively, college academics (Union of College Academics (UACA)) and university academics (Federated Australian University Staff Association (FAUSA)) and three general staff unions from, respectively, Victoria, University of South Australia and Australian National University. To say the least, progressing the amalgamation was difficult. There were two big contentions; one whether the Union should cover all higher education staff or just academics. The other whether the new Union should have three tiers (national, state and branch) or just two (national and branch). The question of who would have the power and authority in the new Union effectively rested on these two matters.

Put plainly, the former FAUSA would dominate an academics-only union and the power would rest with institutional-based branches. Against this, if general staff 
from Australian Colleges and Universities Staff Association (ACUSA were included in the amalgamation, the former FAUSA would not have the numbers against an alliance of former UACA and ACUSA forces. In this case, the existing strong state structures of UACA and ACUSA would have to be accommodated. The book teases out the issues and manoeuvres that consumed the years leading up to the amalgamation and continued afterwards. It was certainly a 'daring and highly contested initiative' (p. 291). I would add the descriptor torrid; it was not for the faint hearted. Like Paul Keating said, 'downhill, one ski, no poles' ((Keating et al, 1990). Friends were lost not made.

The decision to become an industry union covering all staff was won among the possible amalgamation partners. Yet in 1993, the NTEU had next to no general staff membership outside Victoria and its coverage rules for general staff in other states were limited. Becoming an industry union in more than name - that is with members from all grades throughout the country required a contest with other unions with general staff coverage and members. The particular unions involved and their coverage varied between institutions and states. In most places, it included the particular State Public Service Union, operating under the name at least of the Community and Public Sector Union (CPSU), and the Liquor and Miscellaneous Workers Union. The Health Services Union (HSUA) was substantial in NSW and the ACT, the Metal Workers in ACT and the Australian Services Union (Clerical) (ASU Clerical) in Queensland. The ASU (Clerical) was the former Federated Clerks Union that had taken the name but had not consummated an amalgamation with the national ASU that covered local government workers. There were two separate branches - one with members only at James Cook and the other covering the other universities. It was strongest at University of Queensland. Some of this is described in Chapter 2 (pp. 77-82).

By the 2000s, the NTEU had general staff coverage and members throughout the country and John is correct in saying that the considerable risk taken in the late $1980 \mathrm{~s}$ to form an industry union paid off' (p.83). He ascribes this to recruitment 'on the ground' and coverage applications under industrial law. He underplays the 'chance' element that came from the decision of some universities to negotiate single enterprise agreements in the 1997 enterprise bargaining round. In Queensland, for example, this happened at the three regional universities (Central Queensland University (CQU), the University of Southern Queensland (USQ) \& James Cook University (JCU)). It allowed the NTEU to become party to the agreement for all types of staff thus giving de facto if not de jure coverage and representational rights. Second, the NTEU drove the bargaining for everyone - we were better resourced, more informed, had a set of coherent demands, knew what was happening elsewhere and, possibly, were more competent. At all three places, where a single agreement was negotiated, a large movement of members to the NTEU occurred and was led by the delegates of other unions who were on the bargaining teams. This did not occur at places where management insisted on separate general staff and academic agreements. At CQU, for example, NTEU membership more than doubled in 1997 , even without formal coverage and that university was effectively a NTEU site across its ever expanding number of campuses. At the University of the Sunshine Coast, opened in1996, we negotiated an enterprise agreement for all staff with the NTEU as the only union party to the agreement. We were the only union who had recruited members and which engaged the management in enterprise bargaining.

All of this met with strong opposition from the other unions especially the ASU (Clerical) which had the largest coverage in Queensland. After initially refusing to be in the same room as the NTEU at USQ (and partly precipitating the first threat of a non-union agreement in the sector in 1997), the ASU agreed to a non-aggression pact with the NTEU including not objecting to the NTEU becoming party to general staff agreements. From their point of view, this clearly turned out to be a Trojan horse (Mayes, 2013). The ASU and other unions also took strong exception to the NTEU's application to expand its coverage using the 'competitive unionism' provision of the Howard Government's Workplace Relations Act. From the NTEU's short-term perspective, the application was rational; however, it went against principles of union solidarity. It was another time of broken friendships. It also made it much harder to get support from other unions in the very difficult third bargaining round of 1999-2000 and even against the Higher Education Workplace Relations Requirements (HEWRRs) in 2004.

Chapters 3 and 4 of the book are about the Union and enterprise bargaining. John's conclusion of five rounds of bargaining is apt

...the NTEU had survived. It was battered around the edges, but its resistance and persistence, its strategy and its tactics, largely prevailed. (p. 176) and

Given all the difficulties faced by unions in the enterprise bargaining period, the NTEU had maximised its opportunities through a combination of central coordination and flexibility and significant strength on the ground (p. 177) 
No mean feat especially as university employers got tougher in 1999-2000 and then in 2004 the Howard Government made the NTEU public enemy number two after the Construction, Forestry, Mining and Energy Union (CFMEU) and introduced the HWERRS (pp. 155-8).

Perhaps the book understates the level of detailed control that the Federal Government sought to exert over university bargaining. It is hard to over-exaggerate the sheer weight of the demands to roll-back the Union. Each university had to send its draft enterprise agreements for vetting by Minter Ellison to ensure it met the Government's requirements. The word 'union' was almost totally proscribed. In retrospect though, perhaps some universities found this little different from the vetting of agreements by what they called "Big Moscow", the NTEU office in Melbourne. (They, and some branches, saw Brisbane and the Division Office as "Little Moscow").

Further analysis is needed as to why the Government was so enraged about the NTEU. Clearly, it did not like the Union's coordinated bargaining. No doubt, the Union had upset the Government especially in the period of Dr Kemp as Minister; likewise, some vice-chancellors and chancellors probably used their political connections to get an advantage in bargaining. Yet these do not seem sufficient reason for such a draconian and expensive policy. Maybe another contributing factor was that the NTEU had become a labour market leader especially in regional areas where universities were among the largest employers. For instance, the Industrial Relations Director of CSR - Sugar made this abundantly clear in the early 2000s complaining that the NTEU was setting the standard for wages and conditions in its North Queensland and Far-North Queensland mill areas. And, the complaint was about general staff where there was a shared labour pool, not academics. If so, it is an unexpected consequence, and irony, of forming an industrial union.

The NTEU was good at co-ordinated bargaining because it concentrated on outcomes as well as claims. This was unlike some other unions who thought it sufficed to serve a common claim and then see where the chips fell. The NTEU was successful because it was audacious and progressive. The claim for extended maternity leave is a good example; so too the claims for Aboriginal language allowances and employment strategy. The provision in the JCU EBA of 2000 about Indigenisation of the School of Indigenous Australian Studies was one of the first.

The NTEU also looked after the basics. For example, in 1997, at the four places in Queensland where there was a single institution-wide agreement the NTEU was able to extend the disciplinary, dismissal and redundancy provisions applying to academic staff to all staff. Critically this meant that for the first time, general staff could not be subject to summary dismissal. This, and the levels of redundancy pay, was a big breakthrough for administrative, technical and manual occupations in these regional areas. Extending this provision to general staff was the best way (and the equitable way) of keeping it for academic staff.

The job of the NTEU under enterprise bargaining was to get as much as possible out of the employer. John is quite correct in emphasising the significance of getting an industry-wide 'floor price'. It meant the Union had to get involved in where the money went inside universities. We had to make sure the claims of staff were more important than new buildings or grandiose projects. It meant gaining a profound knowledge of the finances of every university and the costs of NTEU claims. If members were to be asked to vote for industrial action, there had to be a convincing argument that our claims could be met. The financial leaflets used to combat management - and especially during non-union ballots - were crucial. By the third round of bargaining, the NTEU knew more about the sources and uses of funds for each university than did most managements.

Even so, we did not always extract enough - John makes this point about the University of Western Australia (pp. 153-4). It was also the case at the University of Queensland in round three. Here, the ASU settled the separate general staff agreement for a wage settlement lower than the NTEU claim but with a clause that this would be 'reviewed' if the NTEU gained a bigger increase for academic staff! After defeating a non-union agreement ballot, the NTEU did get a bigger increase - but there was a distinct sense that there was money left in the pot. It was worse when management duly reviewed the case for a further general staff increase and concluded it was not bound to pay any increase. In one of life's ironies, the capacity of the other unions was such that the NTEU (party to the general staff agreement) even had to write the submission when the unions took a dispute to the Australian Industrial Research Commission (AIRC). The Commission, as we privately expected, upheld the management interpretation of the agreement. However, the branch did learn; with new leadership and energy, it has repeatedly taken-on and prevailed against a very tough management.

Chapter 5 of the book is about the Union's policy work. Suffice to say that while enterprise bargaining got the public attention, the NTEU's policy activity was and is a real strength. As the book describes, there have been crucial impacts - the defeat of the higher education legislation 
proposed by minister Nelson in 2004 (pp. 198-201) and the more recent "A degree should not cost \$100,000" campaign. Higher education was a federal election issue in both 2013 and 2016. The book correctly acknowledges the lobbying efforts of the National President and the General Secretary in 2004 (p. 200). In a footnote to history, the JCU Branch President and I travelled to Mareeba in Far North Queensland to meet with the One Nation Party Senator Len Harris. We were successful. Not only did he vote against the legislation, he also later visited an NTEU picket line outside QUT.

Chapter 6 is about diversity and identity especially Aboriginal, women and LGBTI members. The chapter also has sections on precarious employment - stated as 'a significant future challenge for the Union' (p. 284) and on 'So what is academic work' (pp. 278-9). These two sections fit a little uneasily into the chapter; the issues are discussed below. John concludes that issues of particular concern to women became part of the mainstream of the work of the Union' (p. 285) and representative structures were established for Aboriginal members. These industrial and policy actions were at the forefront of the union movement (p. 286). Even so, the enforcement of the gains made for Aboriginal members in bargaining could have been more forceful. This is partly a structural problem - the Union involves Aboriginal members directly in bargaining: it needs to learn to do so in the monitoring and enforcement of agreements.

The NTEU has, on the whole, done well industrially. However, job insecurity, over-work and precarious work have become epidemic in higher education. Reductions in real government funding, the Coalition Government's assault under Work Choices and HEWRRS and the almost perpetual motion that is management-led restructuring are each part of the explanation. Moreover, insecurity, over-work and precariousness have come to characterise almost all areas of employment in Australia over the last two decades. Even so, it behoves the Union to examine its own backyard. What could have controlled the manifest expansion of managerial prerogatives, restructurings and redundancies? Why is casualisation exceptionally high in universities - especially in academic work?

My sense is that the Union thought that it could make the cost of redundancies so high that it would dissuade managements. The enterprise bargaining settlement on redundancy provisions made at University of New South Wales in early 1997 traded 'money for time' (p113). It also gave away some of the award criteria for redundancy. The UNSW provision became the standard for the sector and, as noted above, was extended to general staff at a number of places. By the standards of the time, the money pay-outs were generous; they remain in advance of the national standard. However, the swag of job losses at almost all universities shows that managements have been willing to pay the price - it is a 'one-off' met from savings in future wages.

The real battles in restructuring and redundancy are about the criteria used to justify 'change' and to be applied in deciding who should be sacked. At one stage, before enterprise bargaining, the academic award required university managers to demonstrate institution-wide financial exigency. This was a strong control - a deficit in a section, department or campus was not, by itself, a sufficient condition to close it down. This particular criterion has gone; at best enterprise agreements require managements to try to avoid job losses. Management of change clauses are about 'consultation' and not about management getting the agreement of the Union.

Job security is, I think, the one area where the NTEU should have been more militant. Contesting the labour process is much more radical than contesting the wage bargain. Restructuring and redundancies have to be fought on the ground with the Union taking-on managerial prerogatives. It needs public argument that the university should not be closing particular disciplines; willingness to expose empire building by senior managers and research directors (and their excessive salaries); and coherent explanation of why contracting-out of services is inimical to the academic enterprise. The overall message is that preserving jobs is good for students and the community.

The tactics are local campaigns, public noise and pushing industrial and strike law to its limits. The focus should be fighting for every job. Where redundancies are unavoidable, the task is to minimise forced redundancies and use agreed and equitable criteria and certainly not 'fill and spill' or performance-based ones. If members are certain the Union will act for them, they will be more likely to act for others. Fighting restructures is not just an 'organising opportunity' but the raison d'être of organising. The NTEU branch structure - with full-time organisers at almost every branch - ought to provide the capacity for this. If not, something is amiss.

Some of the problems are inherent in the enterprise bargaining system introduced in the early 1990s. Under the previous award arrangement, industrial action about managerial decisions was common - including in the preDawkins colleges - even though formally illegal. Under enterprise bargaining, 'protected action' is defined and confined to the negotiating period. One fundamental imbalance in enterprise bargaining is that unions and 
workers have to give a 'no further claims' commitment on concluding an enterprise agreement. Employers are free, however to restructure, contract-out, out-source, declare redundancies and reduce the hours of casuals at any time during the life of an agreement subject only to consultation with those affected. Put plainly, this allows employers to alter the impact of an agreement at any time without making a 'claim' in bargaining. The real answer is to change the legal framework to require that significant restructuring can only occur after it has been agreed with the Union and certified by the Fair Work Commission. In turn, unions should be able to take protected industrial action over restructuring during the term of an enterprise agreement. (See also Guille, 2014).

The casualisation of academic work has allowed employers to use 'teaching-only' academics. The idea that all academics should be teaching and research appointments was an irreducible of the first four rounds of bargaining. It became a dogma and an albatross about which serious discussion was difficult. I note, approvingly, the comment that 'the principle had to give way to the industrial reality of an expanding precariat' (p. 285). The notion of a teaching and research academic also blinkered thinking about setting and managing academic workloads. While the NTEU held very firm on questions of the span of working hours for general staff, it would never contemplate fixed working hours for academics. To such an extent that in the first enterprise agreement covering all staff at JCU, general staff members of the National Executive from Victoria objected strenuously to the 'hours' clause. This allowed the continuation of the existing custom of early morning starts for grounds and maintenance staff by which they got at least some time in temperatures under 30 degrees and with humidity under 90 per cent.Victoria was always conservative in defending conditions. I still think that the Union would have had much more purchase over workloads if there had been a 361/4-hour week between 8.00 and 18.00 , Monday to Friday. But perhaps, it was just too industrial

It is conventional to say that history is about 'how we came to be where we are'. This is just as true whether it is a big 'we' (nation, class, gender,) or small groups, organisations and institutions. Yet history is also about the speculative and the counter-factual; in other words, 'why are we not somewhere else'. John's history is very strong on the first question - in particular, how NTEU came to be a strong bargaining union for general and academic staff. That was his brief.

There is less mention about what the NTEU might have been; one issue is why the tertiary part of the name is limited to public higher education and almost exclusively to public universities. Almost the only exception is a agreement covering the 'private' catholic University of Notre Dame. In the 2000s, after a long struggle, union agreements were made at Bond University but these were lost to Australian Workplace Agreements during the WorkChoices regime. Private for profit provision of degrees is increasing but the NTEU has not actively 'followed' the work other than the C-Management Services half of CQU and the Navitas arms of Victorian universities. Likewise, the NTEU does not cover some of the big nonuniversity research institutes and has low density even in university research centres.

Perhaps though, the bigger counter-factual is whether the NTEU could have become (or should try to become) an industry union for the entire tertiary, post-school sector including vocational education and training (VET) and higher education. The VET sector, including the increasingly corporatised technical and further education institutions (TAFEs), is an open and for-profit market place. It already has $\$ 96,000$ diplomas and there are many providers. In 2015, there were 565 registered private providers in Queensland compared with 372 in NSW and 377 in Victoria (NCVER, 2015).

Perhaps the NTEU is well out of the profit gouging and student-rip-offs of VET. However, in 2015, the Federal Government proposed funding public and private VET colleges for degrees and associate degrees. While the changes were held up in the Senate, they are a live option. Nothing destroys industrial regulation and decimates employment standards faster than product deregulation - consider, for example, the impact of budget airlines on full-service ones like Qantas.The NTEU is going to have to think hard about its future.

My final comments are about where the NTEU fits into the labour movement. All unions, and especially one so recent as the NTEU, are in debt to the legacy of the movement. The phrase 'respected rather than liked', used by John in another context, is apt though maybe over-generous to how the NTEU is seen by other unions. Potentially, the Union could make two major contributions. One is to cooperate with relevant unions in organising workers in areas of "intellectual labour". The aim would be to bring together public and private 'knowledge' producers, widely defined. This could include those in the Commonwealth Scientific and Industry Research Organisation (CSIRO), VET, universities, research institutes and centres, the Australian Broadcasting Corporation (ABC) and libraries, museums, galleries and arts organisations. If innovation is the future of 'jobs and growth', unions have to make it an 
organised site. Moreover, union presence might also be the best chance of ensuring that intellectual work is in the public interest and not just the corporate interest; that is a big public instead of a big pharma.

A second potential contribution is for the NTEU to facilitate research and learning within and for the labour movement. This could be through taking the lead in a Labour College (a renewal for those with long enough memories of the Clyde Cameron College) and in a clearinghouse where NTEU members and others can provide pro bono advice at national and local level to other unions and their members. About all areas, not just the industrial ones.

If the NTEU is a knowledge union, it needs to share it around. There might even be, as a small outcome, more worker and organisational histories as good as John O'Brien's. They will reinforce that being union is a proud and respected pursuit; and that it is a privilege to be trusted to work for a collective.
Howard Guille was the first and only Secretary of the Union of College Academics (Queensland Branch) and then Secretary of the Queensland Division of the NTEU from 1993 to 2006. Contact: hguille@bigpond.net.au

\section{References}

Australian Council of Trade Unions (ACTU). (undated). History of unions. Retrieved from http://www.actu.org.au/about-the-actu/history.

Ellem, B. (1988). Writing a Union's History: The Clothing Trades' Union. The Hummer 20 - April/June.

Guille, H. (2014). What Work Rights are Still Worth Fighting For?, Research Report 2, TJ Ryan Foundation. Retrieved from http://www.tjryanfoundation.org. $\mathrm{au} / \mathrm{cms} /$ page.asp?ID=236.

Keating, P., Carew, E., \& Cook, P, (1990). Keating: shut up and listen and you might learn something, Redfern, New Endeavour Press.

Mayes, J. (2013). Queensland Speaks. Retrieved from http://www. queenslandspeaks.com.au/janice-mayes.

NCVER. (2015). Government-funded students and courses January to September 2015. December 2015. Retrieved from http://tinyurl.com/jckexcx. 


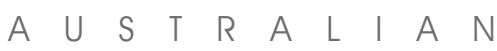




\section{www.aur.org.ou}

Since 1958, Australian Universities' Review has been encouraging debate and discussion about issues in higher education and its contribution to Australian public life.
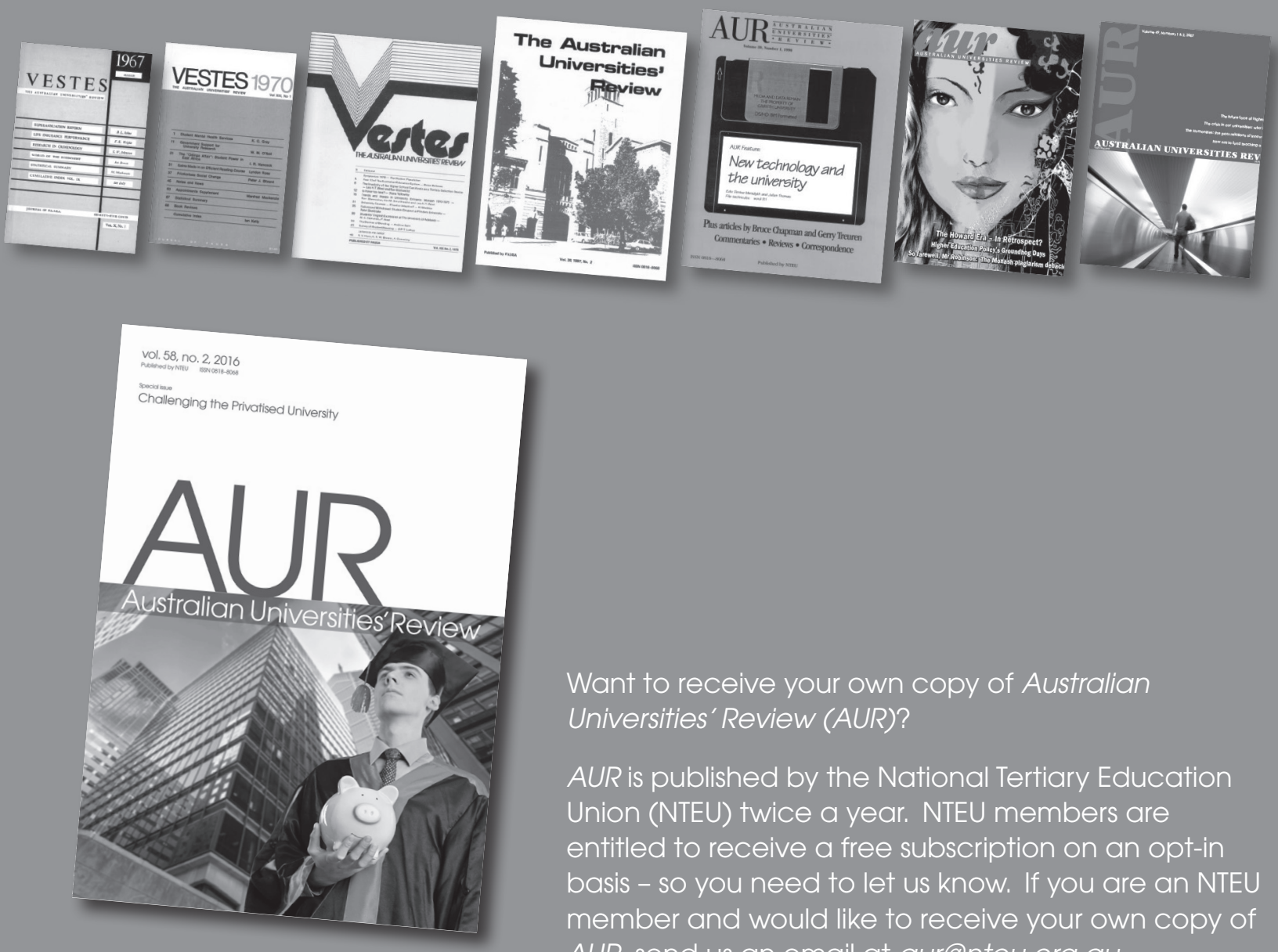

Want to receive your own copy of Australian Universities' Review (AUR)?

AUR is published by the National Tertiary Education Union (NTEU) twice a year. NTEU members are entitled to receive a free subscription on an opt-in basis - so you need to let us know. If you are an NTEU member and would like to receive your own copy of AUR, send us an email at aur@nteu.org.au.

Subscription rates for non-members are available at www.aur.org.au.

If you would like to become a member of NTEU, contact the local Branch office at your institution, or join online at www.nteu.org.au/join. 
Presents:

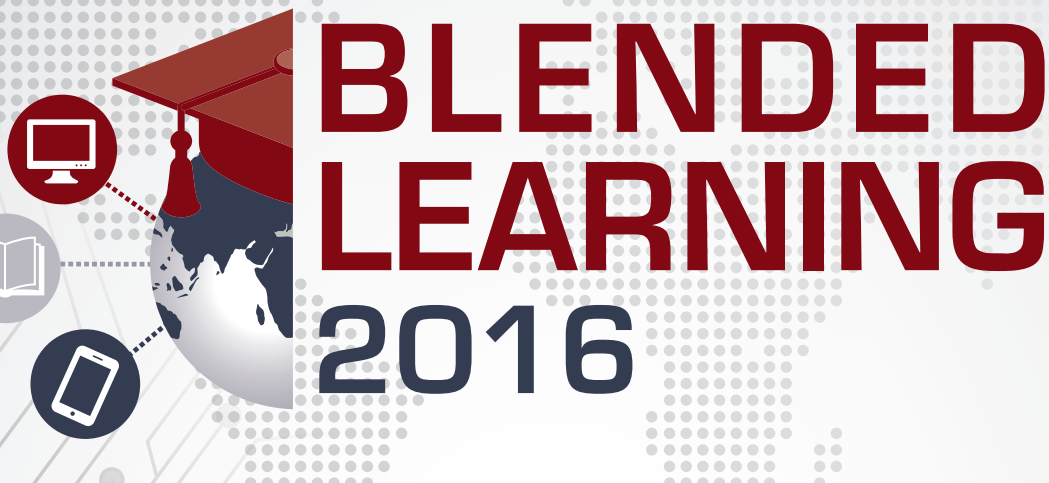

Improving Student Experience and Achievement through Digital Technology, Course Design \& Innovative Teaching Methods

Conference Dates: 20 - 21 October 2016 Venue: The Hilton Sydney

Australian University Review members SAVE 10\%! Simply quote "AUR10" when booking*.

WHY YOU SHOULD ATTEND BLENDED LEARNING 2016?

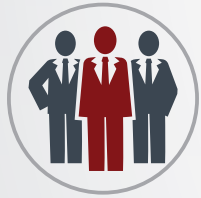

25+ expert speaker

panel from top

universities and institutes

including University

of Sydney, Monash

University, Macquarie

University, University of

Queensland

and many more

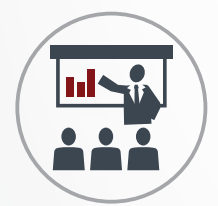

Pre conference Master

Class on Blended

Learning 101 and 4

interactive workshops

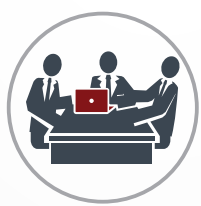

Interactive discussion sessions such as

Solutions Clinic \&

Hackathon specifically

targeted at solving practical real life problems

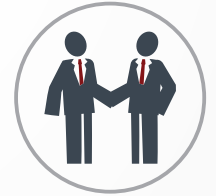

Platform for exchanging insights and ideas with peers and industry leaders in blended learning

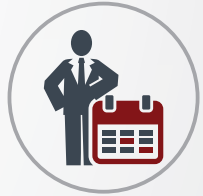

Learning Innovation Week: Co-located with Innovation in Assessment and Credentials and Campus Development, attend sessions from all 3 events interchangeably

Book your place by calling 029229 1000, email registration@iqpc.com.au or online at www.blended-learning.com.au

By registering to attend Blended learning 2016, part of Learning Innovation Week, you will have the opportunity to attend sessions from Campus Review 2016 and Innovation in Assessment and Credentials.

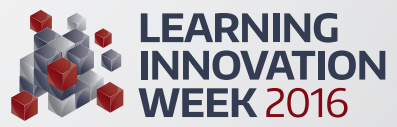

\section{BE PART OF AUSTRALIA'S BIGGEST TERTIARY EDUCATION WEEK!}
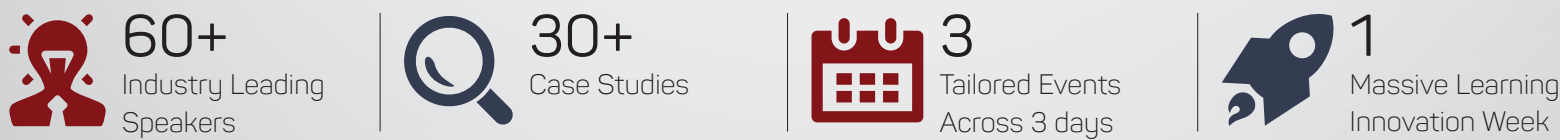


\section{"All of life is a constant education."}

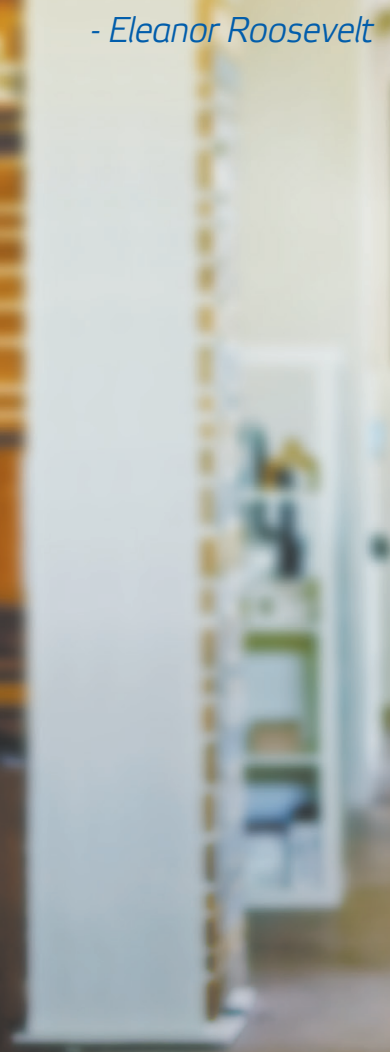

Every day you inspire, helping people grow.

You're the leaders, the educators and the professional staff that make aspiring students' dreams possible.

That's why we're invested in you.

As a customer owned bank, dedicated solely to the education community, our profits go back to you through competitive financial solutions, more personalised service and support of education. Helping each other do more, be more, achieve more.

Tertiary employees and their families, nationwide are welcome to bank with us.

Call 1300654822 | Visit victeach.com.au
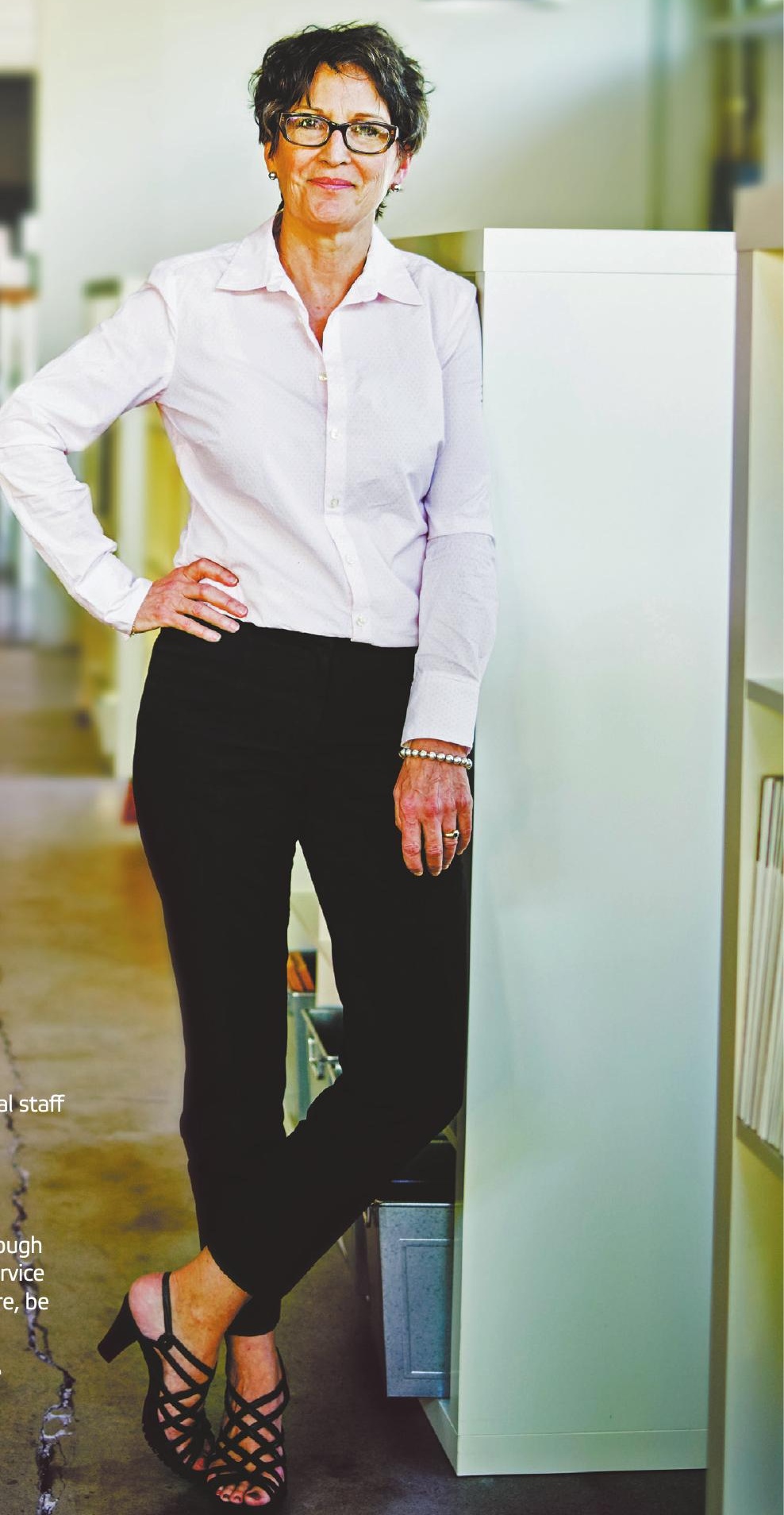